\title{
LITHIUM LITERATURE REVIEW: LITHIUM'S PROPERTIES AND INTERACTIONS
}

\section{Hanford Engineering Development Laboratory}

D.W. Jeppson

J.L. Ballif

W.W. Yuan

B.E. Chou

April 1978

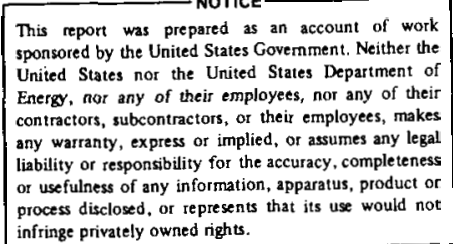

infringe privately owned rights.

HANFORD ENGINEERING DEVELOPMENT LABORATORY

Operated by Westinghouse Hanford Company

A Subsidiary of Westinghouse Electric Corporation

Prepared for the U.S. Department of Energy under Contract No. EY-76-C-14-2170

P.0. Box 1970 Richland, WA 99352 


\section{DISCLAIMER}

This report was prepared as an account of work sponsored by an agency of the United States Government. Neither the United States Government nor any agency Thereof, nor any of their employees, makes any warranty, express or implied, or assumes any legal liability or responsibility for the accuracy, completeness, or usefulness of any information, apparatus, product, or process disclosed, or represents that its use would not infringe privately owned rights. Reference herein to any specific commercial product, process, or service by trade name, trademark, manufacturer, or otherwise does not necessarily constitute or imply its endorsement, recommendation, or favoring by the United States Government or any agency thereof. The views and opinions of authors expressed herein do not necessarily state or reflect those of the United States Government or any agency thereof. 


\section{DISCLAIMER}

Portions of this document may be illegible in electronic image products. Images are produced from the best available original document. 


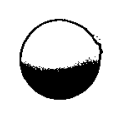
b t

$\cdots$ $\because+$
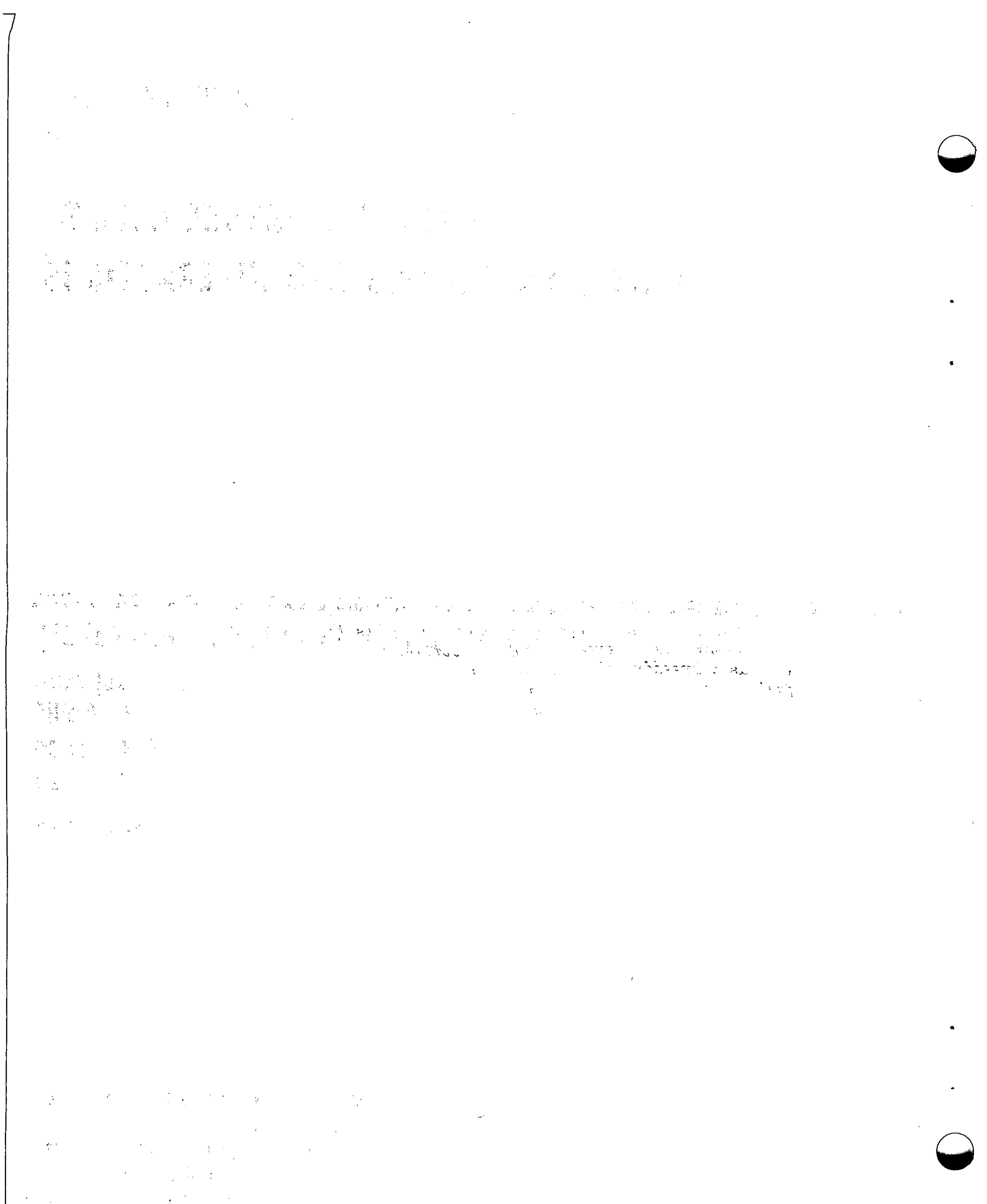

4

$\bullet$

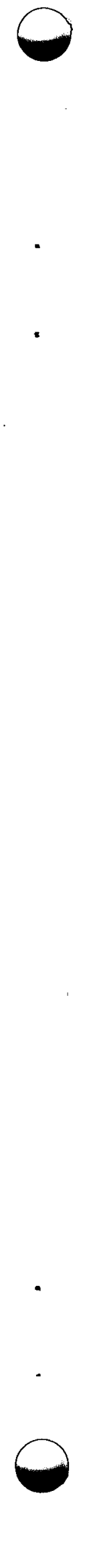


HEDL-TME 78-15

UC-20

LITHIUM LITERATURE REVIEW:

LITHIUM'S PROPERTIES AND INTERACTIONS

D. W. Jeppson, J. L. Ballif, W. W. Yuan and B. E. Chou

March 1978

$\underline{\text { ABSTRACT }}$

The lithium literature has been reviewed to provide a better understanding of the effects of lithium spills that might occur in magnetic fusion energy (MFE) facilities. Lithium may be used as a breeding blanket and reactor coolant in these facilities. Physical and chemical properties of lithium as well as the chemical interactions of lithium with various gases, metals and non-metals have been identified. A preliminary assessment of lithium-concrete reactions has been completed using differential thermal analysis. Suggestions are given for future studies in areas where literature is lacking or limited. 
$\ominus$

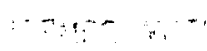

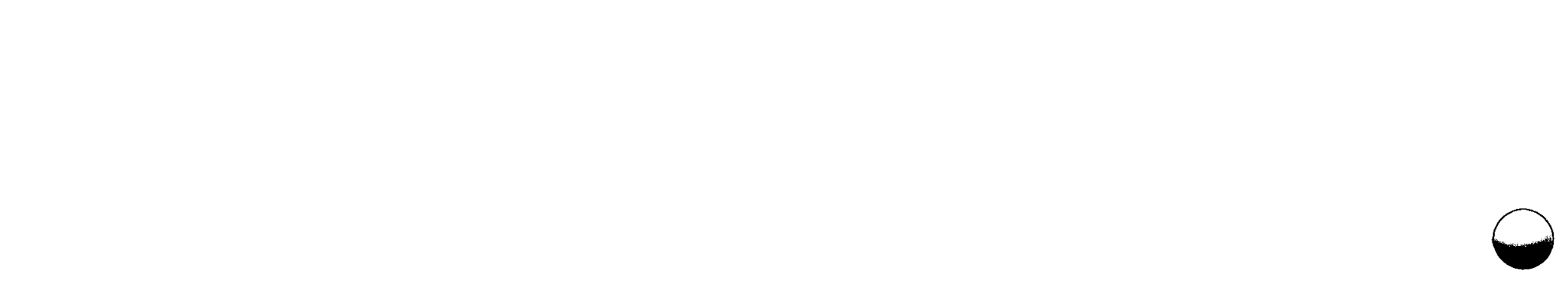

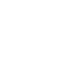

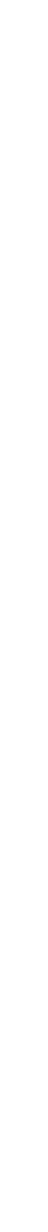<smiles>[Tl]</smiles>

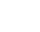
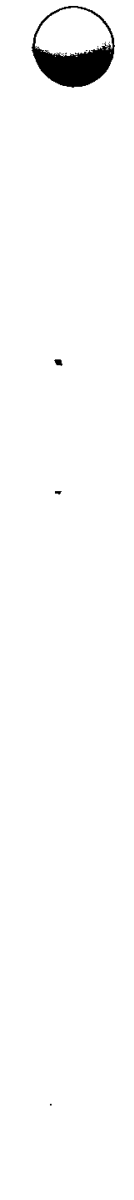


\section{CONTENTS}

$\begin{array}{lc}\text { ABSTRACT } & \frac{\text { Page }}{\text { FIGURES }} \\ \text { TABLES } & \text { vi } \\ \text { I. INTRODUCTION } & \text { viii } \\ \text { II. SUMMARY AND CONCLUSIONS } & 1 \\ \text { III. RESULTS AND DISCUSSION } & 3 \\ \text { A. Chemical Properties of Lithium } & 7 \\ \text { B. Physical Properties of Lithium } & 7 \\ \text { C. Thermal Properties of Lithium } & 9 \\ \text { D. Chemical Interactions of Lithium } & 16\end{array}$

IV. LITHIUM COMPOUNDS 43

V. CORROSION-RESISTANCE OF MATERIALS TO ATTACK BY LITHIUM $\quad 45$

VI. LITHIUM HANDLING, SAFETY AND FIRE CONDITIONS 59

A. Containment 59

B. Ignition 59

C. Fire Extinguishment 61

D. Removal 68

VII. FUTURE STUDIES AND EXPERIMENTATION 71

VIII. REFERENCES 71

APPENDIX: $\begin{aligned} & \text { LITHIUM-CONCRETE STUDIES BY DIFFERENTIAL } \\ & \text { THERMAL ANALYSIS }\end{aligned}$ 


\section{FIGURES}

Figure

1. Vapor Pressure of Lithium

2. Density of Lithium

3. Viscosity of Lithium

4. Surface Tension of Lithium

5. Enthalpy of Lithium

6. Heat Capacity of Lithium

7. Thermal Conductivity of Lithium

8. TGA Curves of Lithium Metal Dispersions Exposed to Various Gases

9. Kinetic Curves of Liquid Lithium Reacting with Oxygen

10. DTA Curve of Lithium Metal Dispersed in a Flowing Nitrogen Atmosphere.

11. Curves of Stirred Liquid Lithium Reacting with Nitrogen at $400^{\circ} \mathrm{C}$

12. Curves of Unstirred Liquid Lithium Reacting with Nitrogen at $400^{\circ} \mathrm{C}$

13. Kinetic Curves of Liquid Lithium Reacting with Nitrogen

14. Reaction Curves Showing the Effect of Temperature on Liquid Lithium Absorption of Hydrogen

15. Reaction Profiles of 100-125 Mesh Lithium Metal Exposed to Circulating Air (50\% r.h., $\left.27^{\circ} \mathrm{C}\right)$

16. Reaction Curves for Lithium Metal Specimens in Moist Oxygen at Various Temperatures
Page

8,9

10

13

12

14,15

14

16,17

15

14,18

17

$8,9,18,19 \quad 19$

$18,20,21$

20

27

24

28

26

25

26

31

30

31

30

28

31

34

27
Reference 


\section{FIGURES (Cont'd)}

Figure

Reference $\quad \underline{\text { Page }}$

17. Distribution of Lithium-Water Reaction Products

27

38

18. Rate Constants of Lithium Metal Reacting with Moist Oxygen at $35^{\circ} \mathrm{C}$

27

40

19. Resistance of Various Materials to Liquid Lithium

1,8

$46-$

48

20. Resistance of Various Materials to Lithium

1

49

21. Resistance of Various Materials to Liquid Lithium

8,9

50

22. Lithium-Ceramics Stability Diagram

39

52

23. Corrosion Resistance of Ceramics to Static Lithium for 100 Hours at $816^{\circ} \mathrm{C}$

1,19

55

24. Corrosion Resistance of Various Metals and Alloys in Lithium

1,42

57 


\section{TABLES}

TABLE

1. Properties of Lithium

2. Vapor Pressure of Lithium

3. Density of Lithium

4. Viscosity of Lithium

5. Surface Tension of Lithium

6. Enthalpy of Lithium

7. Heat Capacity of Lithium

8. Enthalpies and Free Energies of Lithium Reactions

9. Lithium-Hydrogen Reaction

10. Properties of Lithium Compounds

11. Compatibility Test Results of LithiumCeramics Interactions

12. Static 300-Hour Test of Lithium Interactions with Ceramic Insulating Materials at $400{ }^{\circ} \mathrm{C}$

13. Extinguishants for Sma 11 Lithium Fires

14. Extinguishants for Moderate Lithium Fires

15. Lithium Fire Extinguishant Preparation
Reference:

Page

$5,9,10$

8

8,9

10

13

12

14,15

14

16,17

15

14, 18

17

$8,9,18,19$

19

1

22

34

33

$1,5,9,38$

43

40

53

40

54

11

63,64

11

65

11,44

67 
LITHIUM LITERATURE REVIEW:

LITHIUM'S PROPERTIES AND INTERACTIONS

\section{INTRODUCTION}

Because of recent shifts in energy source policy, the application of fusion power for the production of electrical and thermal energy is considered desirable and has come to the attention of many. Increased emphasis and expansion of the Magnetic Fusion Energy (MFE) program is a result of continued progress in fusion power research and positive performance of Tokamak-type devices proving the feasibility of this type of energy source. The design of a MFE reactor is based on a continuous deuterium-tritium (DT) fuel cycle. Tritium does not occur naturally, therefore it must be bred. Inherent features of the reaction determine basic characteristics of DT fusion reactors:

- A special blanket of low atomic number material is required to convert a deuterium beam into (radioactive) tritium as well as provide a biological shield.

- The blanket region will become radioactive due to the breeding of tritium.

- The blanket may also act as a coolant for the reactor.

Liquid lithium has been found to be the preferred material to carry out these functions.

Lithium is not activated to long-lived gamma or neutron emitting isotopes by neutron capture. $(1,2)$ It exhibits a low neutron-absorption cross-section (for the separated isotope ${ }^{2}$ i), low melting point, high boiling point, low vapor pressure, low density, high heat capacity, high 
thermal conductivity and low viscosity. All these characteristics support lithium as a desirable tritium breeder blanket and primary coolant for nuclear fusion reactors. However, alkali metals are expected to be corrosive in operating environments sustaining high temperatures and high fluid flow rates. Lithium is no exception, and exhibits undesirable corrosive properties especially if it contains non-metallic impurities.

In MFE reactors, tritium is expected to be bred by neutron absorption in lithium. Lithium is contained under high vacuum. Whatever gas is present in the void region is usually helium in which lithium is inert under most conditions. Temperatures during normal operation vary between $200^{\circ} \mathrm{C}$ and $550^{\circ} \mathrm{C}$ but may exceed these in some MFE applications. (3) Based on current technology stainless steel is the chief construction material, although refractory metals such as niobium, vanadium, and molybdenum are being considered as base metals for lithium containment. Potential alloying elements are titanium, zirconium and chromium.

Because of the large amount of hot flowing lithium required in MFE use, one must be aware of the hazards of lithium leaks and spills. Both literature research and actual smal1- as we 11 as large-scale experimentation are necessary to increase the state of knowledge concerning lithium and the effects of spills. Information obtained will be directly applicable to the safety assessment of the MFE Fusion Materials Irradiation Testing Facility (FMIT) and other MFE facilities.

This report gives the literature survey results concerning physical and chemical properties of lithium including chemical interactions lithium may undergo with various materials possibly present in MFE facilities. The validity and applicability of these results for large scale, high temperature accident conditions must be verified by actual experimentation. 


\section{SUMMARY AND CONCLUSIONS}

A literature review of lithium and its properties and interactions was performed. However, most such information upon which this report was based deals with lithium reactions in small-scale quantities at low temperatures and with lithium in the solid phase. Because of this, much information about actual accident conditions is lacking. Extrapolation of the results to accident conditions may not be possible in some situations if actual large-scale tests are not performed for verification. Information is lacking regarding the possibilities of reaction propagation, the ultimate end products for lithium reactions, the possibility of an increase in reaction rate with temperature, and the rate of increase for specific reactions.

Some conclusions drawn from the existing literature are these:

1. Chemical and physical characteristics of lithium, especially a large liquidus range, high heat capacity and high thermal conductivity, allow lithium to be used as an effective nuclear reactor coolant. However, the corrosive properties of lithium require precautionary handling.

2. The high boiling point of lithium compared to sodium ( $1347^{\circ} \mathrm{C}$ vs. $883^{\circ} \mathrm{C}$ ) results in a much higher ignition temperature, with possible effects on structures.

3. Bulk solid lithium at room temperature does not burn spontaneousiy in water or air. In dry oxygen, carbon dioxide, air up to $250^{\circ} \mathrm{C}$, and dry nitrogen up to $160^{\circ} \mathrm{C}$, lithium metal dispersions are considered inert.

4. Oxidation of lithium in dry oxygen is low all the way up to the ignition temperature. The ignition temperature of lithium in pure oxygen is uncertain, cited at values as high as $630^{\circ} \mathrm{C}$. 
5. Lithium is the only alkali metal that will react with nitrogen to form a nitride. Thus nitrogen cannot be used as a cover gas as it is in sodium systems. Ignition temperatures for lithium metal in nitrogen are quoted between $170^{\circ} \mathrm{C}$ and $450^{\circ} \mathrm{C}$.

6. Rates, products and temperatures for lithium-air reactions are uncertain and contradictory. Values between $180^{\circ} \mathrm{C}$ and $640^{\circ} \mathrm{C}$ have been reported for the ignition temperature of lithium in air. Discrepancy is due mainly to purity and moisture conditions.

7. Lithium reacts readily with water (vapor and liquid) to form hydrogen gas, a hazard under some accident conditions.

8. Molten lithium is extremely reactive. It will burn on contact with the moist skin of personnel working with it. It also produces, upon burning, aerosols irritating to the respiratory system.

9. Molten lithium reacts noticeably with concrete, other materials containing moisture and with many ceramic insulating materials. Lithium attacks ceramics more aggressively than sodium does.

10. At high temperatures, molten lithium reacts with all known molecular gases but can be handled up to $200{ }^{\circ} \mathrm{C}$ in paraffin vapors. Trace amounts of moisture catalyze lithium-gas reactions.

11. No information was found on the aerosol properties of lithium combustion products (size, distribution, density, shape, chemical nature, or toxicity).

12. No information is included on the effects of radiation on lithium properties and interactions. 
13. Purity of lithium and the materials with which it interacts play a significant role in the nature of most lithium reactions.

14. Small lithium fires have been extinguished with a graphite powder, MET-L-X (a commercial preparation), and a pulverized salt eutectic mixture. Liquid lithium drains and selfextinguishing sump systems have been demonstrated effective for controlling small quantities of burning liquid lithium.

15. Based on an abbreviated study, the following preliminary conclusions may be drawn regarding lithium-concrete interactions:

a. The DTA studies of the magnetite aggregate concrete yielded inconclusive results.

b. The basalt aggregate concrete materials showed the highest apparent heat evolution values of all samples studied.

c. Limestone aggregate concrete samples provided the most reproduc ible heat evolution values and exotherms.

d. The exotherms of the dry Portland Cement paste were attributed to the direct reduction of the silicates to silicides. 
$\ominus$

.

$\theta$ 


\section{RESULTS AND DISCUSSION}

\section{A. CHEMICAL PROPERTIES OF LITHIUM}

Lithium $(L i)$ is a member of the chemical group known as the alkali metals. It is the least reactive of this group. Its binary compounds are more stable than those of the other alkali metals. $(1,4)$ The single "s" electron in the outer shell of a lithium atom is easily removed to form a positive ion. Removal of remaining electrons is difficult. Thus lithium is exclusively monovalent and forms compounds with all anions, organic and inorganic.

Lithium has an atomic number of three and an atomic weight of 6.941 atomic mass units. (5) Having the smallest atomic radius of all metals $(1.50-1: 56 \AA)(6)$, lithium is the lightest of these, with a density only about one-half that of water. Naturally occurring lithium contains two isotopes: 7.52 at.\% lithium-6 (atomic mass 6.017) and 92.48 at.\% lithium-7 (atomic mass 7.018 ). (1)

In its crystalline form, pure lithium is silver white and soft. In a vacuum (residual pressure $=0.04 \mathrm{~mm} \mathrm{Hg}$ ), lithium starts to evaporate above $600^{\circ} \mathrm{C} .{ }^{(7)}$ Solid lithium at room temperature is not as dangerous as other alkali metals, since it does not burn spontaneously in water or air. Molten lithium is extremely reactive. It burns when it contacts moist skin. Its combustion products are irritating to the respiratory system. (1) Lithium imparts a crimson color to a flame. When the metal burns strongly, the flame is dazzling white. Special handling is required because of lithium's corrosive properties.

Commercial lithium contains appreciable quantities of carbon, oxygen and nitrogen. Other contaminants commonly dissolved in lithium or mechanically dispersed in it are lithium compounds of chlorine, hydrogen, calcium, aluminum, iron, silicon, and sodium. (8) Table 1 summarizes some properties of lithium. 
TABLE 1

PROPERTIES OF LITHIUM

\section{Feature}

\section{Name}

Symbol

Atomic Number

Atomic Weight

Isotopes

Boiling Point

Melting Point

Heat of Vaporization

Heat of Fusion

Cube Edge Length of Unit Cel1

Number of Atoms Exposed

upon Immersion in Water of $1 \mathrm{~cm}$ Unit Cube
Reference

Lithium

Li

3

5

6.941 a.m.u.

5

$L i-6$

$L i-7$

$1347^{\circ} \mathrm{C}$

5

$180.54^{\circ} \mathrm{C} \quad 5$

$4680 \mathrm{cal} / \mathrm{g} 9$

$103.2 \mathrm{cal} / \mathrm{g} \quad 9$

$3.51 \AA$

10

$26.1 \times 10^{14} \quad 10$ 


\section{B. PHYSICAL PROPERTIES OF LITHIUM}

\section{Melting Point}

The melting point of lithium is $180.54^{\circ} \mathrm{C}$. (5) $^{(5)}$ other references have cited values from $179^{\circ} \mathrm{C}$ to $186^{\circ} \mathrm{C} .{ }^{(7-12)}$ This temperature is twice as high as sodium but is significantly lower than the melting temperature of most common metals and is one of the reasons why lithium may be used effectively as a reactor coolant and heat transfer medium.

\section{Vapor Pressure and Boiling Point}

The normal boiling point for lithium is given at values from $1317{ }^{\circ} \mathrm{C}$ to $1370{ }^{\circ} \mathrm{C} .(5,7-12)$ These values are slightly low and high respectively-the most reasonable boiling point is around $1347{ }^{\circ} \mathrm{C} .{ }^{(5)}$

Normal operating temperatures of MFE devices range from $200^{\circ} \mathrm{C}$ to $550{ }^{\circ} \mathrm{C}$. Lithium does not boil at normal atmospheric pressure until it reaches a temperature we 11 above those encountered in the MFE devices. This allows the system to be operated unpressurized, thereby reducing design strength requirements and the potential severity of any leaks that might deve iop.

The vapor pressure of lithium is low at the melting point (approximately $10^{-10} \mathrm{~mm} \mathrm{Hg}$ ). Various equations have been derived for calculating vapor pressure at different temperatures. One equation, whose results are in good agreement with others, allows vapor pressure calculations from $700{ }^{\circ} \mathrm{C}$ to $1400{ }^{\circ} \mathrm{C}^{(8)}$ :

$$
\begin{array}{rl}
\log _{10} P=8.00-8143 \mathrm{~T}^{-1} & P \text { units: } \mathrm{mm} \mathrm{Hg} \\
& \text { T units: }{ }^{\circ} \mathrm{K}
\end{array}
$$

Table 2 and Figure 1 show the vapor pressure of $\mathrm{Li}$ in $\mathrm{mm} \mathrm{Hg}$ from around $700{ }^{\circ} \mathrm{C}$ to $1300{ }^{\circ} \mathrm{C}$. 
TABLE 2

VAPOR PRESSURE OF LITHIUM

Temperature $\left({ }^{\circ} \mathrm{C}\right)$

745

890

1084

1156

1236

Ref. $8 ; 9$, Table 14.6
Vapor Pressure $(\mathrm{mm} \mathrm{Hg})$

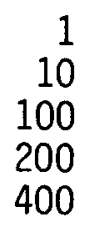

1
10

100

400

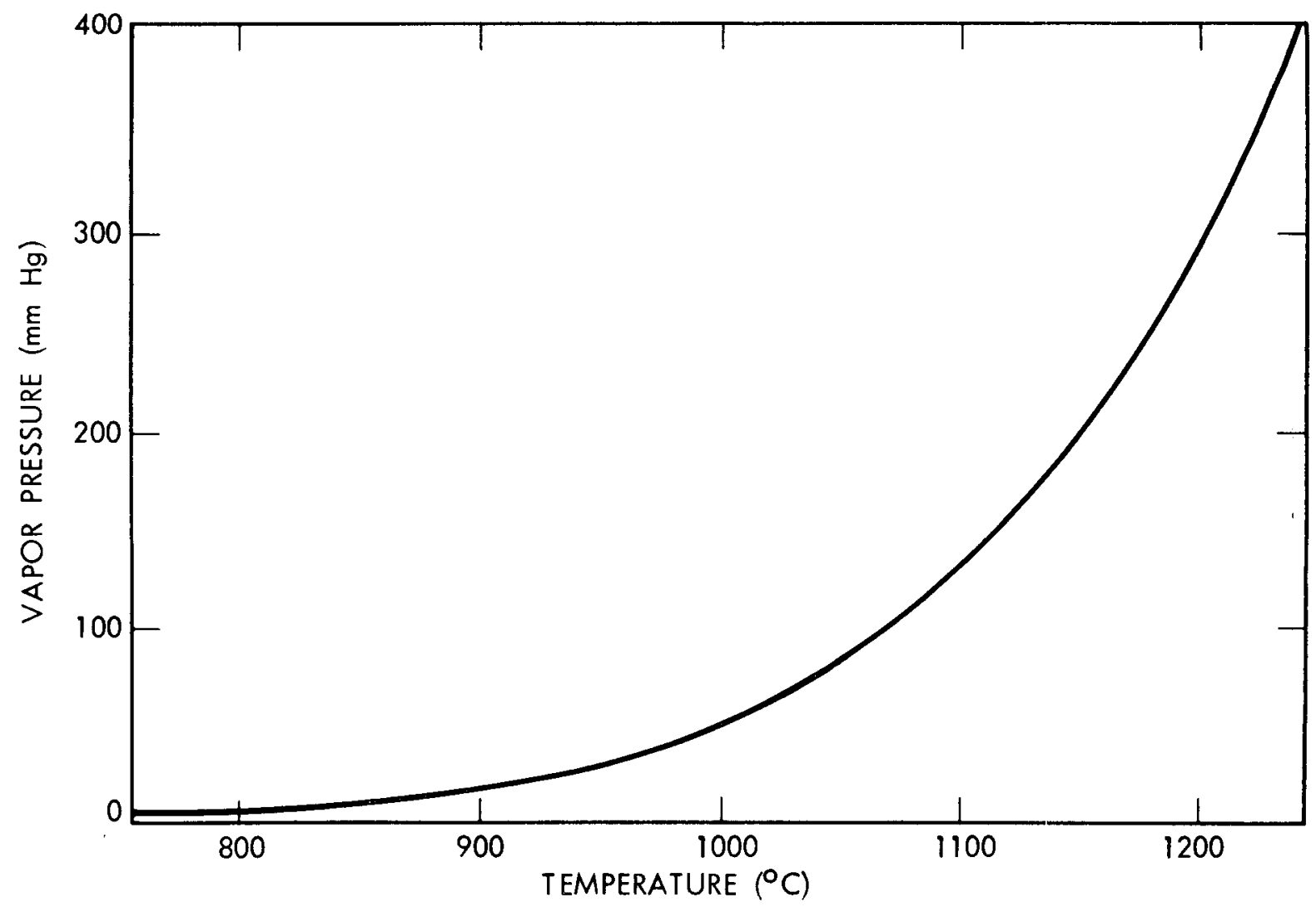

HEDL 7802-039.4

FIGURE 1. Vapor Pressure of Lithium. Ref. 8, 9 


\section{Density}

The following equation allows the calculation of density from $200^{\circ} \mathrm{C}$ to $1600^{\circ} \mathrm{C}$ with an accuracy of $\pm 0.3 \%{ }^{(13)}$ :

$$
\begin{aligned}
=0.515-\left(1.01 \times 10^{-4}\right)(\mathrm{T}-200) \quad & \mathrm{T} \text { range: } 200{ }^{\circ} \mathrm{C}-1600{ }^{\circ} \mathrm{C} \\
& \text { ounits: } \mathrm{g} / \mathrm{cm}^{3} \\
& \text { T units: }{ }^{\circ} \mathrm{C}
\end{aligned}
$$

Table 3 and Figure 2 illustrate the results. The density of liquid lithium is a linear function of temperature and decreases with increasing temperature. Density decreases sharply with increasing temperature above $1600{ }^{\circ} \mathrm{C} .{ }^{(13)}$ Because of the low density, liquid lithium requires less pumping power for a given heat load than other liquid metals.

\section{Viscosity}

Two types of viscosity are defined. Dynamic viscosity is the resistance of a fluid to a change of form. This internal friction is a measure of how difficult it is to make the fluid flow. Kinematic viscosity is the ratio of the dynamic viscosity of the fluid to its density at the temperature under consideration. Two equations for calculating the dynamic viscosity of molten lithium are: $(14,15)$

$$
\log _{10}=0.4936-0.7368 \log _{10} \mathrm{~T}+109.95 \mathrm{~T}^{-1}
$$

\footnotetext{
T range: $180.54{ }^{\circ} \mathrm{C}-1000{ }^{\circ} \mathrm{C}$ units: centipoise

T units: ${ }^{\circ} \mathrm{K}$
} 
TABLE 3

DENSITY OF LITHIUM

\begin{tabular}{cc} 
Temperature $\left({ }^{\circ} \mathrm{C}\right)$ & Density $\left(\mathrm{g} / \mathrm{cm}^{3}\right)$ \\
\hline 200 & 0.515 \\
400 & 0.495 \\
600 & 0.475 \\
800 & 0.454 \\
1000 & 0.434 \\
1200 & 0.414 \\
1400 & 0.394 \\
1600 & 0.374 \\
Ref. 13, Table 2 &
\end{tabular}

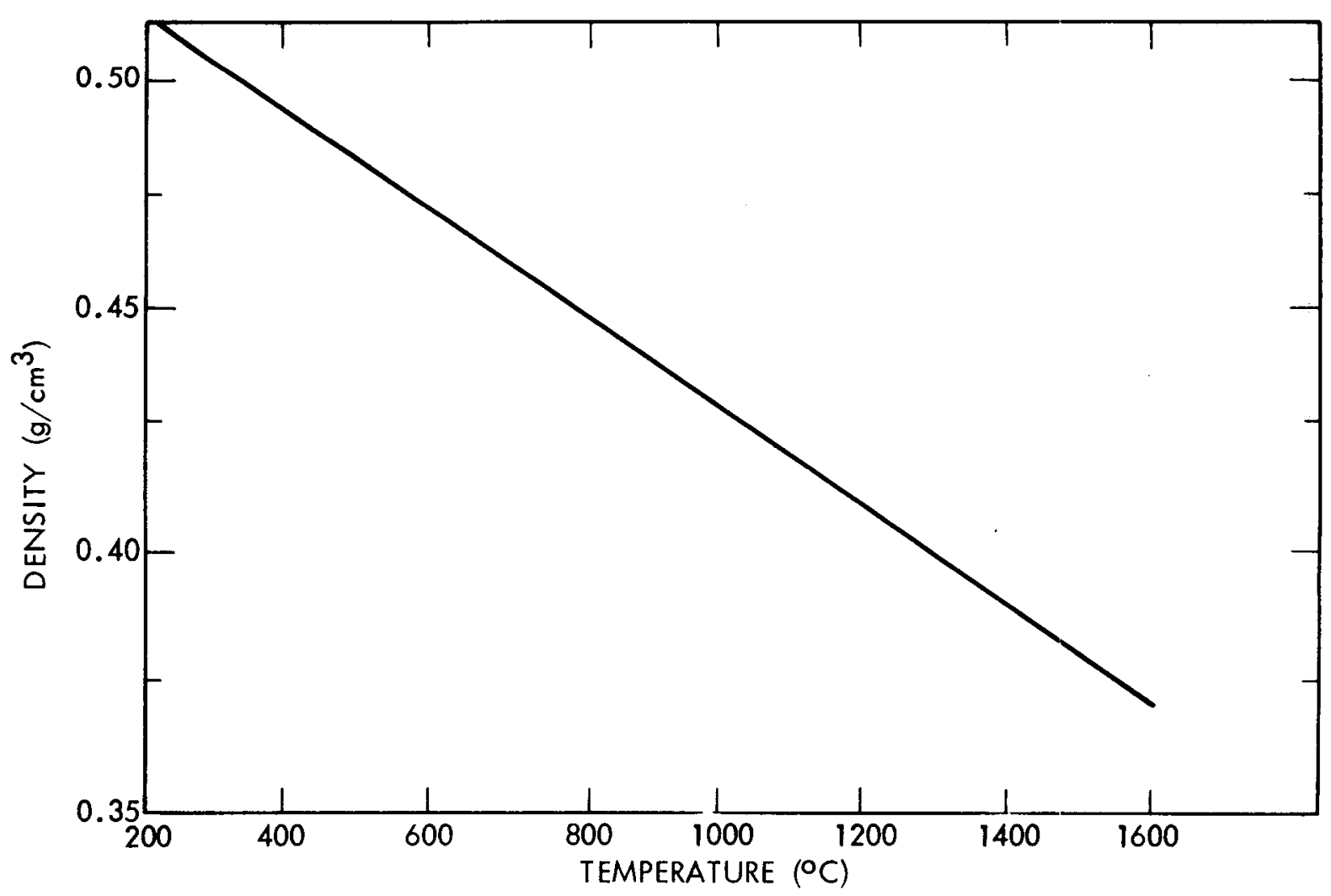

HEDL 7802-039.5

FIGURE 2. Density of Lithium. Ref. 13 


$$
\begin{aligned}
\log _{10 \eta}=726.07 \mathrm{~T}^{-1}-1.3380 \quad & \mathrm{~T} \text { range: } 600{ }^{\circ} \mathrm{C}-1200{ }^{\circ} \mathrm{C} \\
& \text { (especially for extrapo- } \\
& \text { Tation to higher temps.) } \\
& \eta \text { units: centipoise } \\
& \mathrm{T} \text { units: }{ }^{\circ} \mathrm{K}
\end{aligned}
$$

Table 4 and Figure 3 represent dynamic viscosity of lithium as a function of temperature.

\section{5.' Surface Tension}

The molecular forces holding matter together become conspicuous at surfaces of discontinuity, such as the interface between two fluids. At the surface of a liquid (lithium, for example), the absence of liquid molecules above it causes forces to behave as if a membrane were stretched over the liquid surface. This is due to the stronger attraction of liquid molecules to gas molecules (air, for example). The surface tension of the liquid lithium is a function of temperature. It was found during the course of experiments that liquid lithium could not be poured out of a container up to an inch in diameter even by inverting it. The combination of high surface tension and low density was sufficient to hold the metal in the container. Even vigorous shaking could not dislodge it.

An equation describing the surface tension of molten lithium from $200{ }^{\circ} \mathrm{C}$ to $1300^{\circ} \mathrm{C}$ is given as: $(16,17)$

$$
\sigma=0.16(3550-T)-95
$$

$\sigma$ units: dyne $/ \mathrm{cm}$

T units: ${ }^{\circ} \mathrm{K}$

This is illustrated in Table 5 and Figure 4. 
TABLE 4

VISCOSITY OF LITHIUM

Temperature $\left({ }^{\circ} \mathrm{C}\right)$

200

400

600

800

1000

1200

\begin{tabular}{|c|c|}
\hline \multicolumn{2}{|c|}{ Viscosity $(c p)$} \\
\hline $\begin{array}{c}(\text { Ref. 14) } \\
0.569 \\
0.374\end{array}$ & (Ref. 15) \\
\hline $\begin{array}{l}0.283 \\
0.231 \\
0.196\end{array}$ & $\begin{array}{l}0.323 \\
0.218 \\
0.171 \\
0.143\end{array}$ \\
\hline
\end{tabular}

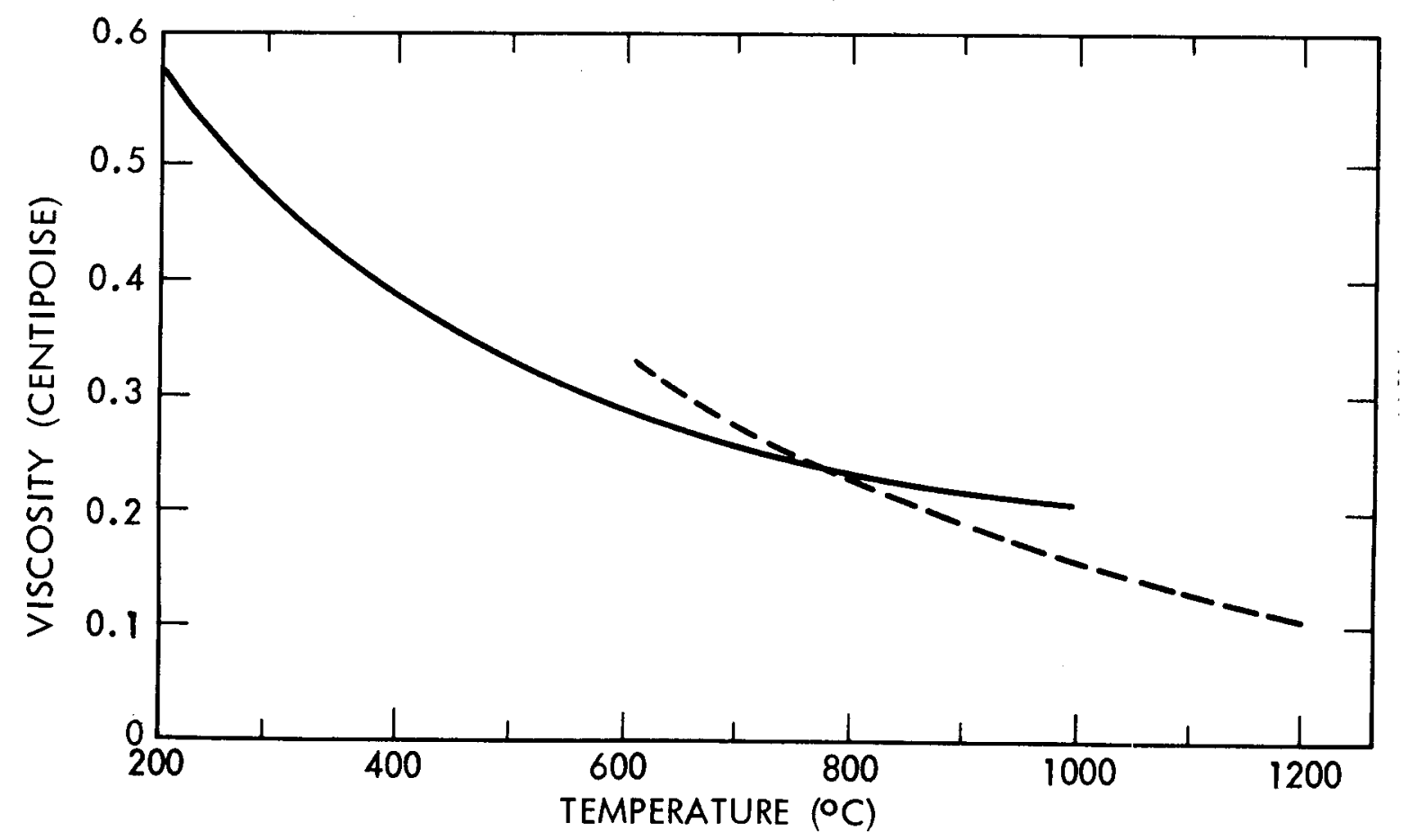

HEDL 7802-039.8

FIGURE 3. Viscosity of Lithium. Ref. 14, 15 


\section{TABLE 5}

SURFACE TENSION OF LITHIUM

\begin{tabular}{cc} 
Temperature $\left({ }^{\circ} \mathrm{C}\right)$ & $\begin{array}{c}\text { Surface Tension } \\
(\text { dynes } / \mathrm{cm})\end{array}$ \\
\cline { 2 - 2 } 200 & 397.3 \\
400 & 365.3 \\
600 & 333.3 \\
800 & 301.3 \\
1000 & 269.3 \\
1200 & 237.3 \\
1400 & 205.3 \\
Ref. 16,17 &
\end{tabular}

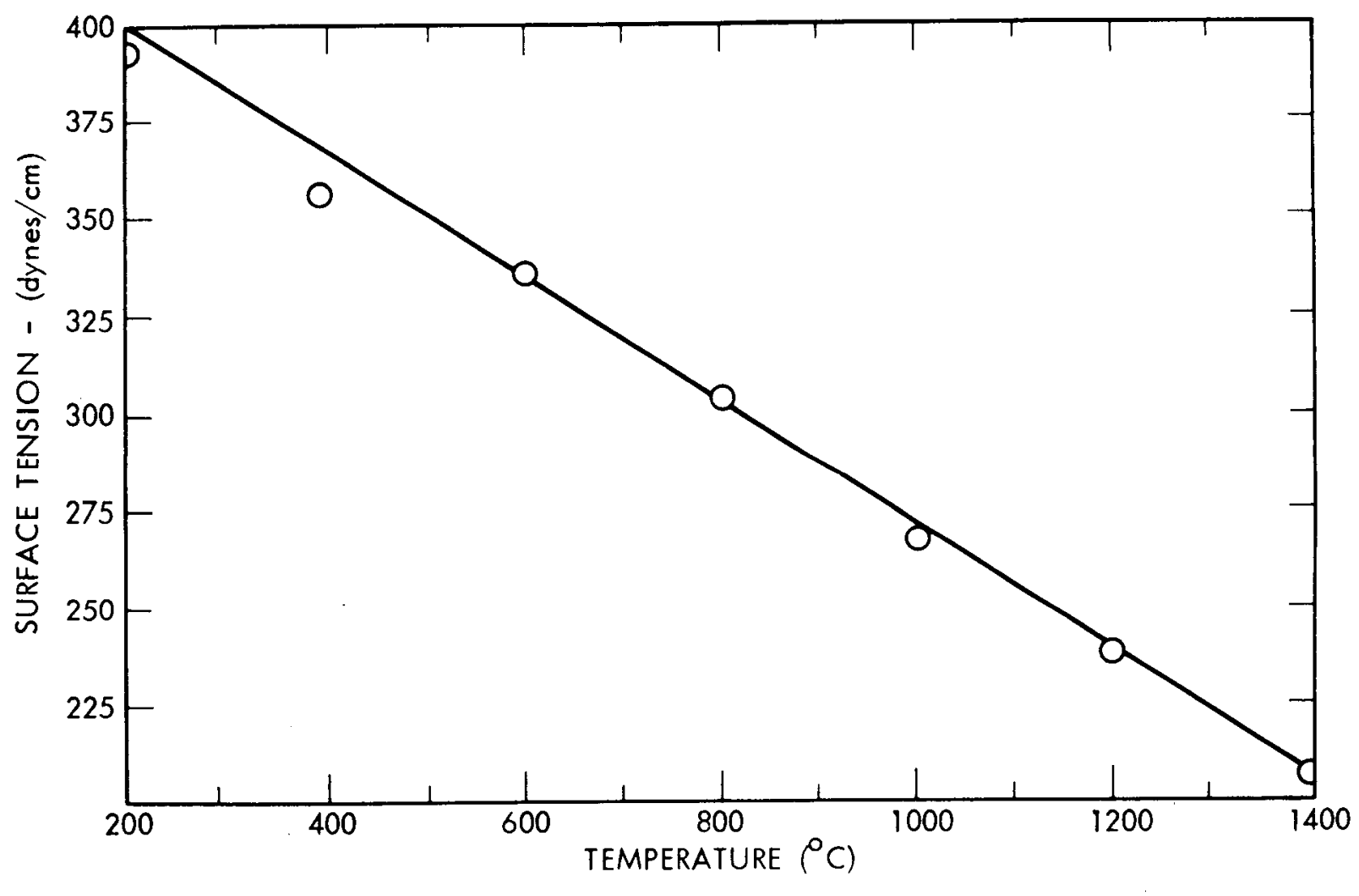

HEDL $7802-039.3$

FIGURE 4. Surface Tension of Lithium. Ref. 16,17 


\section{Wetting}

Wetting describes the ability of a liquid to spread freely over the surface of a solid. Low surface tension usually accompanies higher degrees of wetting. Purified lithium reportedly will not wet stainless stee 1 at $315{ }^{\circ} \mathrm{C}$ but does at $400{ }^{\circ} \mathrm{C} .{ }^{(1)}$ Impure lithium will not wet stainless steel at temperatures below $482{ }^{\circ} \mathrm{C} .(1)$

\section{THERMAL PROPERTIES OF LITHIUM}

\section{Enthalphy}

The enthalpy or heat content $\left(H_{r}\right)$ of a material is a thermodynamic function indicating the amount of internal energy plus pressure-volume (PV) work available in a system. Enthalpy can be determined by either of two equations: $(14,18)$

$$
\begin{aligned}
& H_{T}=270.4+C_{p}(T-453.6) \quad T \text { range: } 190{ }^{\circ} \mathrm{C}-650{ }^{\circ} \mathrm{C} \\
& H_{T} \text { units: } \mathrm{cal} / \mathrm{g} \\
& \text { T units: " } \mathrm{K} \\
& C_{p} \text { : Heat capacity } \\
& \text { (cal } / \mathrm{g}-{ }^{\circ} \mathrm{C} \text { ) } \\
& H_{T}=-5.075+1.0008 \mathrm{~T}-5.173 \times 10^{3} \mathrm{~T}^{-1} \quad \mathrm{~T} \text { range: } 500{ }^{\circ} \mathrm{C}-1300{ }^{\circ} \mathrm{C} \\
& H_{T} \text { units: } \mathrm{cal} / \mathrm{g} \\
& \text { T units: }{ }^{\circ} \mathrm{C}
\end{aligned}
$$

The experimental data verifying the first equation are represented in Table 6 and Figure 5.

2. Heat of Fusion

The heat of fusion for lithium is given as $103.2 \mathrm{cal} / \mathrm{g}^{(11,12,19)}$ at $180.54{ }^{\circ} \mathrm{C}$. 
TABLE 6

ENTHALPY OF LITHIUM

Temperature $\left({ }^{\circ} \mathrm{C}\right)$

185.75

213.78

286.90

357.16

428.28

456.50

492.75

525.95

585.05

593.79

620.41

628.61

647.71

Ref. $18 ; 14$, Table 2
Enthalpy (cal/g)

270.40

303.65

379.15

449.00

521.94

549.32

584.09

618.19

677.62

688.06

713.41

722.49

742.34

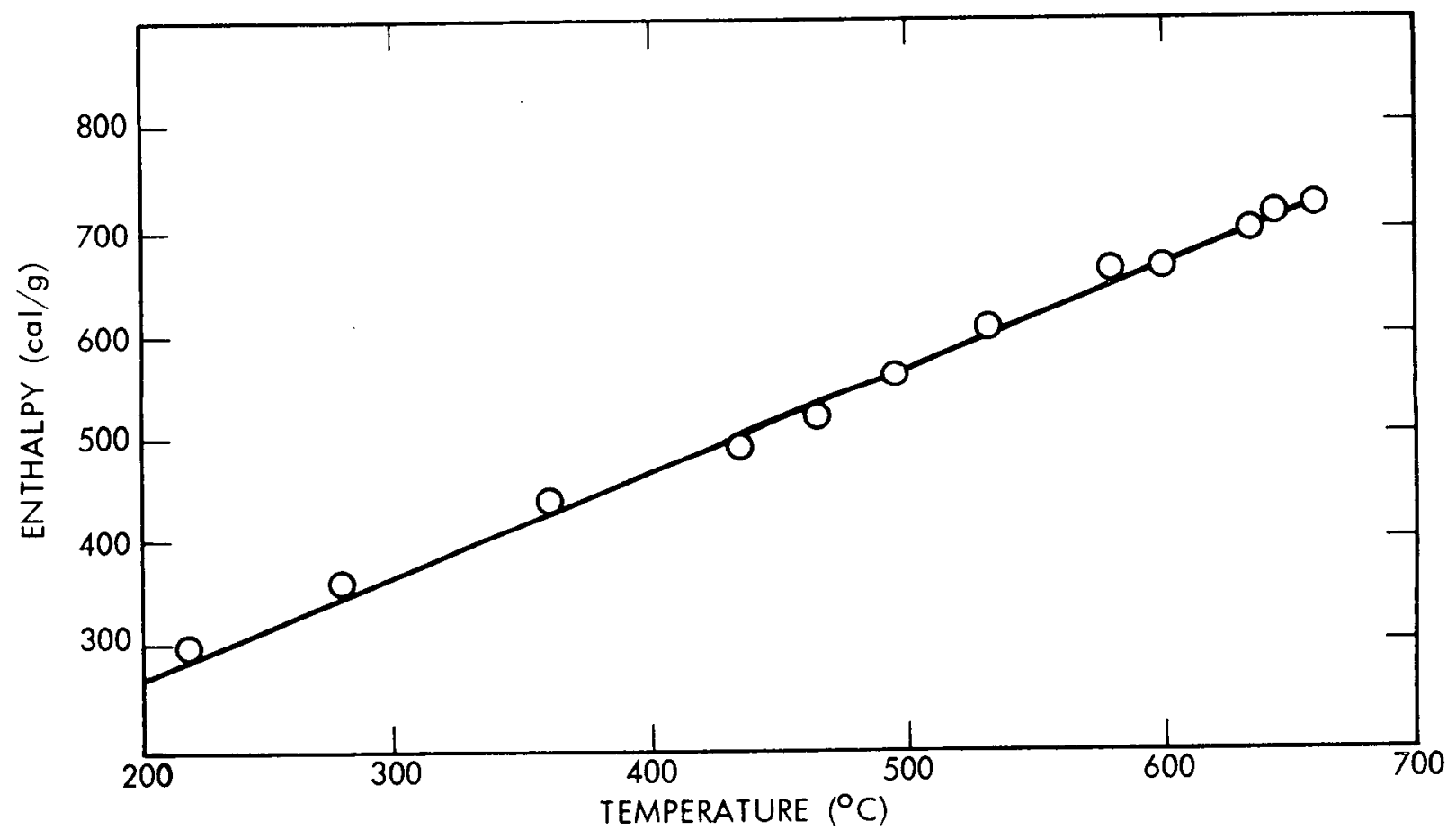

HEDL 7802-039.2

FIGURE 5. Enthatpy of Lithium. Ref. 14,18 


\section{Heat Capacity}

Table 7 and Figure 6 show the heat capacity in calories per gram- ${ }^{\circ} \mathrm{C}$ necessary to raise the temperature of lithium from $0{ }^{\circ} \mathrm{C}$ to $900{ }^{\circ} \mathrm{C}$. Lithium has the highest heat capacity of any solid element, making it useful in heat transfer applications.

\section{Thermal Conductivity}

Three empirical equations for thermal conductivity ( $k$ ) yield a scattering of experimental data (see Figure 4): $(18,20,21)$

$$
\begin{array}{ll}
\mathrm{k}=10.1+2.94 \times 10^{-3} \mathrm{~T} & \begin{array}{l}
\mathrm{T} \text { range: } 250{ }^{\circ} \mathrm{C}-950{ }^{\circ} \mathrm{C} \\
\mathrm{k} \text { units: } \mathrm{Cal} / \mathrm{sec} \cdot \mathrm{m} \cdot{ }^{\circ} \mathrm{C}
\end{array} \\
& \mathrm{T} \text { units: }{ }^{\circ} \mathrm{C} \\
\mathrm{k}=10.48+4.98 \times 10^{-3}(\mathrm{~T}-180.6) & \mathrm{T} \text { range: } 300{ }^{\circ} \mathrm{C}-1100{ }^{\circ} \mathrm{C} \\
-0.58 \times 10^{-6}(\mathrm{~T}-180.6)^{2} & \mathrm{k} \text { units: } \mathrm{Ca} / \mathrm{seC} \cdot \mathrm{m} \cdot{ }^{\circ} \mathrm{C} \\
& \mathrm{T} \text { units: }{ }^{\circ} \mathrm{C} \\
\mathrm{k}=8.24+7.46 \times 10^{-3} \mathrm{~T} & \mathrm{~T} \text { range: } 320{ }^{\circ} \mathrm{C}-830{ }^{\circ} \mathrm{C} \\
& \mathrm{k} \text { units: } \mathrm{Cal} / \mathrm{sec} \cdot \mathrm{m} \cdot{ }^{\circ} \mathrm{C} \\
& \mathrm{T} \text { units: }{ }^{\circ} \mathrm{C}
\end{array}
$$

The best fitted equation obtained by method of least squares for the three above equations is:

$$
\begin{array}{ll}
K=9.59+4.55 \times 10^{-3} \mathrm{~T} & k \text { units: cal } / \mathrm{sec} \cdot \mathrm{m} \cdot{ }^{\circ} \mathrm{C} \\
& T \text { units: }{ }^{\circ} \mathrm{C}
\end{array}
$$

Th is is represented by the dashed line in Figure 7 . 
TABLE 7

HEAT CAPACITY OF LITHIUM

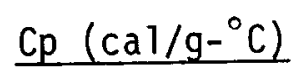

0.784

0.844

0.905

1.012

1.058

1.040

1.020

1.015

1.010

1.000

0.998

0.997

0.996

0.995

$0.995 \pm 1 \%$
Temperature $\left({ }^{\circ} \mathrm{C}\right)$

0

50

100

180.6

200

250

300

350

400

450

500

550

600

650

$650-900$

Ref. 8, 19; 9, Table 14.6; 18, Table 4

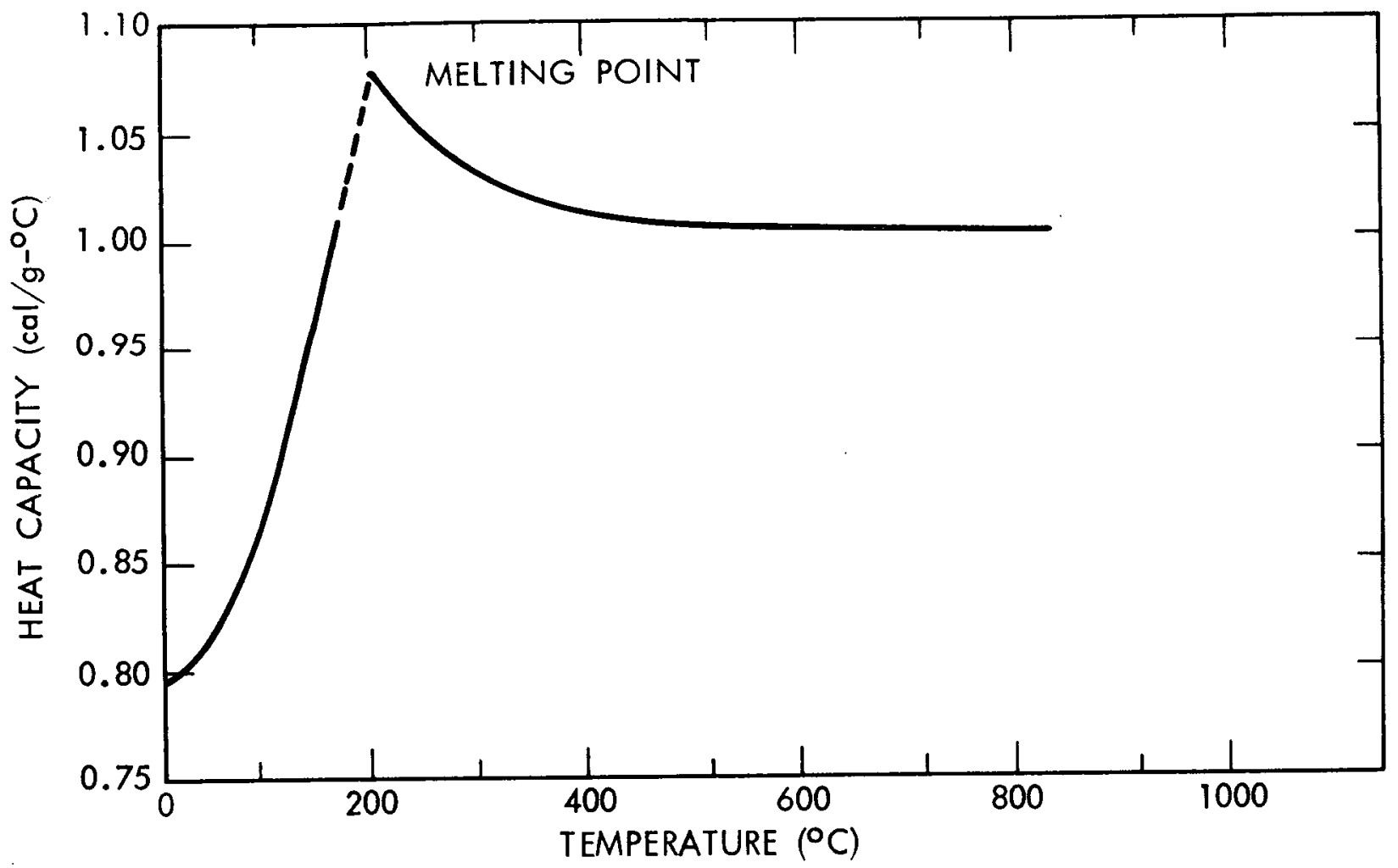

FIGURE 6. Heat Capacity of Lithium. Ref. 9,18,19,8

HEDL 7802-039.13 


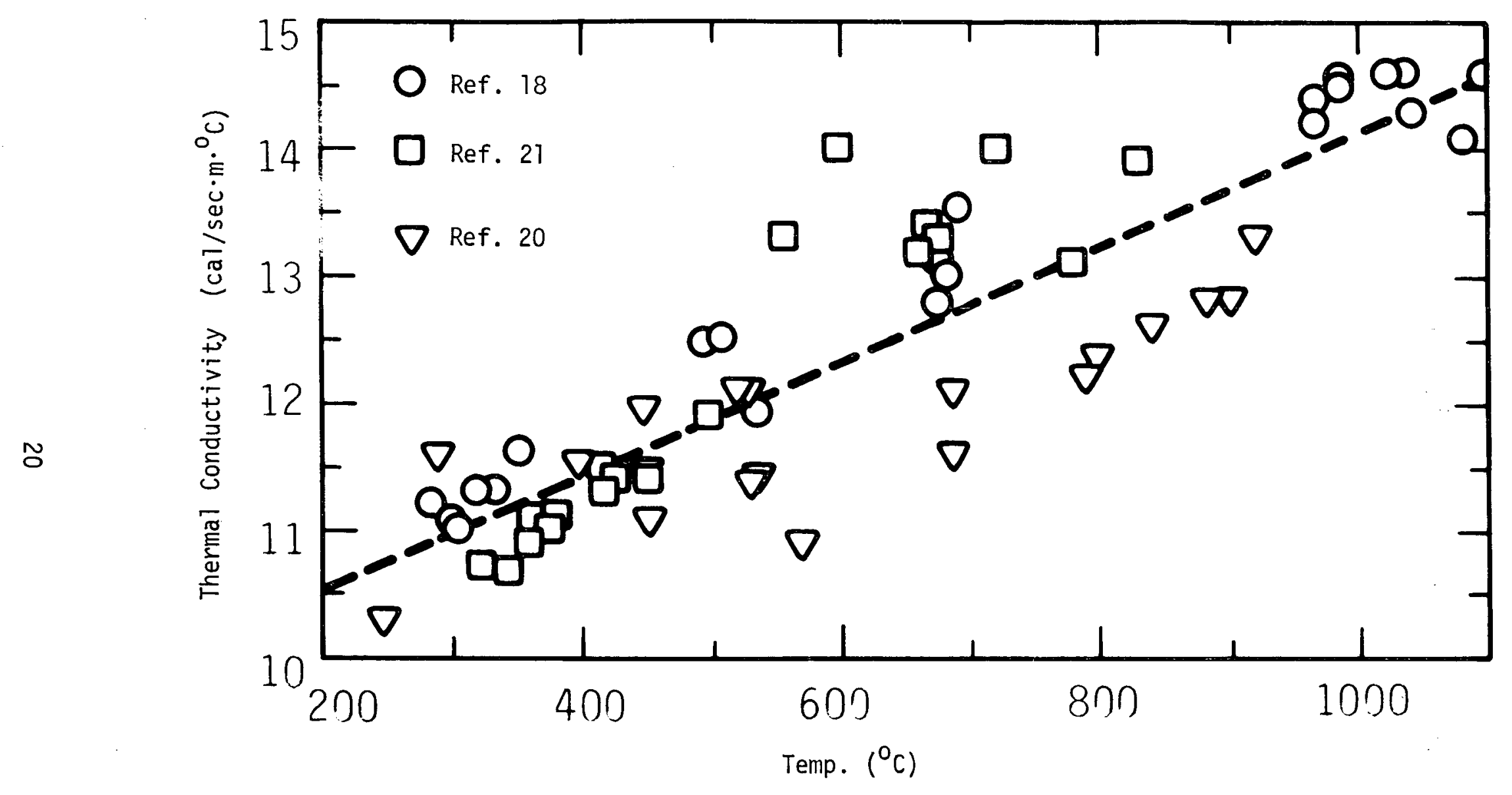

HEDL 7711-63.2

FIGURE 7. Thermal Conductivity of Lithium. Ref. 18,20,21 


\section{CHEMICAL INTERACTIONS OF LITHIUM}

\section{General}

Although lithium is the least reactive of the alkali metals, it still undergoes many chemical reactions and is not found naturally in the free form. Lithium reacts vigorously with the halogens, emitting light. ${ }^{(8)}$ It reacts violently with most inorganic acids, but cold concentrated sulfuric acid attacks it slowly. ${ }^{(1,22)}$ Molten lithium reacts vigorously with concrete and other materials containing moisture and rapidly with ceramic insulating materials. $(1,23)$ At high temperatures, molten lithium reacts with all known molecular gases but can be handled up to about $200{ }^{\circ} \mathrm{C}$ in paraffin vapors. ${ }^{(24)}$ It is considered inert in helium under most conditions. Trace amounts of mo isture catalyze lithium-gas reactions. Liquid lithium will not react with oxygen or carbon dioxide in air at its melting point in the absence of water; but 10 to 15 partsper-million (ppm) moisture will cause lithium to react with air, nitrogen, oxygen and carbon dioxide at room temperature. ${ }^{(1)}$ Lithium reacts readily with air and water and with traces of oxygen, carbon, nitrogen and hydrogen even in the inert fluids in which it is stored. Contamination with these materials promotes corrosion of metals by lithium. The stable binary compounds--lithium oxide, lithium nitride, lithium hydroxide, lithium hydride and lithium chloride are very corrosive. ${ }^{(8)}$ Metallic impurities also catalyze lithium reactions.

Table 8 gives the enthalpies and free energies for various lithium reactions. (1) More negative values indicate a higher tendency for the reaction to proceed as written. The values are all taken at room temperature $\left(25^{\circ} \mathrm{C}\right)$. 
TABLE 8

ENTHALPIES AND FREE ENERGIES OF LITHIUM REACTIONS

\section{Reaction}

$2 \mathrm{Li}(\mathrm{c})+1 / 2 \mathrm{O}_{2} \rightarrow \mathrm{Li}_{2} \mathrm{O}(\mathrm{c})$

2. $\mathrm{Li}(\mathrm{c})+\mathrm{O}_{2}(\mathrm{~g}) \rightarrow \mathrm{Li}_{2} \mathrm{O}_{2}(\mathrm{c})$

$\mathrm{Li}(\mathrm{c})+1 / 2 \mathrm{H}_{2}(\mathrm{~g})+1 / 2 \mathrm{O}_{2}(\mathrm{~g}) \rightarrow \mathrm{LiOH}(\mathrm{c})$

$\mathrm{Li}(\mathrm{c})+3 / 2 \mathrm{H}_{2}(\mathrm{~g})+\mathrm{O}_{2}(\mathrm{~g}) \rightarrow \mathrm{LiOH}^{*} \mathrm{H}_{2} \mathrm{O}(\mathrm{c})$

$\mathrm{Li}(\mathrm{c})+\mathrm{H}_{2} \mathrm{O}(\mathrm{l}) \rightarrow \mathrm{LiOH}(\mathrm{c})+1 / 2 \mathrm{H}_{2}(\mathrm{~g})$

$\mathrm{Li}(\mathrm{c})+\mathrm{H}_{2} \mathrm{O}(\mathrm{l}) \rightarrow \mathrm{LiOH}\left(\right.$ in $\left.\mathrm{H}_{2} \mathrm{O}\right)+1 / 2 \mathrm{H}_{2}(\mathrm{~g})$

$\operatorname{Li}(\mathrm{c})+1 / 2 \mathrm{~F}_{2}(\mathrm{~g}) \rightarrow \operatorname{LiF}(\mathrm{c})$

$\mathrm{Li}(\mathrm{c})+1 / 2 \mathrm{Cl}_{2}(\mathrm{~g}) \rightarrow \mathrm{LiCl}(\mathrm{c})$

$\mathrm{Li}(\mathrm{c})+1 / 2 \mathrm{I}_{2}(\mathrm{~g}) \rightarrow \mathrm{LiI}(\mathrm{c})$

$3 \mathrm{Li}(\mathrm{c})+1 / 2 \mathrm{~N}_{2}(\mathrm{~g})+\mathrm{Li}_{3} \mathrm{~N}(\mathrm{c})$

$\mathrm{Li}(\mathrm{c})+1 / 2 \mathrm{H}_{2}(\mathrm{~g}) \rightarrow \mathrm{LiH}(\mathrm{c})$

$2 \mathrm{Li}(\mathrm{c})+3 / 2 \mathrm{CO}_{2}(\mathrm{~g}) \rightarrow \mathrm{Li}_{2} \mathrm{CO}_{3}(\mathrm{c})+1 / 2 \mathrm{c}(\mathrm{c})$

$2 \mathrm{Li}(\mathrm{c})+3 \mathrm{CO}(\mathrm{g}) \rightarrow \mathrm{Li}_{2} \mathrm{CO}_{3}(\mathrm{c})+2 \mathrm{C}(\mathrm{c})$

$\mathrm{Li}(\mathrm{c})+\mathrm{NH}_{3}(\mathrm{~g}) \rightarrow \mathrm{LiNH}_{2}(\mathrm{c})+1 / 2 \mathrm{H}_{2}(\mathrm{~g})$

$2 \mathrm{Li}(\mathrm{c})+2 \mathrm{C}(\mathrm{c})+\mathrm{Li}_{2} \mathrm{C}_{2}(\mathrm{c})$

$2 \mathrm{Li}(\mathrm{c})+\mathrm{Mo}(\mathrm{c})+2 \mathrm{O}_{2}(\mathrm{~g}) \rightarrow \mathrm{Li}_{2} \mathrm{MoO}_{4}(\mathrm{c})$

$\mathrm{Li}(\mathrm{c})+\mathrm{Al}(\mathrm{c})+2 \mathrm{H}_{2}(\mathrm{~g}) \rightarrow \mathrm{LiAlH}_{4}(\mathrm{c})$

$\mathrm{Li}(\mathrm{c})+\mathrm{Sn}(\mathrm{c}) \rightarrow \mathrm{LiSn}(\mathrm{c})$

$\mathrm{Li}(\mathrm{c})+\mathrm{Pb}(\mathrm{c}) \rightarrow \mathrm{LiPb}(\mathrm{c})$

$\mathrm{Li}(\mathrm{c})+\mathrm{Tl}(\mathrm{c}) \rightarrow \operatorname{LiTI}(\mathrm{c})$

$\mathrm{Li}(\mathrm{c})+\mathrm{Hg}(\mathrm{c}) \rightarrow \mathrm{LiHg}(\mathrm{c})$

$3 \mathrm{Li}(\mathrm{c})+2 \mathrm{Sb}(\mathrm{c}) \rightarrow \mathrm{Li}_{3} \mathrm{Sb}_{2}(\mathrm{c})$

$3 \mathrm{Li}(\mathrm{c})+\mathrm{Bi}(\mathrm{c}) \rightarrow \mathrm{Li}_{3} \mathrm{Bi}(\mathrm{c})$

$2 \mathrm{Li}(\mathrm{c})+\mathrm{H}_{2} \mathrm{SO}_{4}(\mathrm{l}) \rightarrow \mathrm{Li}_{2} \mathrm{SO}_{4}+\mathrm{H}_{2}(\mathrm{~g})$

$\mathrm{Li}(\mathrm{c})+\mathrm{CH}_{3} \mathrm{OH}(\ell) \rightarrow \mathrm{LiOCH}_{3}\left(\right.$ in $\left.\mathrm{CH}_{3} \mathrm{OH}\right)$

$+1 / 2 \mathrm{H}_{2}(\mathrm{~g})$

$\mathrm{Li}(\mathrm{c})+\mathrm{C}_{2} \mathrm{H}_{5} \mathrm{OH}(\ell) \rightarrow \mathrm{LiOC}_{2} \mathrm{H}_{5}\left(\right.$ in $\left.\mathrm{C}_{2} \mathrm{H}_{5} \mathrm{OH}\right)$

$$
+1 / 2 \mathrm{H}_{2}(\mathrm{~g})
$$

Ref. 1, Table 5
$\Delta H^{\circ}\left(25^{\circ} \mathrm{C}\right) \mathrm{G} \quad\left(25^{\circ} \mathrm{C}\right)$

$\frac{k c a l}{-142.650}-\frac{k c a l}{-133.950} \frac{\text { References }}{80}$

$\begin{array}{lll}-151.9 & -138.1 & 92\end{array}$

$\begin{array}{lll}-116.589 & -105.676 \quad 93\end{array}$

$\begin{array}{lll}-188.926 & -163.437 & 93\end{array}$

$\begin{array}{lll}-48.7 & -48.99 & 6\end{array}$

$-53.142 \quad 91$

$-146.300-139.650 \quad 80$

$\begin{array}{lll}-97.700 & -92.500 & 80\end{array}$

$-64.790 \quad(-62.200) \quad 80$

$\begin{array}{lll}-47.500 & -37.300 \quad 80\end{array}$

$\begin{array}{lll}-21.61 & -16.72 & 75\end{array}$

$\begin{array}{lll}-148.6 & -128.4 & 94\end{array}$

$\begin{array}{lll}-210.45 & -171.38 & 94\end{array}$

$-32.46 \quad 6$

$-14.275$

$-365.25 \quad 95$

$-24.67 \quad 96$

$-16.8 \quad 75$

$-14.6 \quad 75$

$-12.8 \quad 75$

$-20.8 \quad 75$

$-43.5 \quad 75$

$-55.2 \quad 75$

$-148.92 \quad 6$

$\begin{array}{ll}-55.1 & 6\end{array}$

$-51.6$

6 


\section{Lithium-Gas Reactions}

TGA Studies $^{(25)}$-- Thermogravimetric analysis was used to study lithium metal-gas reactions for wet and dry dynamic gases. Heating at a rate of $0.67 \%$ minute, lithium metal dispersion samples held in small quartz cups were subjected to various dynamic gaseous atmospheres (argon, air, nitrogen, oxygen, carbon dioxide). Flow rates were around $150 \mathrm{ml} / \mathrm{min}$ at ambient conditions. For dry gas analyses, the high purity gases were passed through a column of anhydrous magnesium perchlorate. To achieve wet gases of $50 \%$ relative humidity at room temperature (partial pressure of water $=9.03 \mathrm{~mm} \mathrm{Hg}$ at $20^{\circ} \mathrm{C}$ ), the gases were dispersed through a saturated solution of sodium dichromate dihydrate. The results are depicted in Figure 8 . Conclusions drawn from this are:

- Dry carbon dioxide, oxygen and air up to $250^{\circ} \mathrm{C}$ and dry nitrogen up to $160{ }^{\circ} \mathrm{C}$ appear inert with respect to lithium metal dispersions.

- With the presence of water vapor in each gas, continuous and significant weight gains were observed over the heating period indicating lithium-gas reactions.

- When exposed to a 11 the moist gases, a black surface forms over the lithium metal. It is composed of anhydrous lithium hydroxide and a little lithium oxide.

Use of metal dispersions is characterized by a high available surface area. This tends to exaggerate reaction rates since the possibility of rate-controlling diffusion effects are minimized. The sequence of events is unchanged in nature but possibly accelerated in time. The results are specific for a given heating rate, gas flow rate and high purity of gases. Because of this, reaction rates and temperatures may be different in actual uncontrolled conditions. 


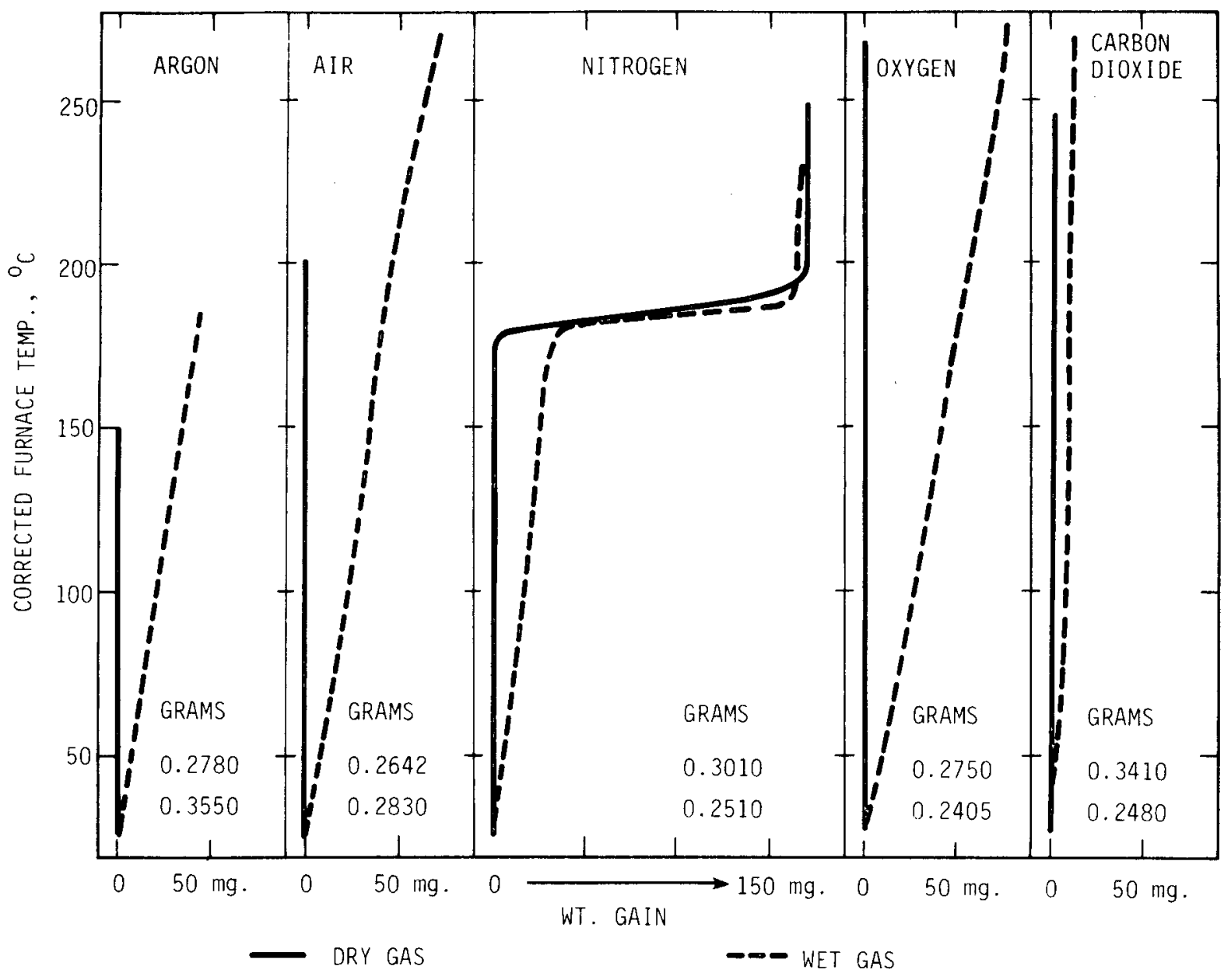

HEDL 7711-63.11

FIGURE 8. TGA Curves of Lithium Metal Dispersions Exposed to Various Gases. Ref. 27, Figure 4 


\section{Lithium-0xygen Reactions}

Lithium is highly resistant to oxidation even at elevated temperatures in pure oxygen or even in dry air atmospheres. $(10,25,26)$ The rate of oxidation of lithium is low all the way to the ignition temperature cited in one report as $630{ }^{\circ} \mathrm{C} .(26)$ No reaction of solid lithium in dry oxygen occurs below $250^{\circ} \mathrm{C}$. With mo ist oxygen, the reaction proceeds exothermically: ${ }^{(1)}$

$$
2 \mathrm{Li}(\mathrm{s})+1 / 2 \mathrm{O}_{2}(\mathrm{~g}) \rightarrow \mathrm{Li}_{2} \mathrm{O}(\mathrm{s}) \quad \Delta \mathrm{H}_{25}{ }^{\circ} \mathrm{C}=-142.65 \mathrm{kcal} / \mathrm{mole}
$$

1.152 grams of oxygen combine with 1.0 grams of lithium to produce $10.33 \mathrm{kcal}$ of energy. ${ }^{(9)}$

The oxide coating that forms on the surface of solid lithium at low temperature may prevent further reaction of lithium with oxygen. A specimen of solid lithium in moist oxygen (partial pressure of water $=$ $4.6 \mathrm{~mm} \mathrm{Hg}$ ) at $35^{\circ} \mathrm{C}$ forms a white reaction product on the surface of the metal. If the specimen is then exposed to dry oxygen, the reaction rate drops to zero with no further oxide forming under these conditions. (27)

The reaction of liquid lithium with oxygen was carried out from $210^{\circ} \mathrm{C}$ to $640{ }^{\circ} \mathrm{C}$ with pressures of $130 \mathrm{~mm} \mathrm{Hg}$ to $1.0 \mathrm{~mm} \mathrm{Hg} .{ }^{(28)}$ The oxide film formed initially was observed throughout the entire experiment. Figure 9 illustrates the kinetic curves of reaction of liquid lithium with oxygen. From this, the reaction may be divided into three segments. The first represents non-steady-state reaction. The second is described by a logarithmic rate law and has an activation energy of $15.3 \mathrm{kcal} / \mathrm{mole}$. The terminal segment indicates continuous growth of the oxide film and follows a linear rate law. The activation energy for this last segment is $15.6 \mathrm{kcal} / \mathrm{mole} .^{(28)}$ Values may differ for flowing lithium containing different degrees of impurities.

Figure 10 shows the DTA curve of lithium metal dispersed in a flowing nitrogen atmosphere. 


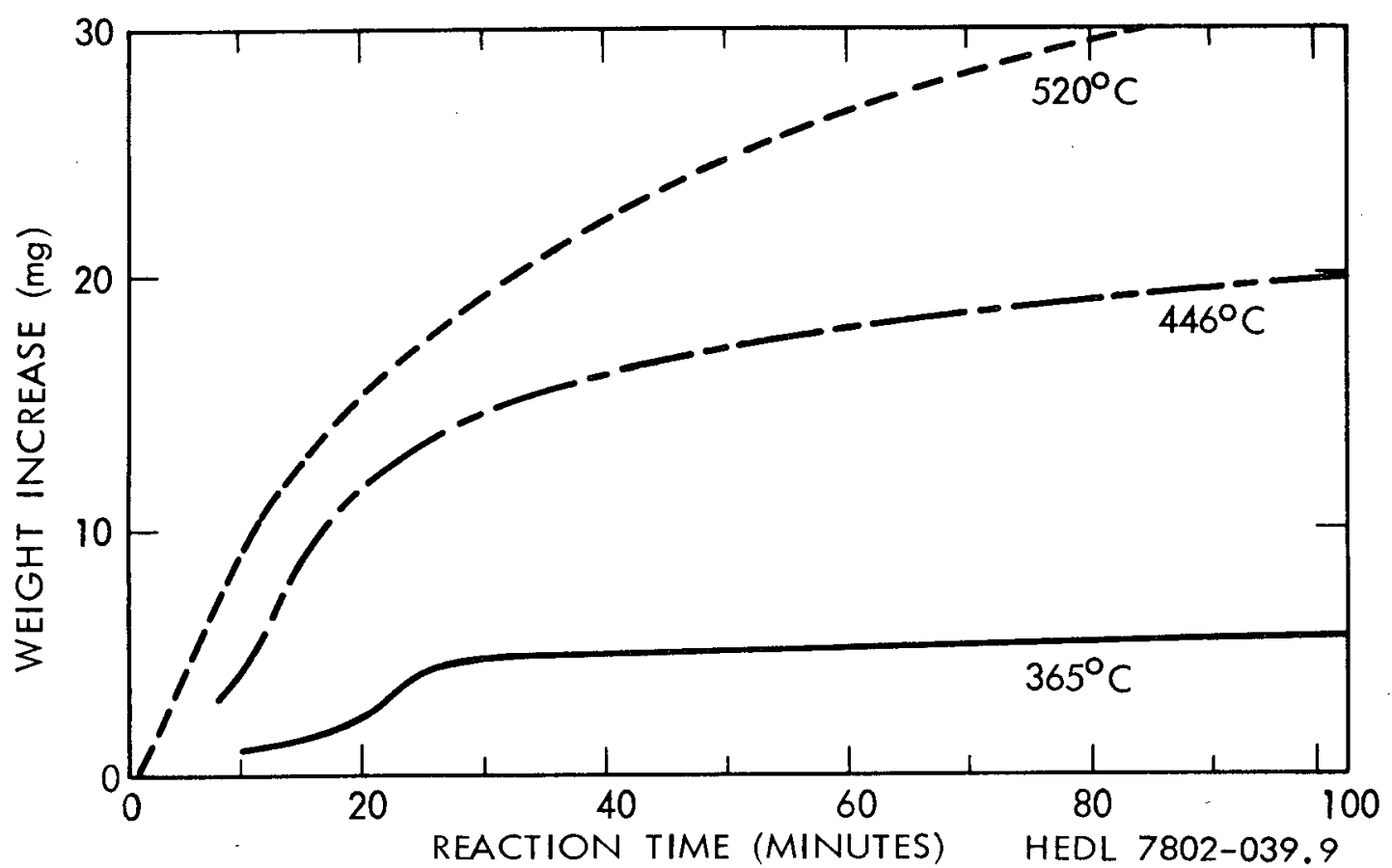

FIGURE 9. Kinetic Curves of Liquid Lithium Reacting with Oxygen. Ref. 28, Fig. 1

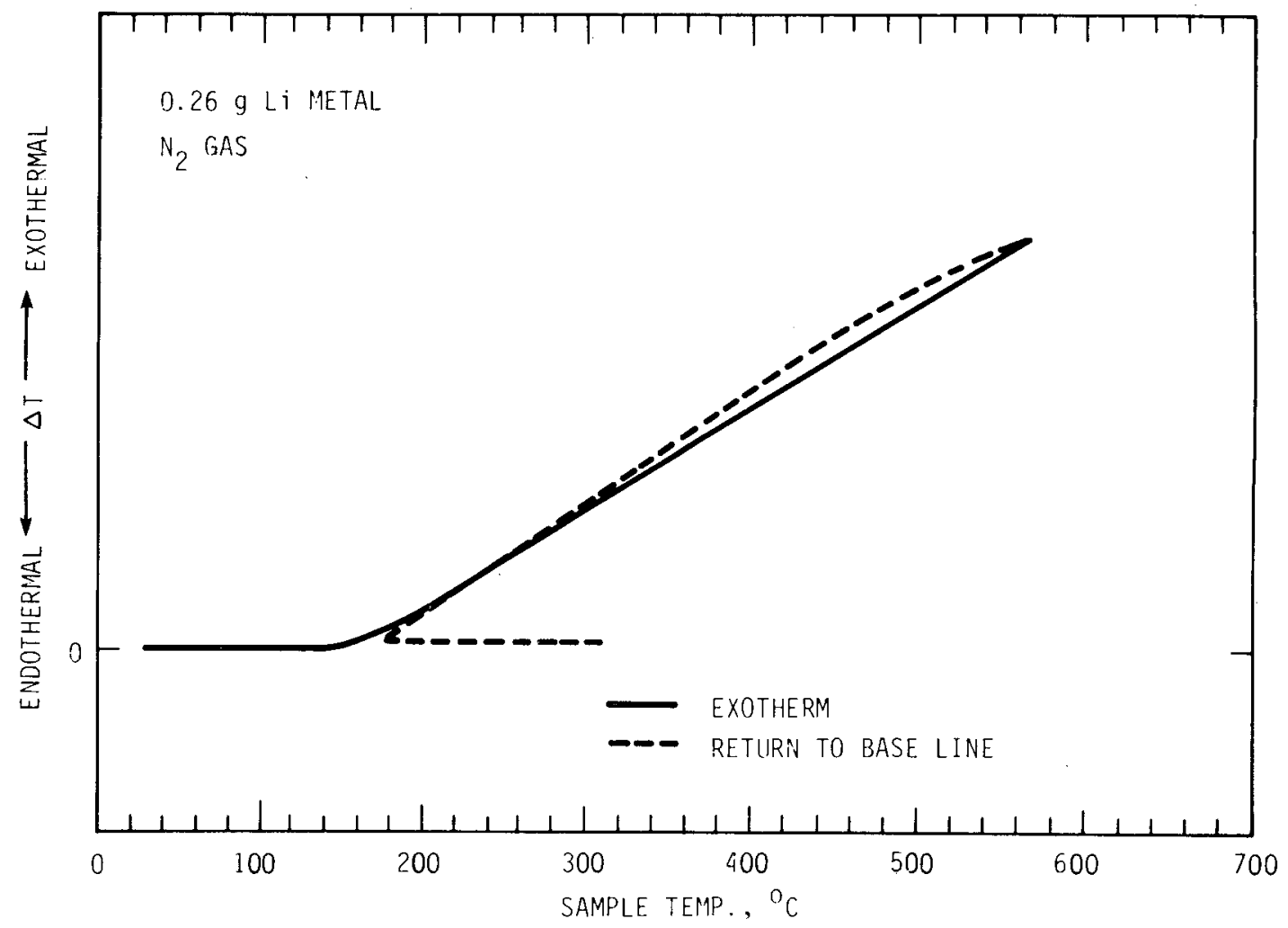

HEDL 7711-63.3

FIGURE 10. DTA Curve of Lithium Metal Dispersed in a Flowing Nitrogen Atmosphere. Ref. 25, Figure 6 
Free energies of formation have been calculated for lithium oxide at different temperatures. ${ }^{(1)}$ The results show an ultimate decrease in free energy with an increase in temperature. More negative values indicate a more exothermic, energetic reaction and therefore a release of more energy.

\begin{tabular}{|c|c|c|}
\hline$G(\mathrm{k} \mathrm{cal} / \mathrm{g}$-atom $\mathrm{C})$ & $\mathrm{T}\left({ }^{\circ} \mathrm{C}\right)$ & Reference \\
\hline $\begin{array}{l}-134 \\
-177 \\
-111\end{array}$ & $\begin{array}{r}25 \\
527 \\
000\end{array}$ & $\begin{array}{l}29 \\
30\end{array}$ \\
\hline-92 & 1227 & 30 \\
\hline
\end{tabular}

\section{Lithium-Nitrogen Reactions}

Lithium is the only alkali metal that will react with nitrogen gas to form a nitride: ${ }^{(31)}$

$6 \mathrm{Li}(\mathrm{s})+\mathrm{N}_{2}(\mathrm{~g}) \rightarrow 2 \mathrm{Li}_{3} \mathrm{~N}(\mathrm{~s}) \quad \Delta \mathrm{H}_{25}{ }^{\circ} \mathrm{C}=-47.50 \mathrm{kcal} / \mathrm{mole}$

Greater than $10 \mathrm{ppm}$ mo isture or elevated temperatures will increase the rate and extent of reaction of lithium and nitrogen. Dry nitrogen will not react with lithium up to about $160{ }^{\circ} \mathrm{C}$. At room temperature with mo isture present, reaction proceeds exothermically, forming a thin protective coating of reddish-brown to black lithium nitride (LiN). The latter is hygroscopic, yielding ammonia in the presence of water. Lithium is more susceptible to nitridation than oxidation at moderate temperatures. $(10,25)$ In a stream of dry nitrogen, the reaction between litihium and nitrogen is 10 to 15 times more rapid than in air. (7) oxygen and hydrogen inhibit the interaction of lithium and nitrogen. Presence of oxygen in nitrogen greater than 14 volume \% or hydrogen over 3.5 volume \% may completely prevent reaction at lower temperatures. (7) With lesser amounts, the reaction proceeds much slower.

Powdered lithium $(<100 \mu$ particle size), when heated in nitrogen flowing at $100 \mathrm{ml} / \mathrm{min}$ in a tube furnace apparatus, ignited at $388{ }^{\circ} \mathrm{C}$ 
and $410{ }^{\circ} \mathrm{C} .(32)$ other ignition temperatures have been quoted at $170{ }^{\circ} \mathrm{C}$, $450{ }^{\circ} \mathrm{C}$ and dull red heat. $(25,32)$

A differential thermal analysis (DTA) was performed on lithium metal dispersions in dry dynamic nitrogen atmospheres at a heating rate of $5^{\circ}$ /minute. (25) The reaction occurred around $170{ }^{\circ} \mathrm{C}$ and was rapid and exothermic. Figure 10 illustrates the results. Formation of appreciable quantities of anhydrous lithium hydroxide (18.6 wt.\%) was requisite before significant formation of lithium nitride occurred. The velocity of the reaction increased to a maximum value, then dropped to zero. (7) Thus, the presence of a lithium hydroxide film on the metal surface is necessary for lithium-nitrogen reactions and explains lithium's susceptibility to low temperature nitridation under moist conditions.

High temperatures were encountered during the rapid nitridation of lithium. Upon ignition in nitrogen, temperatures around $600{ }^{\circ} \mathrm{C}$ were reached in less than one minute with a 0.26 gram lithium dispersion sample. (25) Ignition occurred without fusion and coalescence (mixing) of the metal implying that rapid diffusion of reactant nitrogen through a bed of porous, solid lithium and lithium nitride is possible. With a compact mass of liquid lithium, nitridation may be slower due to diffusion controlling of the reaction.

Reaction rates between dry nitrogen and lithium have been examined for stirred and stationary liquid lithium. (28) With stirring, three stages were observed in which the rate laws followed rectilinear, log-arithmic and parabolic laws successively and independent of pressure. Without stirring, the rectilinear stage was not observed. Reaction rates were strongly temperature dependent. Solubility of nitrogen in the lithium was also an important factor.

With stirring in the presence of nitrogen, liquid lithium spread over the total internal surface area of the containing vessel. Thus 
reaction rates were all influenced by dimensions. An activation energy of $33 \mathrm{kcal} / \mathrm{mole}$ was obtained at the stage in the reaction when rates obeyed the rectilinear law. This lasted approximately 35 minutes. As product accumulated, even stirring could not continually maintain a "fresh" surface for reaction and the logarithmic relationship took over.

This occurred in the region of 12 to $30 \%$ of the total reaction. The reaction was not inhibited by the surface films but proceeded with a parabolic rate law. Activation energy was measured at $1.5 \mathrm{kcal} / \mathrm{mole}$ for surfaces carrying a continuous nitride film. The final reaction product was a ruby-red crystalline lithium nitride.

Without stirring, the lithium-nitrogen reaction was completed in an average of 80 minutes for 0.5 grams of lithium. The region from 33 to $80 \%$ of the total reaction followed the parabolic law. Figures 11 and 12 illustrate the reaction curves of nitrogen with stirred and unstirred lithium at $400{ }^{\circ} \mathrm{C}$. Figure 13 shows the kinetic curves for the reaction at different temperatures.

Free energies of formation have been calculated for lithium nitride at different temperatures. $(1,29,33)$ The results show a decrease in free energy with increasing temperature:

\begin{tabular}{|c|c|c|}
\hline$\Delta \mathrm{G}(\mathrm{kca}) / \mathrm{mo}) \mathrm{e}$ & $I\left({ }^{\circ} \mathrm{C}\right)$ & Reference \\
\hline $\begin{array}{l}-37.3 \\
-20.1 \\
+\quad 3.8\end{array}$ & $\begin{array}{r}25 \\
527 \\
1227\end{array}$ & $\begin{array}{l}29 \\
33 \\
33\end{array}$ \\
\hline
\end{tabular}

\section{Lithium-Hydrogen Reactions}

Lithium readily reacts with hydrogen forming a stable but reactive, high-melting hydride. The reaction proceeds as follows: ${ }^{(1)}$
$\operatorname{Li}(s)+1 / 2$
$\mathrm{H}_{2}(\mathrm{~g}) \rightarrow \mathrm{LiH}(\mathrm{s})$
$\Delta H_{25}{ }^{\circ} \mathrm{C}=-21.61 \mathrm{kcal} / \mathrm{mole}$ 


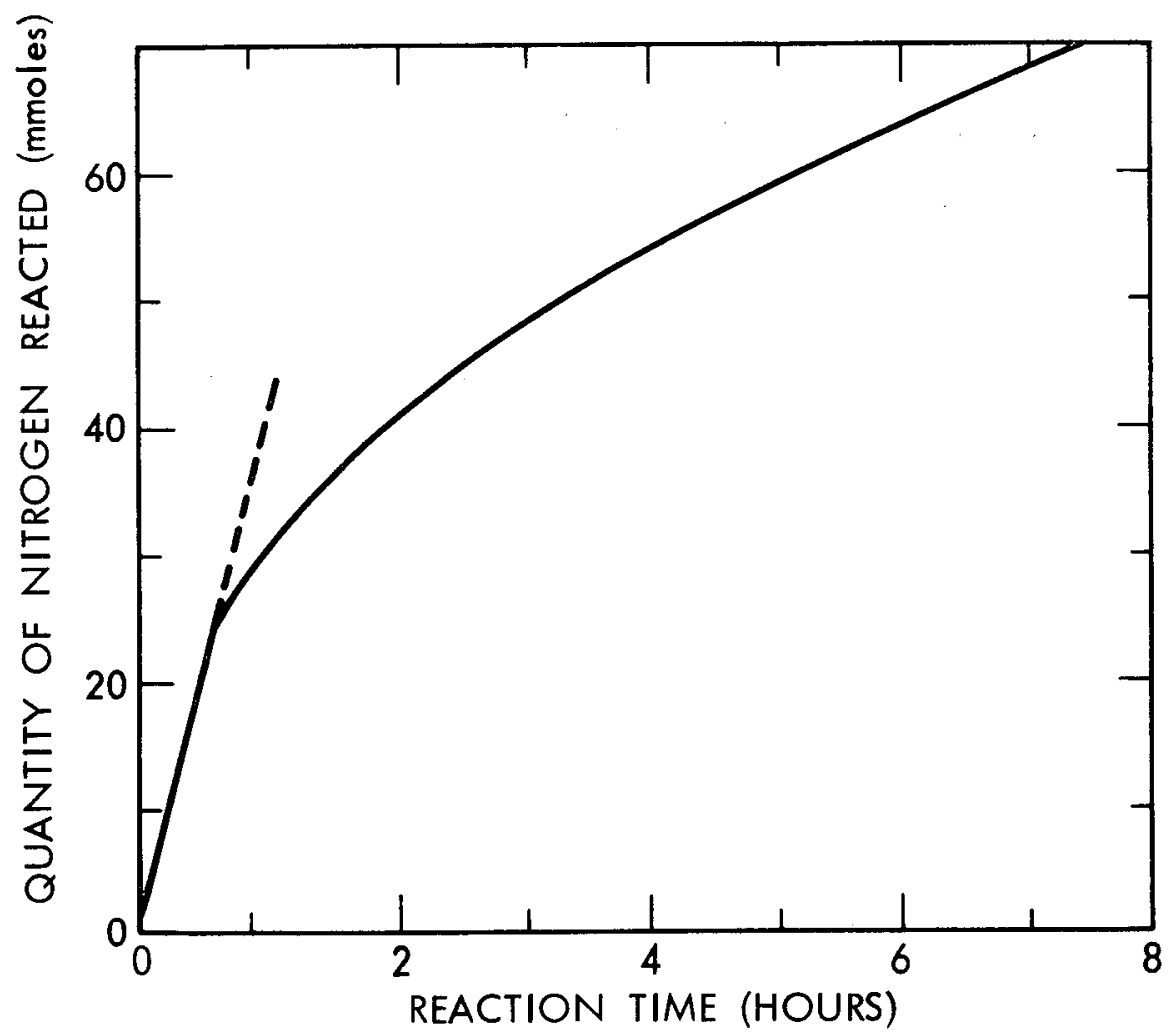

HEDL 7802-039. 14

FIGURE 11. Curves of Stirred Liquid Lithium Reacting with Nitrogen at $400^{\circ} \mathrm{C}$. Ref. 31 , Figure 6

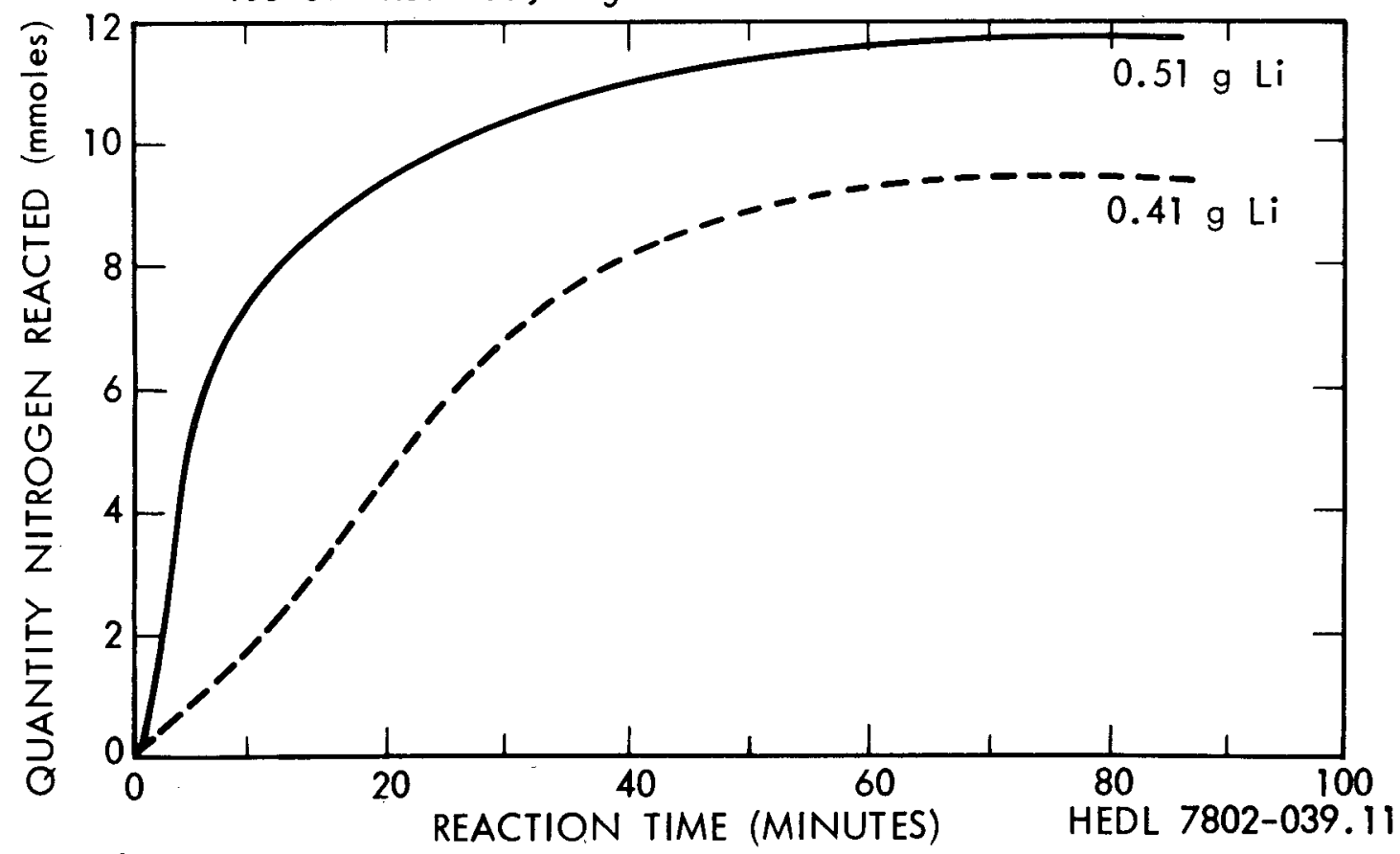

FIGURE 12. Curves of Unstirred Liquid Lithium Reacting with Nitrogen at $400^{\circ} \mathrm{C}$. Ref. 31 , Figure 2 


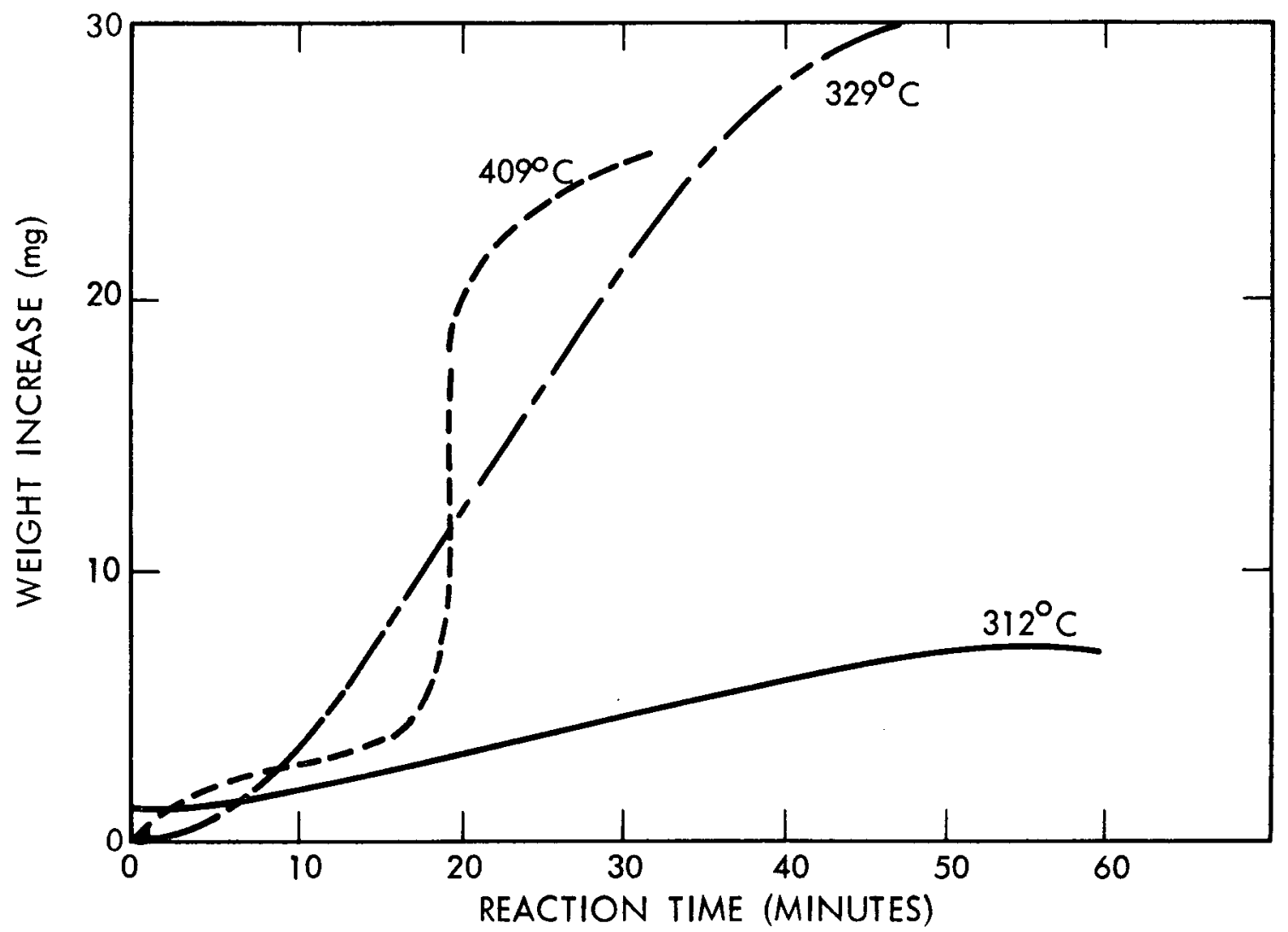

HEDL 7802-039.1

FIGURE 13. Kinetic Curves of Liquid Lithium Reacting with Nitrogen. Ref. 28, Figure 5 
Lithium hydride, depending upon formation conditions, is either white crystalline powder or needle-like crystals. The reaction rate of hydrogen with a clean liquid lithium surface is first order and linear with an activation energy of $12.6 \mathrm{kcal} / \mathrm{mole}{ }^{(34)}$ This activation energy is less than both values for the reactions between hydrogen and sodium or potassium. The ratio of reaction rates at $250{ }^{\circ} \mathrm{C}$ for lithium, potassium and sodium is $43: 4: 1$ respectively. (34) As expected, the rate of reaction increases with increasing temperature. Table 9 and Figure 14 show the effect of temperature on the absorption of hydrogen.

The reaction between molten lithium and purified gaseous hydrogen at high temperatures starts around $400{ }^{\circ} \mathrm{C}$, terminating quick ly at $710{ }^{\circ} \mathrm{C} .{ }^{(7)}$ Explosions and ignitions occur sometimes due to impurities in the initial products. The above values pertain to static, relatively pure systems. Other environments may yield different rates and temperatures.

\section{Lithium-Carbon Dioxide Reactions}

Dry carbon dioxide will not react with lithium at temperatures up to $300{ }^{\circ} \mathrm{C} .{ }^{(1)}$ With moisture present, lithium and pure carbon dioxide react to form lithium carbonate: ${ }^{(1)}$

$2 \mathrm{Li}(\mathrm{s})+3 / 2 \mathrm{CO}_{2}(\mathrm{~g}) \rightarrow \mathrm{Li}_{2} \mathrm{CO}_{3}(\mathrm{~s})+1 / 2 \mathrm{C}(\mathrm{s}) \Delta \mathrm{H}_{25}{ }^{\circ} \mathrm{C}=148.6 \mathrm{kcal} / \mathrm{mole}$

Lithium carbonate is comparatively insoluble in water in contrast to corresponding alkali salts. ${ }^{(9)}$ Formation of the protective carbonate coating slows the reaction significantly. Powdered lithium $(<100 \mu$ particle size), when heated in carbon dioxide flowing at $100 \mathrm{ml} / \mathrm{min}$ in a tube reactor, ignited at $330{ }^{\circ} \mathrm{C} .(32)$

\section{Lithium-Air Reactions}

Lithium reacts slowly in dry air. In moist air it oxidizes more rapidly. Solid lithium becomes coated with lithium nitride, lithium hydroxide, lithium hydroxide monohydrate, lithium carbonate and lithium 
TABLE 9

\section{LITHIUM - HYDROGEN REACTION}

Rate Constants (K)

\begin{tabular}{c}
$\begin{array}{c}\text { Temper ature } \\
\left({ }^{\circ} \mathrm{C}\right)\end{array}$ \\
\hline 217 \\
244 \\
257 \\
270 \\
295
\end{tabular}
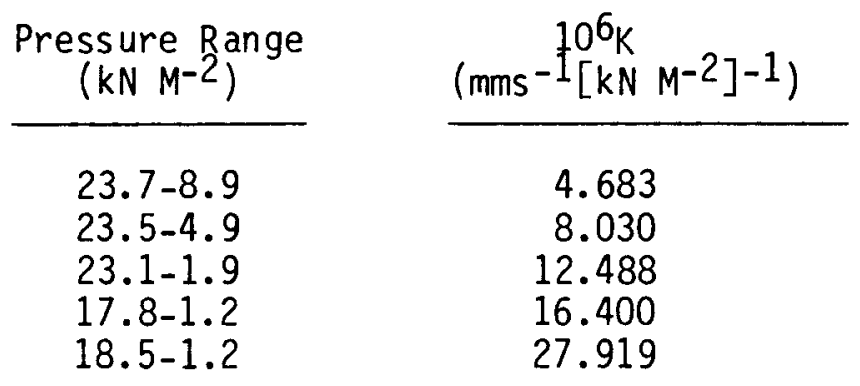

Ref. 34, Table 1

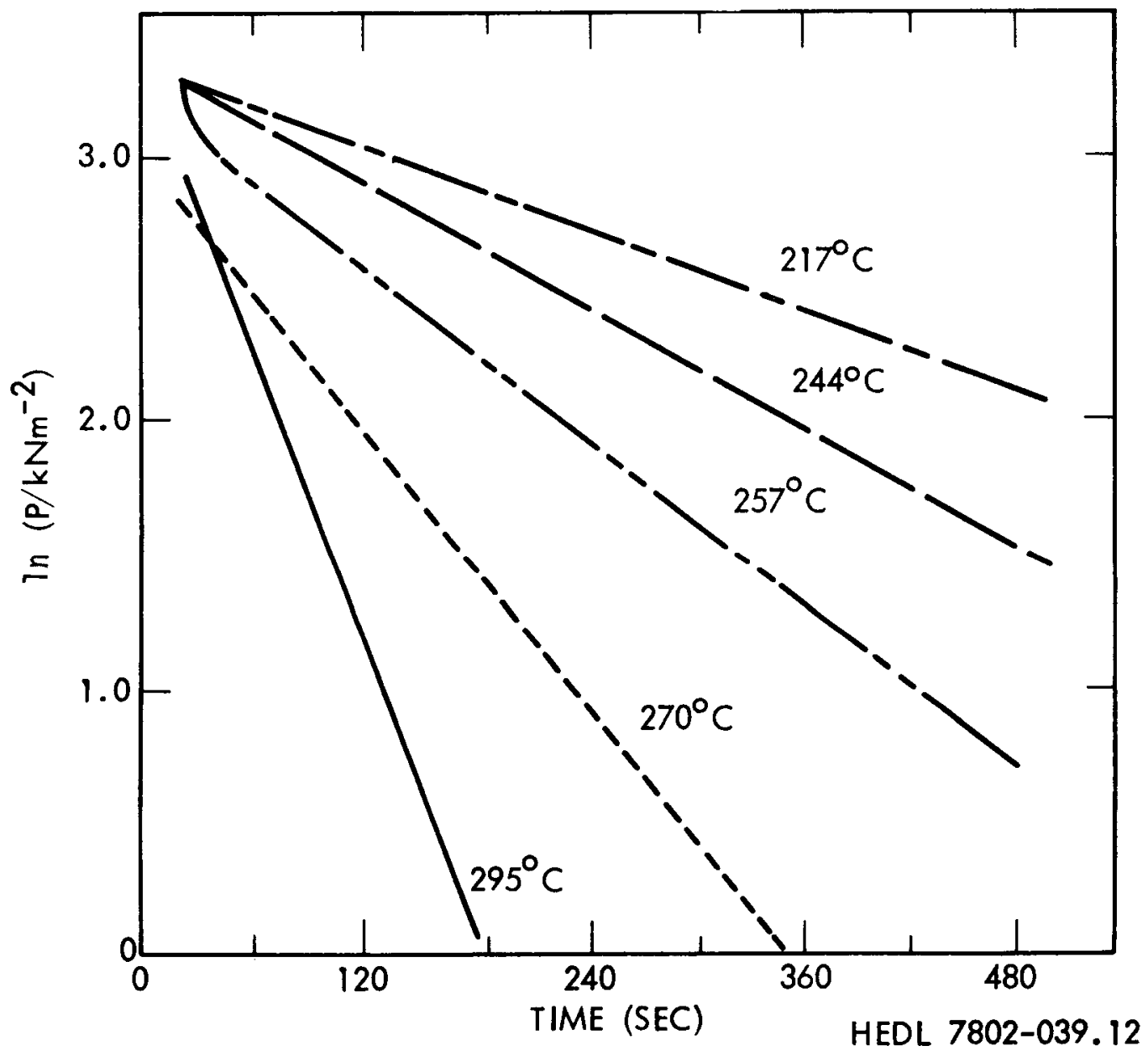

FIGURE 14. Reaction Curves Showing the Effect of Temperature on Liquid Lithium Absorption of Hydrogen. Ref. 34, Figure 1 
oxide. Actual reaction rates, products, and temperatures are contradictory. Values between $180^{\circ} \mathrm{C}$ and $640^{\circ} \mathrm{C}$ have been reported for the ignition temperatures of lithium in air. (11) In one study, lithium metal dispersion samples were exposed to circulating air at $50 \%$ relative humidity and $27{ }^{\circ} \mathrm{C}$. The ultimate reaction product was lithium carbonate. The temperature rise during the early period of atmospheric attack was noteworthy. Figure 15 illustrates these results. Information regarding liquid lithium-air reactions was lacking.

\section{Lithium-Water Reactions (Liquid and Vapor)}

Lithium reacts with water to form lithium hydroxide and hydrogen gas. It combines with water in both air and nitrogen atmospheres, with the lithium-water reactions taking precedence over the lithium-nitrogen reaction. (10) Bulk solid lithium reacts slowly with cold water. The hydrogen formed does not ignite in air. Very finely divided lithium (high total surface area per unit weight or high surface-to-volume ratio) greatly enhances the reactivity over a like weight of the bulk material. Lithium dispersions are quite reactive and ignite (hydrogen gas flames) if thrown into water at room temperature in either air or argon. (10)

The reaction proceeds as written with the heat of reaction measured at $25{ }^{\circ} \mathrm{C}$ as $-53.142 \pm 0.019 \mathrm{kcal} / \mathrm{mole}:^{(35)}$

$$
\mathrm{Li}(\mathrm{s})+1001 * \mathrm{H}_{2} \mathrm{O}(1) \rightarrow \mathrm{LiOH} \cdot 1000 \cdot \mathrm{H}_{2} \mathrm{O}+1 / 2 \mathrm{H}_{2}(\mathrm{~g})
$$

* Number represents concentration corrections related to heats of dilution.

The observed reactivity or rate of a reaction is often related to the rate at which heat is liberated during a chemical combination rather than to the total amount of heat evolved over a prolonged time period. (10) 


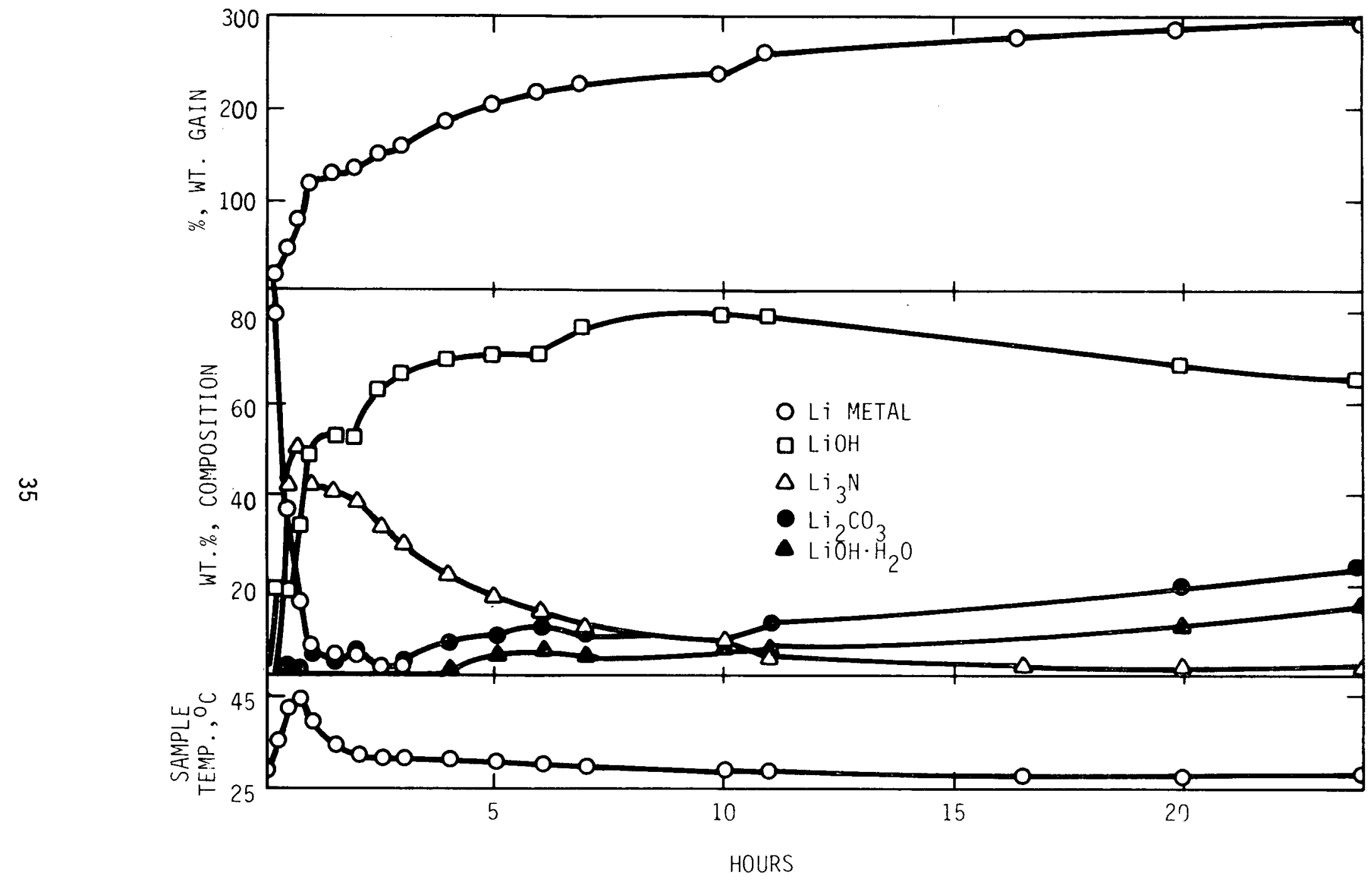

HEDL 7711-63.1

FIGURE 15. Reaction Profiles of 100-125 Mesh Lithium Metal Exposed to Circulating Air. $\left(50 \%\right.$ r.h., $\left.27^{\circ} \mathrm{C}\right)$ Ref. 25 , Figure 2 
Therefore, factors influencing the rate of heat evolution in an alkali metal-water reaction must be considered. The total amount of metal surface or the number of metal atoms exposed to water at any instant will primarily control the rate of heat released assuming relatively little hindrance of lithium metal-water contact due to hydrogen gas liberation. Two anomalieș exist despite the tendencies just discussed:

- Solid lithium metal is considerably less reactive with water than sodium in air environments despite relatively small differences in the initial number of atoms exposed to water.

- Other alkali metals are known to be more reactive towards water than sodium or lithium despite larger unfavorable differences in the number of exposed atoms.

In reaction with liquid water at room temperature under an argon atmosphere, an irregularly shaped piece of solid lithium retained its original geometrical configuration when put in water. The reason for this phenomenon is that the water in contact with lithium metal acts as a heat sink to prevent fusion. A thermocouple embedded in a 3/8-inch sphere of lithium immersed in 250 cubic centimeters $\left(\mathrm{cm}^{3}\right)$ of room temperature water under argon or air indicated a maximum bulk temperature of on ly $98^{\circ} \mathrm{C}$ to $103^{\circ} \mathrm{C}$. (10) Immersion of solid lithium in a slurry of ice and water exposed to air results in pronounced diminution of activity. The bulk temperature of a 3/8-inch sphere on ly reaches a maximum of $40{ }^{\circ} \mathrm{C}$. This proves the effectiveness of the surrounding water as a heat sink. (Note: only valid when volume of water volume of lithium.) For large pieces of solid lithium in restricted volumes of water, the relative insolubility of the product ( $\mathrm{LiOH}$ ) may impede the reaction. Suitable coatings of lithium hydroxide may have some protective effects on the lithium meta1. However, hydrogen and metal oxidation by air might increase the vigor of a water-initiated sequence of events. 
In boiling water under an argon atmosphere, solid lithium reacts without combustion. If allowed to stand in flowing steam, a white coating forms consisting of $\mathrm{LiOH}, \mathrm{LiOH} \cdot \mathrm{H}_{2} \mathrm{O}$ and $\mathrm{Li}_{2} \mathrm{O}$. Within five minutes, the edges of the coating become incandescent. Liquid lithium metal flows through the cracks in the coating and starts to burn brilliantly. (10) The initial protective effects of the LiOH coating as it becomes thicker and develops cracks and strains, loses its protective character. It still functions like a thermal insulator to raise the metal to melting and ignition temperatures by retaining the heat of the lithium-steam reaction. At this point, the reaction tends to become quite vigorous. Hydrogen gas is one of the combustion products in this alkali metal-steam flame.

The reaction of solid lithium with water vapor (in moist argon and oxygen atmospheres) was studied from $20{ }^{\circ} \mathrm{C}$ to $45{ }^{\circ} \mathrm{C}$ and from $45{ }^{\circ} \mathrm{C}$ to $75^{\circ} \mathrm{C} .(27,36)$ Water vapor was present in partial pressures up to $100 \mathrm{~mm}$ $\mathrm{Hg}$. Three reaction stages were identified:

- Formation at a constant rate of a lithium hydroxide film,

- Localized nucleation and growth by spreading of lithium hydroxide monohydrate at the outer surfaces of the hydroxide film,

- Simultaneous formation and hydration of the hydroxide at a constant rate culminating in the complete conversion of the metal to lithium hydroxide monohydrate.

Figure 16 shows the reaction curves using a mo ist oxygen atmosphere for the $25{ }^{\circ} \mathrm{C}$ to $42{ }^{\circ} \mathrm{C}$ temperature range. The initial step took approximately three to four hours with reaction rate remaining constant. The surface acquired a black glossy tarnish identified as partially formed lithium hydroxide. The intermediate step required one to four hours 


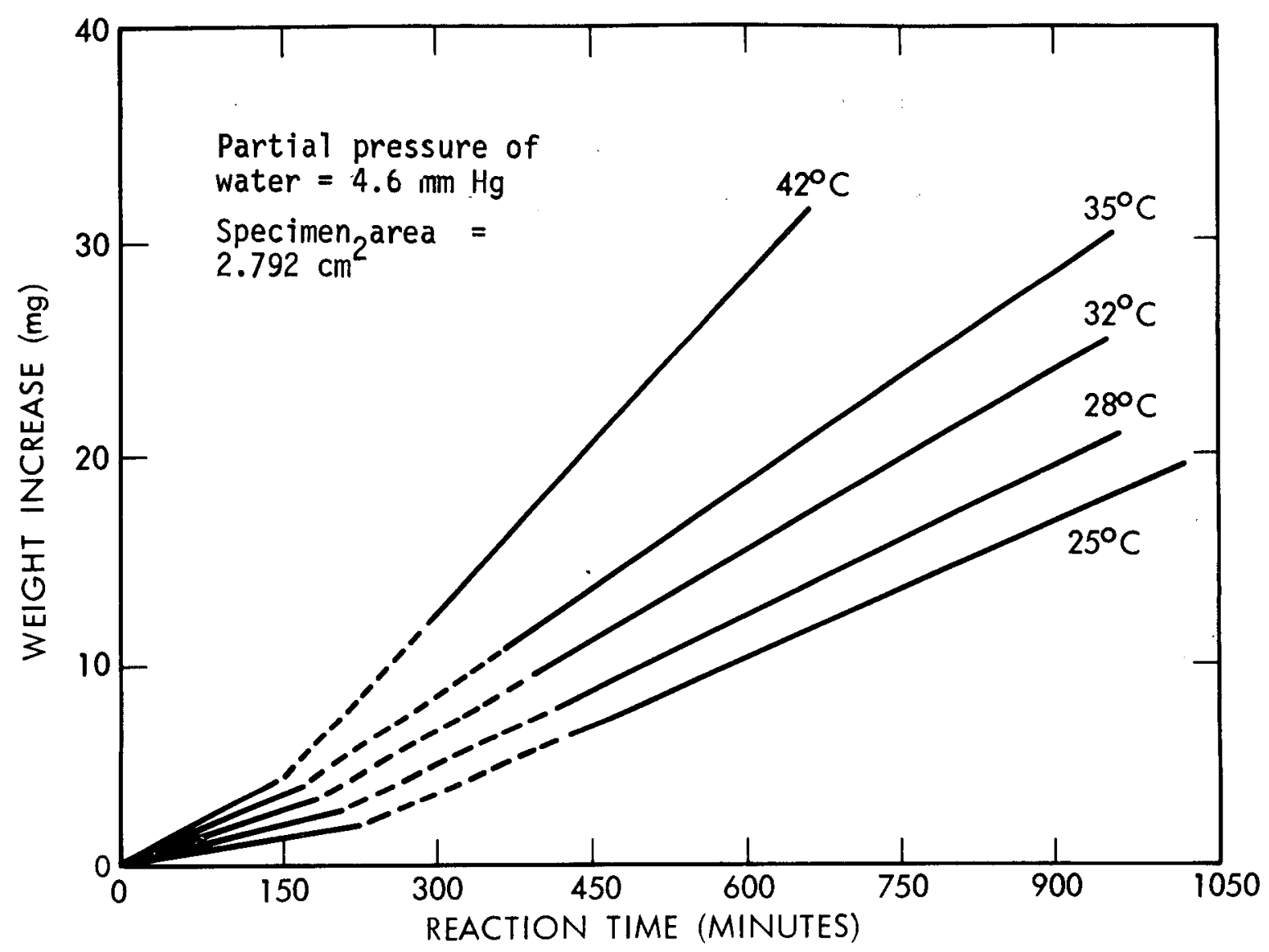

HEDL 7802-039.10

FIGURE 16. Reaction Curves for Lithium Metal Specimens in Moist 0xygen at Various Temperatures. Ref. 27, Figure 1

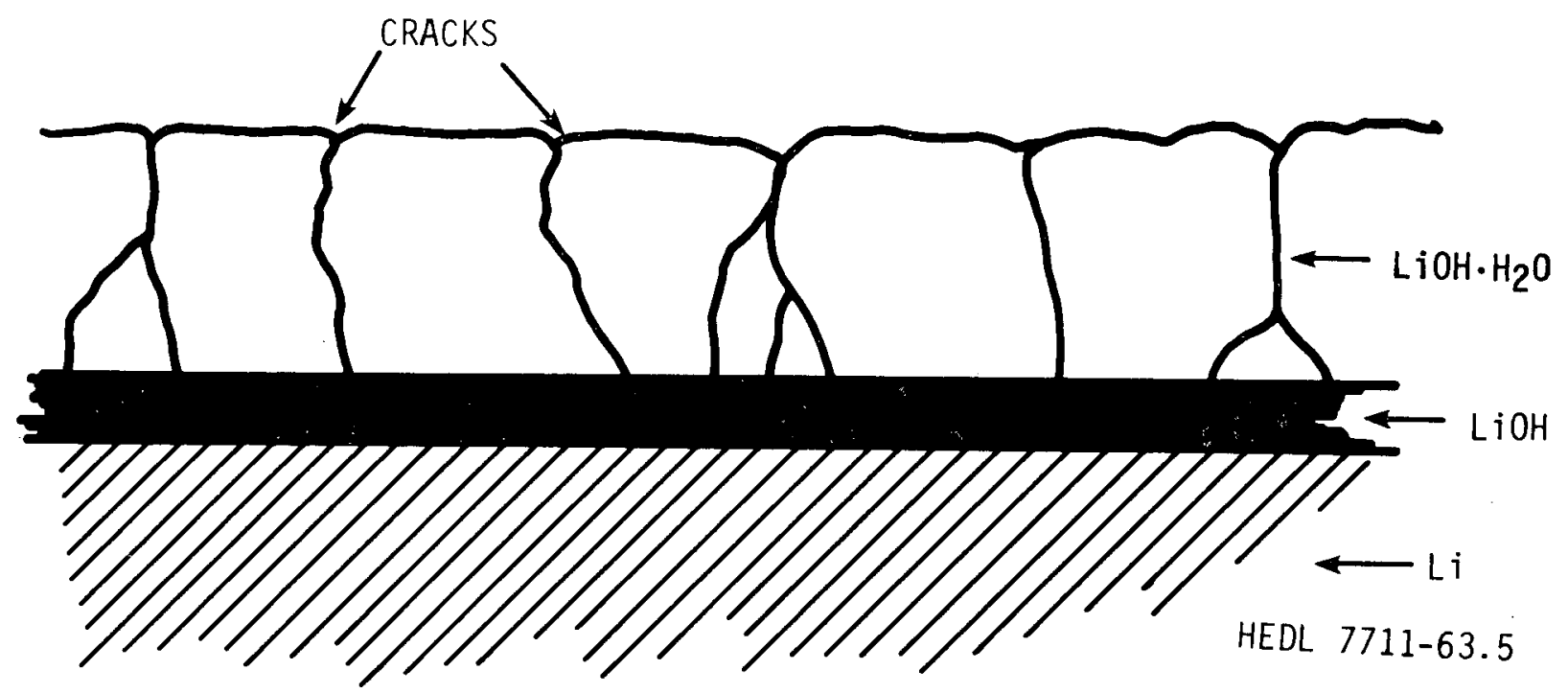

FIGURE 17. Distribution of Lithium-Water Reaction Products. Ref. 27, Figure 5 
(depending upon the temperature) during which the reacton rate increased continuousiy. White reaction product appeared at the edges of the lithium and grew laterally across the surface, confirming the presence of lithium hydroxide and lithium hydroxide monohydrate. Figure 17 illustrates the assumed distribution of reaction products. The final stage of the reaction proceeded at a constant rate approximately one and one-half times the rate of the first step. The actual range was between 1.3 and 1.9 times faster with the latter value holding for the low reaction temperatures. ${ }^{(27)}$ The entire surface was white and uniformly thick. Lithium hydroxide monohydrate was the on ly product present. Activation energies encountered at the initial and final stages of the reaction were $11.7 \pm 2.5 \mathrm{kcal} / \mathrm{mole}$ and $7.7+1.8 \mathrm{kcal} / \mathrm{mole}$, respectively, for the $20{ }^{\circ} \mathrm{C}$ and $4 \overline{5}{ }^{\circ} \mathrm{C}$ temperature range. $(\overline{2} 7)$

Figure 18 shows the dependence of the reaction rate at $35^{\circ} \mathrm{C}$ on water vapor pressure. Reaction rates for the initial and final stages of reaction increase rapidly with pressures between 2.9 and $4.6 \mathrm{~mm} \mathrm{Hg}$. A further increase in pressure causes a slower increase in the reaction rates. (27)

At temperatures between $45^{\circ} \mathrm{C}$ and $75^{\circ} \mathrm{C}$ and water vapor pressures between 22 and $55 \mathrm{~mm} \mathrm{Hg}$, the reaction rate constant is independent of pressure. (36) The reaction is diffusion controlled, dependent upon the diffusion of the reacting species across the developing hydroxide film. Activation energies encountered for vapor partial pressures of 50 and $100 \mathrm{~mm} \mathrm{Hg}$ are around $6.2 \mathrm{kcal} / \mathrm{mole}$ and $5.5 \mathrm{kcal} / \mathrm{mole}$, respectively. (36) At pressures greater than $55 \mathrm{~mm} \mathrm{Hg}$, reaction rate will again be pressure dependent.

Two separate and distinct types of explosions might occur when hot molten lithium and liquid water are brought into contact. (37) The first is a physical phenomenon--the sudden vaporization and overheating 


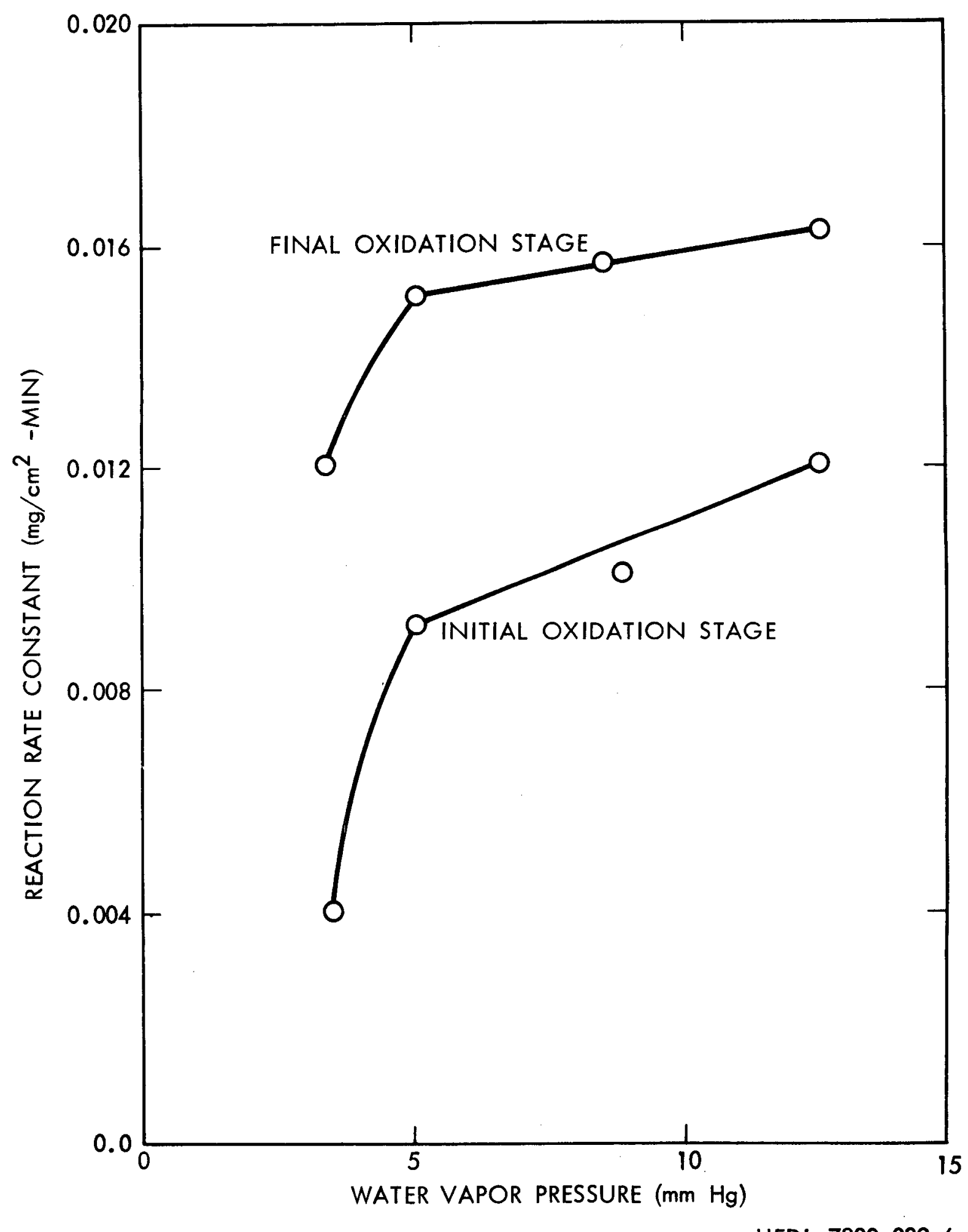

HEDL 7802-039.6

FIGURE 18. Rate Constants of Lithium Metal Reacting with Moist 0xygen at $35^{\circ} \mathrm{C}$. Ref. 27 , Figure 4 
of a mass of water resulting in the generation of high pressures and maybe a boiler type explosion. The second is a chemical reaction:

$$
\text { Metal (1) }+n \mathrm{H}_{2} \mathrm{O}(1) \rightarrow \text { Metal } \mathrm{O}_{n}+\mathrm{n} \mathrm{H}_{2}(\mathrm{~g})
$$

This may take place with extreme rapidity and violence accompanied by a release of heat. The reactive metal must be molten before contacting water for both results to occur. In the physical reaction, only relatively large masses are effective in producing an explosion. In the chemical reaction, a fine state of subdivision of liquid metal and large interfacial area between the two immiscible reacting phases are required. Most important, however, the metal must be capable of displacing two hydrogens from water molecules with great rapidity. With lithium, only one hydrogen is displaced with formation of lithium hydroxide as the preferred reaction product. Therefore, this chemical reaction should not be feasible for lithium.

It is postulated that to cause an explosion when a mass of hot lithium falls into a pool of water. The lithium must contact the bottom of the containing vessel while part of its mass is still fluid. If water is trapped between the molten metal and the bottom of the vessel, cooling of the metal will result in heating of the trapped water forming steam and causing dispersal. No evolution of hydrogen or any other chemical reaction occurs between the system's components.

The nature of the surface on which the metal rests is important. If the solid interface is not readily wetted by liquid water (hydrophobic), it is difficult to obtain the trapping necessary for sustaining an explosion. If the interface is hydrophilic (clings to water), an explosion can occur under conditions where none would occur, for example, with a smooth metallic bottom. Layers of rust, lime, gypsum, aluminum and iron hydroxide especially promote settling. Coating a surface with oil, grease, tar, paint and other surface finishes with little or no affinity for water tends to prevent trapping of water and thus explosions. 
Most of the available information for lithium-water reactions pertains to solid lithium reacted on a very small scale. It is reported that for lithium, rate laws do not depend on whether the metal is liquid or solid but on the nature of the reaction films formed. Thus the laws may be extrapolated into the liquid range. (37) Whether this holds true for all temperatures and quantities of lithium and water is not known. 


\section{LITHIUM COMPOUNDS}

The four most predominant compounds formed from lithium reactions are lithium hydride $(\mathrm{LiH})$, lithium oxide $\left(\mathrm{Li}_{2} \mathrm{O}\right)$, lithium nitride $\left(\mathrm{Li}_{3} \mathrm{~N}\right)$, and lithium hydroxide $(\mathrm{LiOH})$. Table 10 lists some properties and descriptions of these. All are stable but extremely reactive and corrosive compounds.

TABLE 10

PROPERTIES OF LITHIUM COMPOUNDS

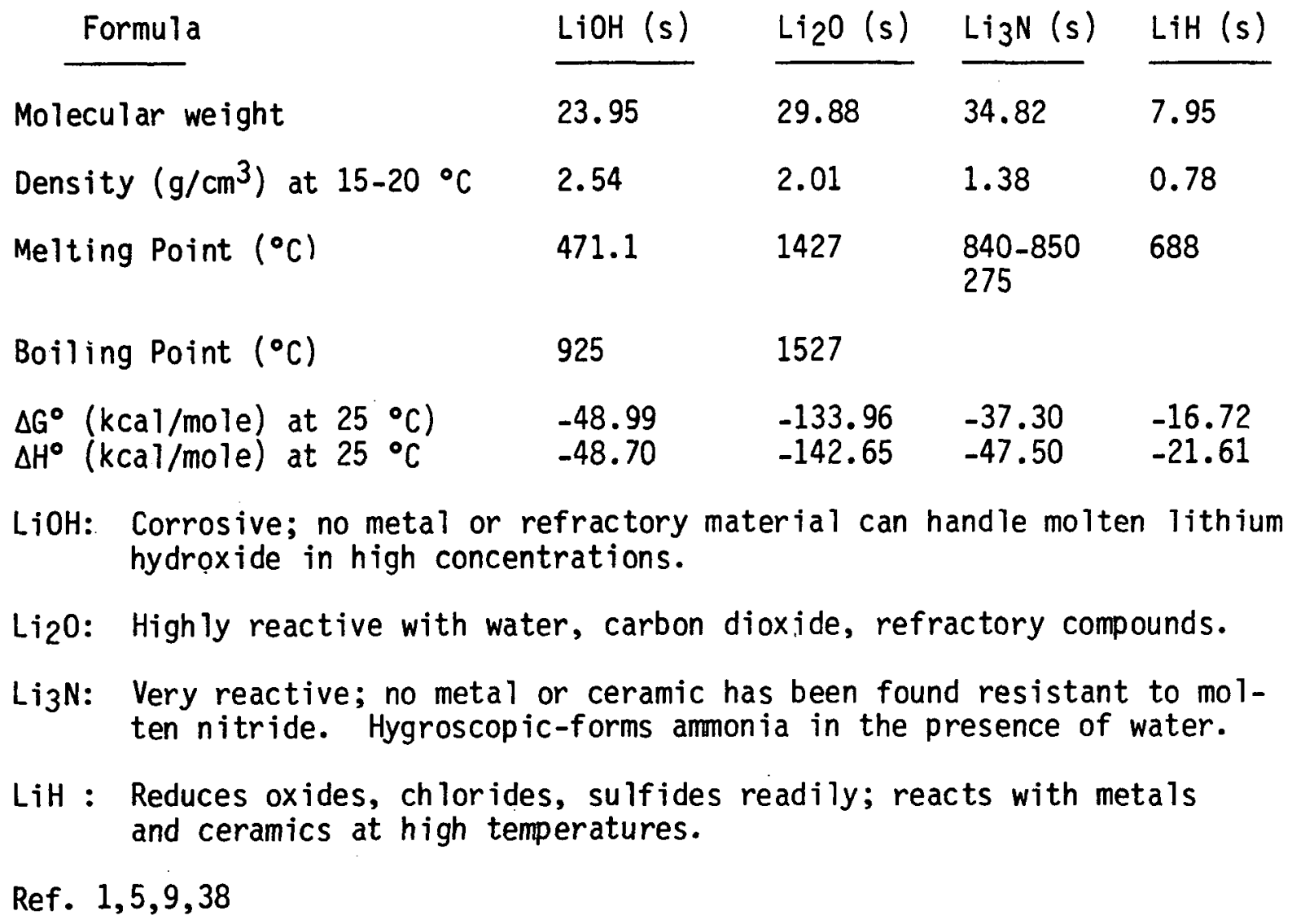




\section{CORROSION-RESISTANCE OF MATERIALS TO ATTACK BY LITHIUM}

\section{General $(1,8)$}

Glasses, plastics and ceramics are all attacked by molten lithium near the melting point. Severe attack is due to formation of relatively stable but highly corrosive lithium oxide, nitride and carbide. Nonmetallic impurities in the liquid metal have a profound effect on the compatibility behavior of lithium and other materials. For example, molten lithium nitride, readily formed from liquid lithium-nitrogen reactions is highly reactive. No metal or ceramic material has been found resistant to it. Molten lithium hydroxide, a possible impurity since oxygen is present in solid lithium as hydroxide rather than the oxide, is very corrosive. No refractory material or metal can handle it at high concentration. Molten lithium chloride, found in commercial lithium, attacks iron and copper. Molten lithium hydride resulting from lithium exposed to hydrogen gas or moisture is reactive with metals and ceramics at high temperatures.

Armco steel shows good resistance at temperatures up to $600{ }^{\circ} \mathrm{C}$. It is generally resistant to attack up to $1000{ }^{\circ} \mathrm{C}$ and higher. High purity molten lithium may be held in quartz containers up to $285^{\circ} \mathrm{C}$. However, commercial lithium readily attacks glass, quartz, porcelain and other silicate materials. Lithium attacks most oxides of structural metals, less stable metal carbides, silicides, rubbers and plastics. Figures 19, 20 and 21 show the resistance ratings of various materials to liquid lithium under different conditions.

2. Ceramics and Insulating Materials $(1,39)$

Corrosion resistance of ceramics is an extremely sensitive function of the impurity concentration, deposition of the reaction products on the ceramic surfaces in contact with lithium, and the size and distribution (porosity) of pores with respect to grain boundaries. From a 


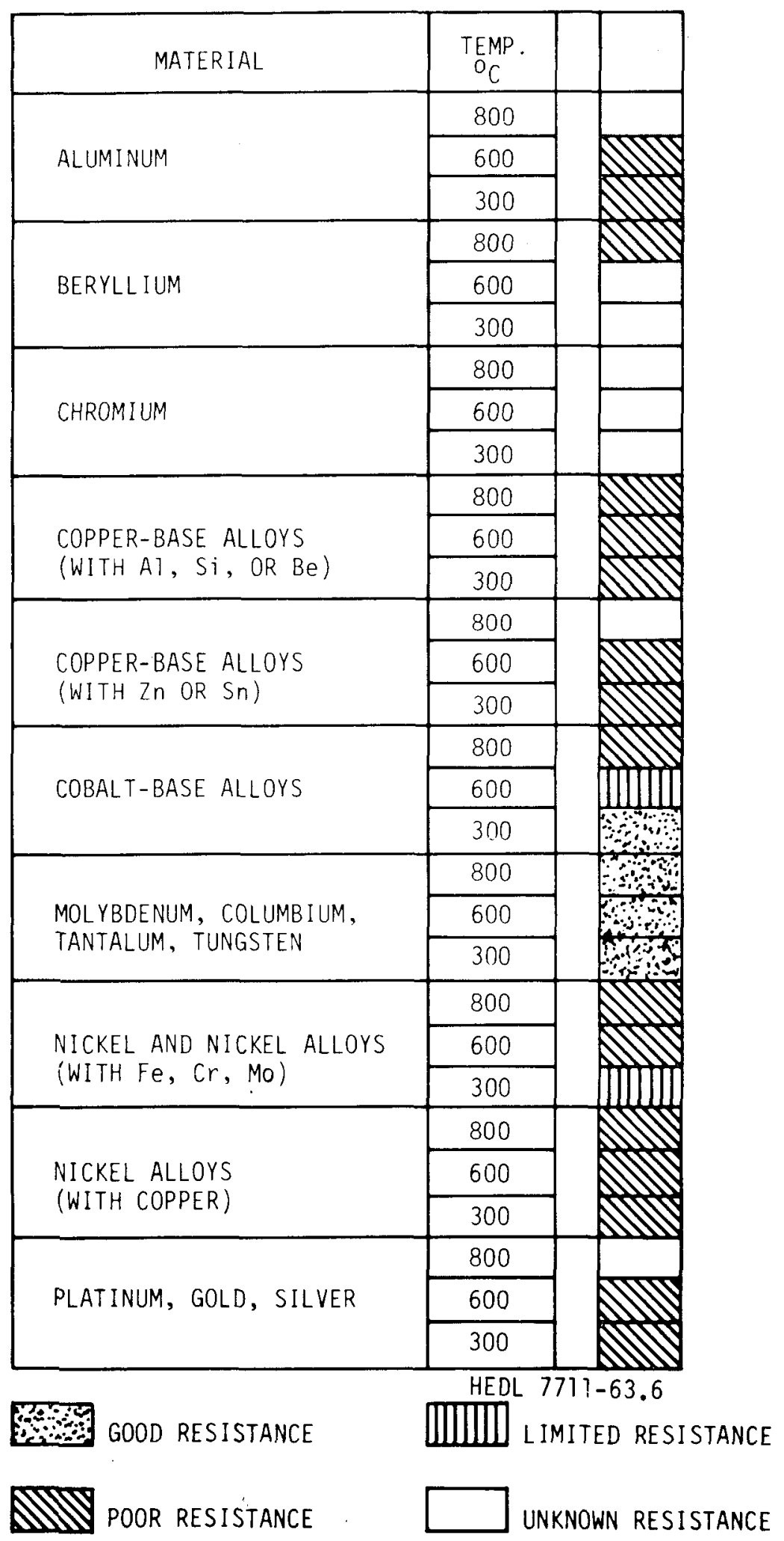

FIGURE 19. Resistance of Various Materials to Liquid Lithium. Ref. 8; 1, Figure 11 


\begin{tabular}{|c|c|c|}
\hline MATERIAL & $\begin{array}{l}\text { TEMP. } \\
{ }^{O} \mathrm{C}\end{array}$ & \\
\hline \multirow{3}{*}{ TITANIUM } & 800 & \\
\hline & 600 & \\
\hline & 300 & \\
\hline \multirow{3}{*}{ ZIRCONIUM } & 800 & \\
\hline & 600 & \\
\hline & 300 & \\
\hline \multirow{3}{*}{ ALUMINA (DENSE) } & 800 & $A$ \\
\hline & 600 & \\
\hline & 300 & \\
\hline \multirow{3}{*}{ GRAPHITE (DENSE) } & 800 & \\
\hline & 600 & \\
\hline & 300 & \\
\hline \multirow{3}{*}{ BERYLLIA (DENSE) } & 800 & \\
\hline & 600 & \\
\hline & 300 & \\
\hline \multirow{3}{*}{ MAGNESIA (CRUCIBLE) } & 800 & \\
\hline & 600 & \\
\hline & 300 & \\
\hline \multirow{3}{*}{ PORCELAIN/SILICATES } & 800 & \\
\hline & 600 & \\
\hline & 300 & \\
\hline \multirow{3}{*}{ PYREX GLASS } & 800 & \\
\hline & 600 & \\
\hline & 300 & \\
\hline \multirow{3}{*}{ FUSED QUARTZ } & 800 & \\
\hline & 600 & \\
\hline & 300 & ANI \\
\hline
\end{tabular}

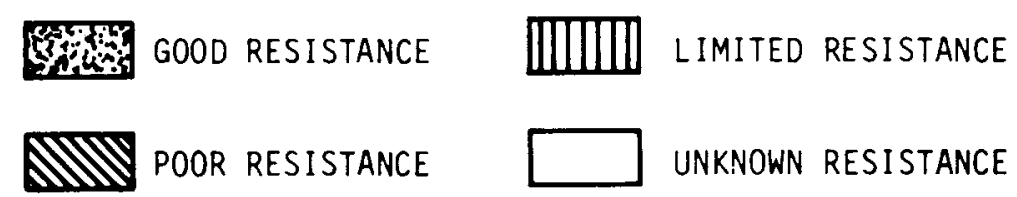

FIGURE 19. Resistance of Various Materials to Liquid Lithium (Cont'd) 


\begin{tabular}{|c|c|c|}
\hline MATERIAL & $\begin{array}{l}\text { TEMP. } \\
{ }^{\circ} \mathrm{C}\end{array}$ & \\
\hline \multirow{3}{*}{ PURE IRON } & 800 & \multirow{3}{*}{ 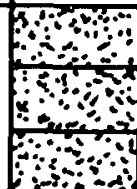 } \\
\hline & 600 & \\
\hline & 300 & \\
\hline \multirow{3}{*}{ MILD CARBON STEEL } & 800 & \\
\hline & 600 & \\
\hline & 300 & \\
\hline \multirow{3}{*}{$\begin{array}{l}\text { LOW-CHROMIUM STEEL } \\
\text { (WITH V, MO, OR Si) }\end{array}$} & 800 & \\
\hline & 600 & \\
\hline & 300 & \\
\hline \multirow{3}{*}{$\begin{array}{l}2 \text { TO } 9 \% \text { CHROMIUM STEEL } \\
\text { (WITH Ti, MO, OR Si) }\end{array}$} & 800 & \\
\hline & 600 & \\
\hline & 300 & \\
\hline \multirow{3}{*}{$\begin{array}{l}\text { FERRITIC STAINLESS STEEL } \\
\text { (12 T0 } 27 \% \text { CHROMIUM) }\end{array}$} & 800 & \multirow{3}{*}{ 隹 } \\
\hline & 600 & \\
\hline & 300 & \\
\hline \multirow{3}{*}{$\begin{array}{l}\text { AUSTENITIC STAINLESS STEEL } \\
(18-8 \text { AND } 25-20 \mathrm{Cr}-\mathrm{Ni})\end{array}$} & 800 & \\
\hline & 600 & \\
\hline & 300 & Fid \\
\hline \multirow{3}{*}{ GRAY CAST IRON } & 800 & \\
\hline & 600 & \\
\hline & 300 & \\
\hline
\end{tabular}

GOOD RESISTANCE

盂盂 LIMITED RESISTANCE

POOR RESISTANCE

UNKNOWN RESISTANCE

FIGURE 19. Resistance of Various Materials to Liquid Lithium (Cont'd) 


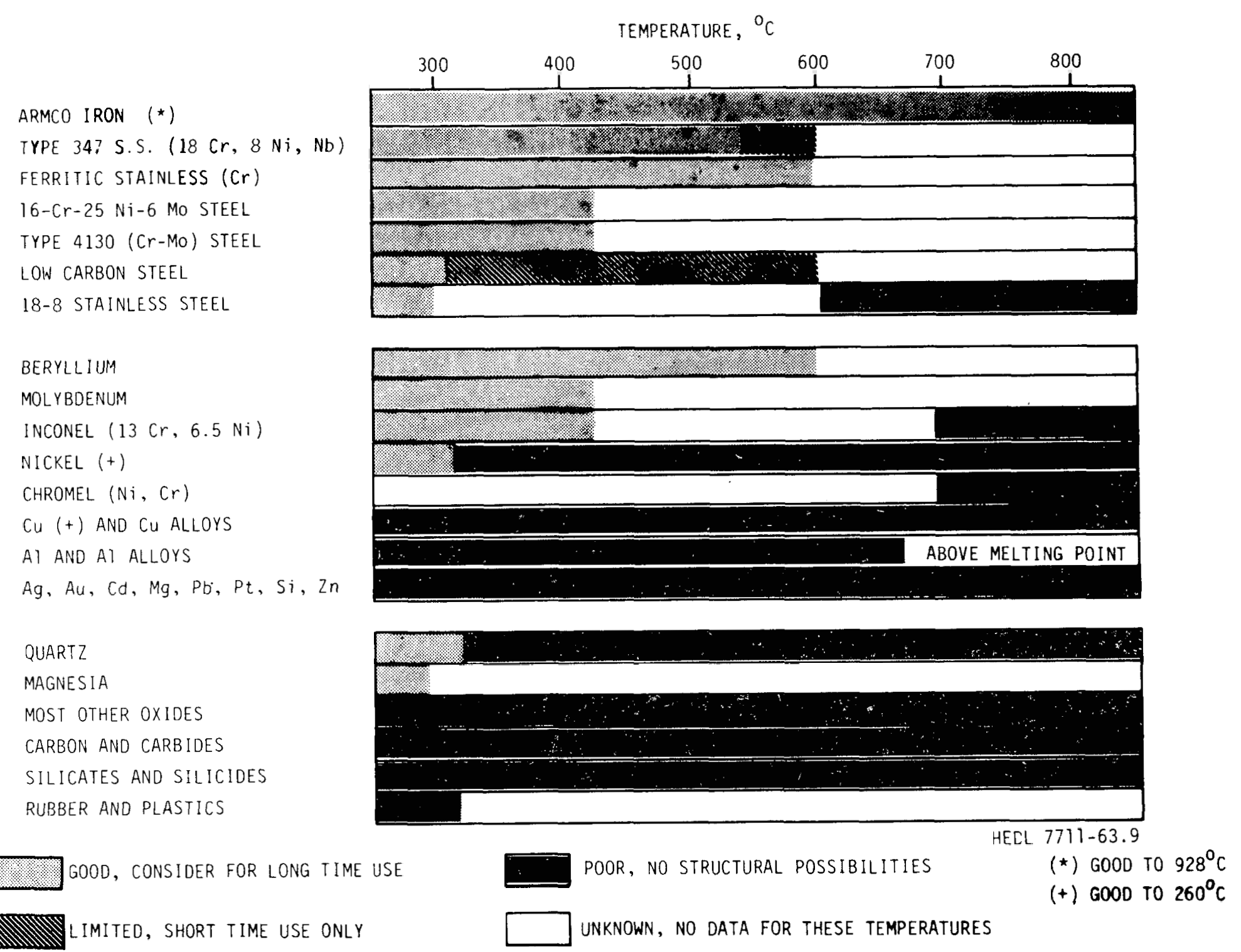

FIGURE 20. Resistance of Various Materials to Lithium. Ref. 1, Figure 12 
Ferrous Metals

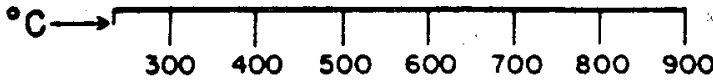

Pure Iron
Low-Corbon Steel
Low-Chromium Steel (4130)
Ferritic-Chromium Stainless Steel
Austenitic Cr-Ni Stainless Steel

Nonferrous Metals

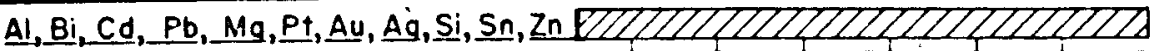

Beryllium. Chromium, Vanadium $1 Z Z 2$

Zirconium, Titanium

Columbium, Tontalum, Molybdenum

Nickel and Nickel-base Alloys IIIIIIIIIIIIIEZZZZZZLZZZZZZD

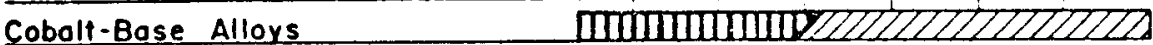

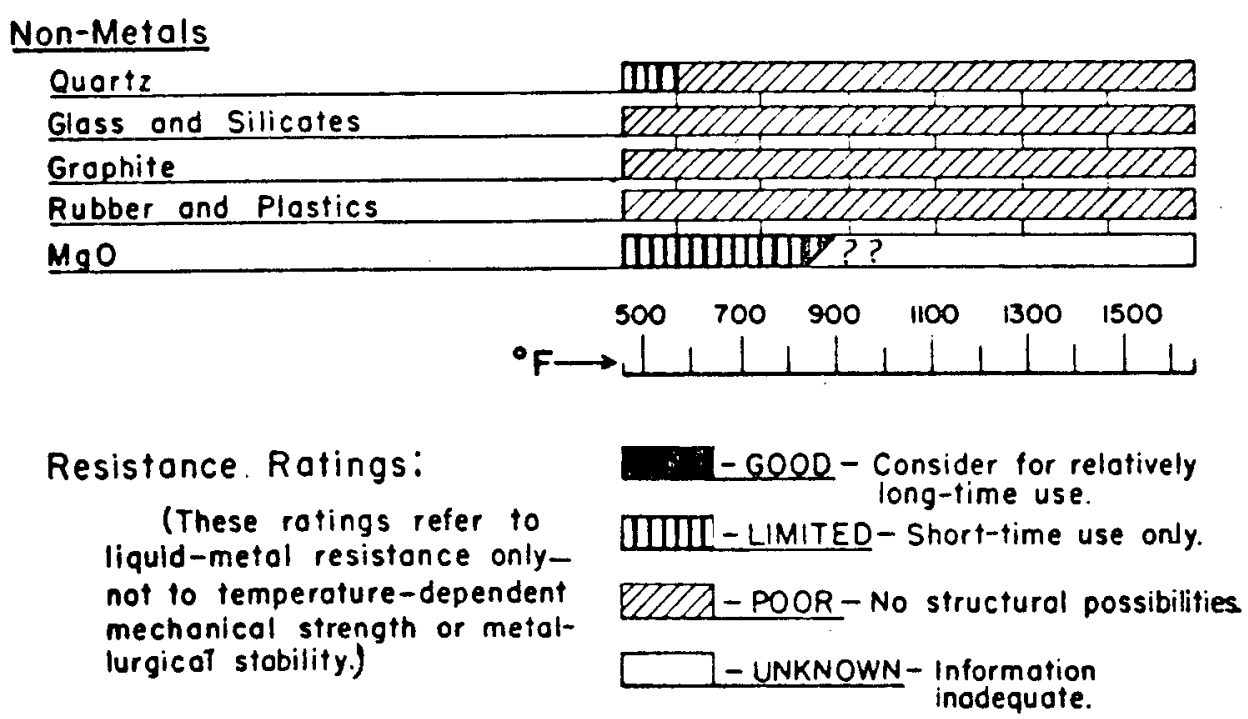

FIGURE 21. Resistance of Various Materials to Liquid Lithium. Ref. 8; 9, Figure 14.2 
thermodynamic point of view, relatively higher levels of concentration of non-metallic impurities in liquid lithium are desired. With impure lithium systems, the oxide ceramics ( $\mathrm{ThO}_{2}, \mathrm{BeO}, \mathrm{Y}_{2} \mathrm{O}_{3}, \mathrm{MgO}$ ) are reported compatible with lithium only if the oxygen level in lithium is greater than a $10^{3} \mathrm{ppm}$ level. At an oxygen level less than or equal to $1 \mathrm{ppm}$ in lithium, the following oxide ceramics are thermodynamically incompatible: $\mathrm{Al}_{2} \mathrm{O}_{3}, \mathrm{MgAl}_{2} \mathrm{O}_{4}$ (spinel), $\mathrm{MgO}, \mathrm{ThO}_{2}, \mathrm{Be} 0, \mathrm{Y}_{2} \mathrm{O}_{3}, \mathrm{ZrO}_{2}$, $\mathrm{TiO}_{3}$ (rutile), $\mathrm{Li}_{2} \mathrm{O}, \mathrm{SiO}_{2}$. At a nitrogen level less than or equal to $10^{-3} \mathrm{ppm}$, all nitrogen ceramics (AlN, BN, $\mathrm{Si}_{3} \mathrm{~N}_{4}, \mathrm{Li}_{3} \mathrm{~N}$ ) are incompatible. $A 1 N, B N$, and $\mathrm{Si}_{3} \mathrm{~N}_{4}$ are compatible if nitrogen levels are greater than $10^{3} \mathrm{ppm}$. Figure 22 illustrates these results.

In conclusion, the compatibility conditions for oxide and nitride ceramics in a liquid lithium environment were found more severe than in a liquid sodium environment. Thermodynamically, only BeO, $\mathrm{Y}_{2} \mathrm{O}_{3}, \mathrm{Si}_{3} \mathrm{~N}_{4}$, $\mathrm{BN}, \mathrm{AlN}, \mathrm{ThO}_{2}$, and $\mathrm{MgO}$ are expected to be compatible with a liquid lithium environment from temperatures between $27^{\circ} \mathrm{C}$ and $1427{ }^{\circ} \mathrm{C}$. (These conclusions are subject to thermodynamic criterion only. Stability of a compound thermodynamically is a necessary but not sufficient condition for compatibility). ${ }^{(39)}$

A second set of compatibility test results were contradictory to the above. A series of tests run at $1093^{\circ} \mathrm{C}$ were performed with the following results: (1)

- Light attack was observed on samples of $\mathrm{Sm}_{2} \mathrm{O}_{3}$ after 500 hours, $\mathrm{ThO}_{2}$ after 1000 hours, TiC and $\mathrm{ZrC}$ after 2000 hours, and $\mathrm{ThO}_{2}-\mathrm{Y}_{2} \mathrm{O}_{3}$ mixtures after 3000 hours.

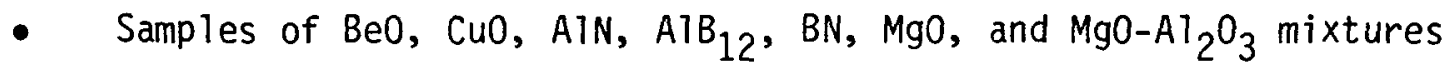
were very badly attacked at $1093^{\circ} \mathrm{C}$ in less than 500 hours.

Tables 11 and 12 and Figure 23 show the results of other compatibility tests for the corrosion of ceramics by lithium. 


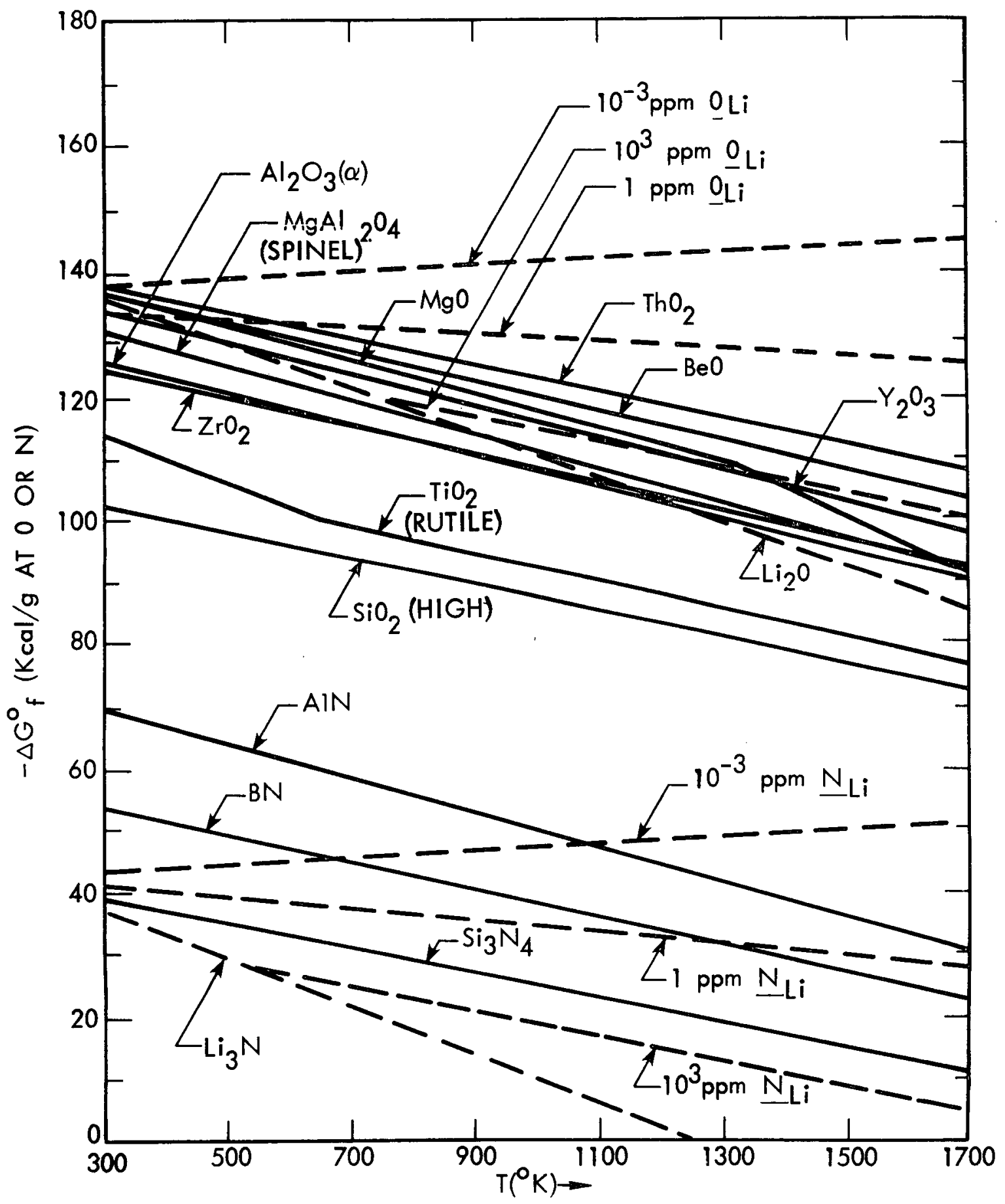

HEDL 7802-039.7

FIGURE 22. Lithium-Ceramics Stability Diagram. The standard free energy of insulating ceramics formation and the chemical potentials of oxygen and nitrogen in liquid lithium (dotted line) vary as a function of temperature. Ref. 39, Figure 2 
TABLE 11

COMPATIBILITY TEST RESULTS

OF LITHIUM-CERAMICS INTERACTIONS

\section{Material}

Mg0, single crystal

Mg0, hot pressed polycrystalline

Be 0

$\mathrm{CaZrO}_{3}$

$\mathrm{Si}_{3} \mathrm{~N}_{4}$ (Norton)

$\mathrm{Si}_{3} \mathrm{~N}_{4}$ (Westinghouse)

SiALON

$\mathrm{BN}$

$\mathrm{Y}_{2} \mathrm{O}_{3}$

$\mathrm{ZrO}_{2}$

Ref. 40, Table 4
Results

Optical clarity retained; weight loss $\sim 1 \%$

Severe general attack

Some penetration of grain boundaries; loss of integrity

Integrity maintained; conductive layer formation

cracked

Destroyed

Cracked

Discoloration; substantial corrosion; loss of integrity

Little evidence of general attack; some grain boundary penetration

Incompatible 
STATIC 300-HR TEST OF LITHIUM INTERACTIONS WITH CERAMIC INSULATING MATERIALS AT $400^{\circ} \mathrm{C}$

\section{Material}

$\mathrm{Al}_{2} \mathrm{O}_{3}$

$\mathrm{MgO}$

$\mathrm{Be} 0$

$\mathrm{ThO}_{2}$

$\mathrm{Y}_{2} \mathrm{O}_{3}$

$\mathrm{ZrO}_{2}$

$\mathrm{MgAl}_{2} \mathrm{O}_{4}$

$\mathrm{CaZrO}_{3}$

$\mathrm{BN}$

$\mathrm{Si}_{3} \mathrm{~N}_{4}$

SiALON
Possible Use with Lithium

No

Yes

Yes

Yes

Yes

No

No

?

Yes

Yes

?

Ref. 40, Table 2 


\begin{tabular}{|c|c|c|c|c|c|}
\hline \multirow{2}{*}{ MATERIAL } & \multirow{2}{*}{$\begin{array}{l}\text { THEORETI ICAL } \\
\text { DENSITY }(\%)\end{array}$} & \multicolumn{4}{|c|}{ LITHIUM } \\
\hline & & $B A D$ & POOR & FAIR & GOOD \\
\hline & \\
\hline$Z r B_{2}$ & & & & & \\
\hline $\mathrm{B}_{4} \mathrm{C}$ & $80-90$ & 4 & & & \\
\hline \multicolumn{6}{|l|}{ SiC } \\
\hline TiC & 97.4 & & 6 & 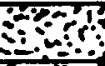 & 4 \\
\hline $2 r c$ & 100 & & 0 & 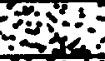 & \\
\hline $\mathrm{Cr}_{3} \mathrm{C}_{2}$ & 98.7 & & 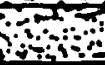 & 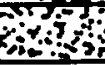 & is \\
\hline $\mathrm{BN}$ & $60-98$ & & & & \\
\hline \multicolumn{6}{|l|}{ TiN } \\
\hline $\mathrm{Si}_{3} \mathrm{~N}_{4}$ & 67.7 & & & & \\
\hline $\mathrm{Be} 0$ & 96 & & & & \\
\hline Mg0 (a) & 100 & 60 & & & \\
\hline $\mathrm{Al}_{2} \mathrm{O}_{3}(\mathrm{a})$ & 100 & & & & \\
\hline \multicolumn{6}{|l|}{$\mathrm{ZrO} \mathrm{O}_{2}(\mathrm{~b})$} \\
\hline $\mathrm{Sm}_{2} \mathrm{O}_{3}(\mathrm{c})$ & 79 & & & & \\
\hline $\operatorname{Re}$ OXIDES (d) & 90 & & & & \\
\hline $\mathrm{ThO}_{2}$ & $75-80$ & & & & \\
\hline $\mathrm{Mg} \mathrm{Al}{ }_{2} \mathrm{O}_{A}$ & 100 & & & & \\
\hline $\mathrm{MoSi}_{2}$ & & & & & \\
\hline
\end{tabular}

PIECES OF THE TESTED LithiUM FEMAINed

No VISIBLE TRACE OF THE TESTEC SPECIMEN

(a) SPECIMEN FROM A SINGLE CRYSTAL

(b) CaO-STABILIZED

(c) A 1000-HOUR TEST

(d) A 500-HOUR TEST. (BODY COMPOSITION: 45.0 TO $49.5 \% \mathrm{Sm}_{2} \mathrm{O}_{3}$; 22.5 TO $27 \% \mathrm{Gd}_{2} 0_{3}$; BALANCE PRIMARILY OTHER RARE-EARTH OXIDES.)

FIGURE 23. Corrosion Resistance of Ceramics to Static Lithium for 100 Hours at $816^{\circ} \mathrm{C}$. Ref. $19 ; 1$, Figure 14 


\section{Metals $(1,3)$}

Stainless steels represent the primary containment material for lithium-cooled MFEs. Compatibility is highly dependent upon lithium purity, alloy treatment, flow rates and lithium handling procedures. Corrosion rates decrease with decreasing temperature in high purity systems and show less intergranular attack.

Austenitic and ferritic stainless steel with less than 0.12 wt.\% carbon exhibit good resistance to lithium attack. Stainless steels of the austenitic types $302,303,304,316$, and 347 are resistant to corrosion by molten commercial lithium up to $315{ }^{\circ} \mathrm{C}$ for 7 days and $480{ }^{\circ} \mathrm{C}$ for 3 days. Low carbon steels (SAE-1020) have good resistance to attack at $300{ }^{\circ} \mathrm{C}$ and limited resistance at $600{ }^{\circ} \mathrm{C}$. Of the refractory metals, columbium, tantalum, and molybdenum are relatively stable at $1000^{\circ} \mathrm{C}$, zirconium and titanium are fair, but vanadium, beryllium and chromium are severely attacked. High temperature attack due to oxygen, carbon and nitrogen impurities in either the refractory metal or lithium itself is especially bad with respect to corrosion in refractory metals. Nickel shows good resistance at $225{ }^{\circ} \mathrm{C}$, limited at $300{ }^{\circ} \mathrm{C}$, and poor at $600{ }^{\circ} \mathrm{C}$.

Aluminum, barium, bismuth, calcium, cadmium, gold, lead, magnesium, platinum, silicon, silver, strontrium, thallium, tin, zinc, and their alloys all react with molten lithium yielding products of no structural usefulness. Copper and copper alloys such as aluminum bronze show poor resistance. High temperature cobalt-base alloys are also attacked.

Figure 24 illustrates the results of corrosion resistance of various metals and alloys to lithium.

\section{Lithium-Concrete Interactions}

DTA measurements to determine lithium-concrete reaction temperatures, heats of reaction, and to identify reaction products for three types of concrete aggregates and Portland cement have been recently completed (attached as Appendix). 
IRON

LOW-ALLOY STEELS

FERRITIC ( $\mathrm{Fe}-\mathrm{Cr}$ ) STAINLESS STEELS

AUSTENITIC (FE-Ni-Cr)
STAINLESS STEELS

NICKEL

NICKEL - BASE ALLOYS (INCONEL)

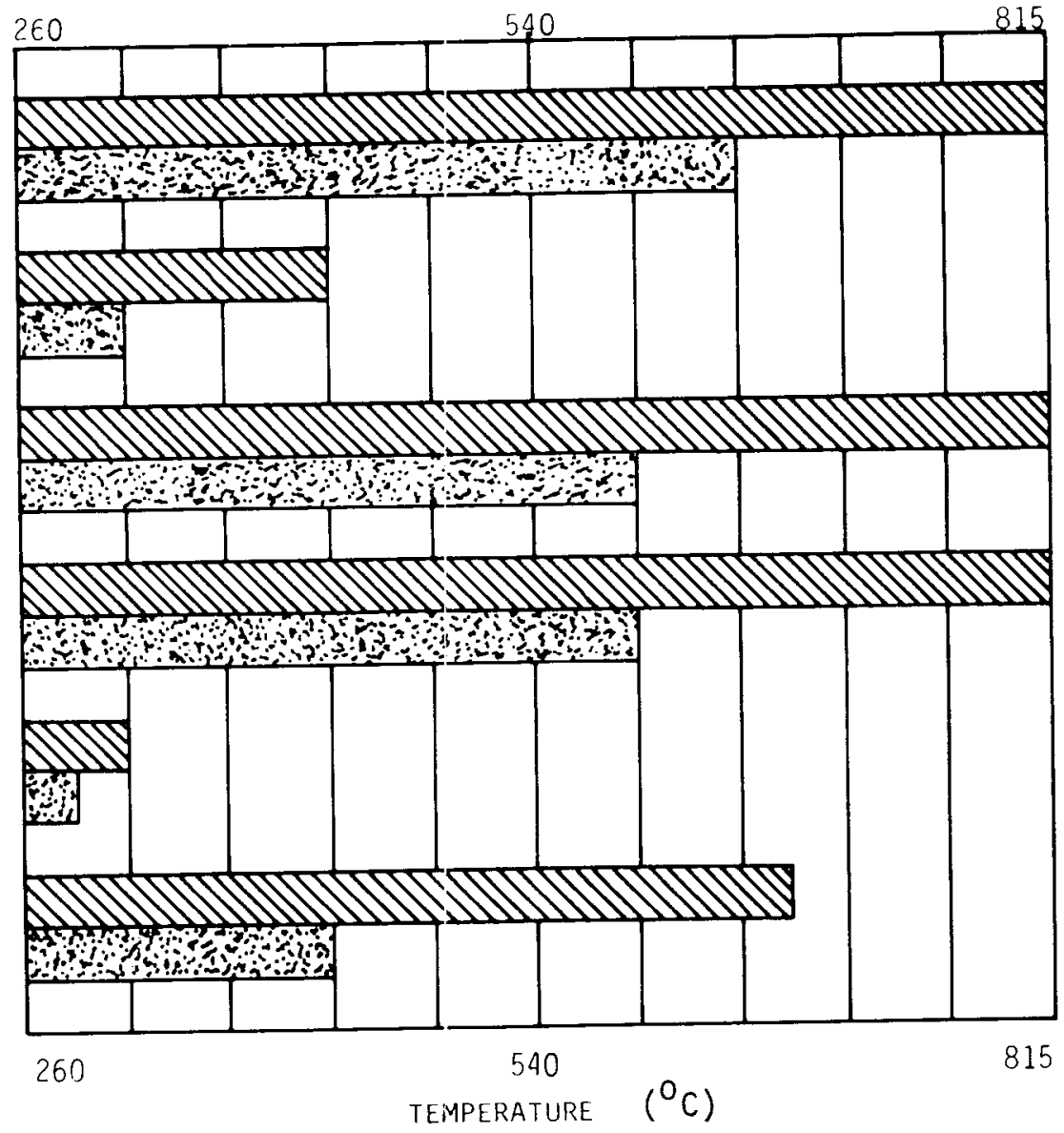

STATIC SYSTEMS

SYMAS DYNAMIC SYSTEMS

FLOW RATE $<10 \mathrm{fpm}$

TEMP. GRADIENT, $\sim 95^{\circ} \mathrm{C}$

PIPE SIZE, 0.7 in. i.d.

Bars indicate approximate temperatures below which a system might be operated for 1000 hours with less than 0.005 in. of attack or container surface removal.

HEDL 7711-63.4

FIGURE 24. Corrosion Resistance of Various Metals and Alloys in Lithium. Ref. 42; 1, Figure 12 

VI. LITHIUM HANDLING, SAFETY, AND FIRE CONDITIONS

Lithium-cooled controlled thermonuclear reactors require large quantities of hot flowing lithium. The reactive nature of lithium coupled with the radioactive content of the coolant after use demand special consideration of the hazards associated with lithium, especially leaks or fires. Major hazards result from vigorous reactions or fires due to contact with water, air, chlorinated hydrocarbons or other reactive agents, or personnel injury from direct contact with lithium or lithium reaction products. To accommodate for the reactivity of lithium, areas in which it is to be used should be dry, without sprinkler systems, fireresistant and appropriately ventilated. (1)

\section{A. LITHIUM CONTAINMENT}

Lithium should be packaged in metal containers holding up to 200 pounds of solid lithium, with a protective atmosphere of helium, argon or hydrocarbon fluids. (1) In the presence of an inert atmosphere of paraffin vapor, lithium can be handled at temperatures up to $200{ }^{\circ} \mathrm{C}-$ it can be melted and poured without great difficulty. ${ }^{(24)}$ Stainless steels and irons contain lithium up to $700{ }^{\circ} \mathrm{C}$; heat resistant refractory metals to over $1500{ }^{\circ} \mathrm{C} .{ }^{(1)}$ Care should be taken to uphold the purity of the lithium since contamination increases lithium reactivity.

\section{B. LITHIUM IGNITION}

Combustion reactions involve carbon dioxide, oxygen and nitrogen of the atmosphere. The final product is essentially all oxide. ${ }^{(11)}$ There is much disagreement in the literature as to the actual ignition temperature of lithium. Measurement of the spontaneous ignition temperature of a pool or spray of liquid lithium depends on metal purity, humidity of the heating gas used, pressure, sample size, different treatments undertaken, apparatus, and techniques used. Therefore, reproducibility and 
verification of results is difficult. Ignition occurs when the quantity of heat produced by the oxidation reaction is greater than the loss of heat from the lithium to the system. It is often determined by the character of the oxide crust formed by the oxidizing reaction.

Solid lithium is not easy to ignite. Even a small piece must be heated for some time before a sustained reaction takes place. (11) Molten lithium will not spontaneously ignite in dry air at temperatures up to $400{ }^{\circ} \mathrm{C}$. ${ }^{(11)}$

Une study reported an ignition temperature of $445{ }^{\circ} \mathrm{C} .{ }^{(43)}$ At temperatures above $445{ }^{\circ} \mathrm{C}$, nodulation appeared. The surface of the metal transformed slowly, looking warped where it displayed yellow oxide particles. Ignition occurred at this spot on the surface, spreading to the whole mass of metal. A very hard residue in the form of cauliflower remained.

Other studies (11) make reference to a porous, coral-like growth of lithium oxide and lithium nitride which floats on the hot molten metal and acts as a wick and catalyst for the combustion reaction. In the presence of this coral (or lithium corrosion products), ignition can occur at temperatures around $200^{\circ} \mathrm{C}$. Combustion begins promptly if a piece of cold coral-like residue is dropped into molten lithium. This seems to be a specific effect since other materials (asbestos, sand, iron oxide) do not initiate combustion likewise. Without the coral-like compound, hot liquid lithium may be stirred, poured and handled in air without igniting. At temperatures over $600{ }^{\circ} \mathrm{C}$ (around $640 \mathrm{c}^{(7)}$ ), spontaneous ignition will take place with pure metallic lithium.

Once initiated, combustion slowly spreads across the molten metal surface through a laterial growth until the entire exposed surface is taken up by the combustion process. Expansion from a pea-sized fire to a burning area of 2 to. 3 square feet takes around 10 minutes, starting with 
molten metal at $200{ }^{\circ} \mathrm{C}$ with a depth of 3 to 4 inches. In still air, the temperature of the molten metal rises to an asymptote around $400{ }^{\circ} \mathrm{C}$. A large temperature gradient exists across the burning layer since surface temperatures around $800{ }^{\circ} \mathrm{C}$ were observed. The rate of combustion with respect to lithium oxide formation appears to be strongly diffusion controlled. Very slight drafts of air accelerate combustion extensively. This is not true for lithium nitride formation. A stream of nitrogen directed onto a burning surface did not accelerate combustion appreciably. The proportion of oxide to nitride formation occurring may therefore be expected to increase as convection above a burning surface increases, with both the temperature of the fire and rate of heat generation increasing. The heat of formation of oxide is around three times that of nitride.

In this study (11), it was emphasized that very different rates of fire propagation can be observed if molt:en metal is suddenly dumped at a high temperature (around $800^{\circ} \mathrm{C}$ ) into a metal catch pan.

Combustion is accompanied by emission of dense, white and opaque fumes, tending to mask the seat of the fire. This is very similar to that seen with sodium. Splattering of hot metal, accidental contact of hot lithium with water, or other highly reactive materials, radiation to and ignition of nearby combustible materials, escape of molten metal and the production of large volumes of irritating fumes are all principle dangers of large lithium fires.

\section{LITHIUM FIRE EXTINGUISHMENT}

Lithium fires are hard to control and extinguish Fire control consists of cooling the reacting mass, preventing diffusion of reacting gases to the combustible surface and prevention of evolvement of combustible vapor or aerosols. Metal catcli pans, dump tanks for rapid draining of the system if leaks develop, and flooding with inert atmosphere all aid in containing spills and diminish the possibilities for 
large lithium fires. A few studies have been made examining the effectiveness of different extinguishants on lithium fires. The results are subject to carefully controlled testing conditions and may vary in an actual accident situation.

In one study, both powdered sodium chloride ( $\mathrm{NaCl}$, also known as MET-L-X) and graphite were found effective in extinguishing lithium fires. Other possible extinguishants were cited as zirconium silicate, potassium chloride (KCl), and lithium chloride. A powdered carbon preparation, LITH-X, was also recommended. Conventional fire extinguishing agents were strongly discouraged since lithium readily reacts with the water, carbon dioxide, sodium carbonate, aqueous foams, soda acid mixtures and carbon tetrachloride $\left(\mathrm{CCl}_{4}\right)$ found in these agents. (1) One to two pounds reagent per pound of burning lithium sufficed to extinguish the fire. For dispersions of burning lithium in organic liquid, extinguishment was accomplished by application of sodium bicarbonate followed by MET-L-X. Fumes were reduced by use of electrostatic precipitators and scrubbers. For floors with steel drainage troughs, an angle with at least a $7^{\circ}$ slope leading to a sump was necessary to help prevent serious lithium fires. (1)

The results of a second study(11) were quite comprehensive and are illustrated in Tables 13 and 14. The most effective of the extinguishants tested was a ternary inorganic eutectic: $\mathrm{NaCl}-\mathrm{KCl}-\mathrm{BaCl}_{2}$. The MET-L-X mentioned above was also found to be good. The following conclusions were drawn from the study:

- The ternary inorganic eutectic is ineffective when applied from a pressurized extinguisher.

- The effectiveness of any extinguishant is influenced by the application rate. Thus for any given size and type of fire, an optimum application rate exists which permits attainment of fire control in minimum time. 
TABLE 13

\section{EXTINGUISHANTS FOR SMALL LITHIUM FIRES}

Effect of various agents on small quantities $(1.3 \mathrm{~g})$ of burning lithium.

Extinguishing Agents Explosive Vigorous Little/None Good Fair Poor
1. Lead (shot)

$X$

$X$

2. Lead (powder)

3. Brass (granular)

4. Sodium bicarbonate

5. Lithium chloride

o

$X$

$x$
6. Potassium chloride

7. Lithium and potassium chlorides (50-50)

8. Celite 545

9. Graphite

10. Pyrene G-1 Powder

11. Sodium Chloride

12. Lith $X$

13. Boric acid

14. Graphite in \#30 motor oil

15. Celite and \#30 motor oil

Ref. 11, Table I $x$

$x$

$x$

X

$X$

$x$

X-burns

X-burns $x$

$x$

$x$

$x$

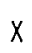

$x$

X

$x$

$x$

$x$

$x$

$x$

$x$

\section{Comments}

Good quenching but extinguishing action not complete.

$x \quad$ Small explosion occurred third trialpossibly a contaminant.

Good quenching action; extinguishant

if lithium is completely blanketed.

$x \quad$ Acted as fuel rather than extinguisher. Too hygroscopic for storage.

$x \quad$ Moderate sparking occurred.

Effective cooling; sparking more vigorous than with $\mathrm{KCl}$ alone.

$x \quad$ Appeared to be combustible. Complete extinguishment if entire burning surface well covered. Same as above.

$x \quad$ Much sparking; poor quenching properties.

Lithium must be covered compietely for extinguishment.

Secondary fire develops - is of short duration. Coating of oxide blankets 1 ithium.

May be too viscous-thins out when in contact with burning lithium. Very little oil fire.

Same as above. 


\section{TABLE 13}

\section{EXTINGUISHANTS FOR SMALL LITHIUM FIRES (Cont'd)}

\section{Extinguishing Agents \\ Effectiveness \\ Good Fair Poor}

16. Pyrene G-1 and \#30

motor oil

X-burns

$$
\text { LB650X }
$$

18. G.E. Silicon oil

$$
\text { 9996-1000 and graphite }
$$

19. Sand

20. Trimethoxyboroxine (1 iquid)

22. Unicel ND (blowing agent)

23. Petroleum oil

24. Boric acid anhydride

25. Unicel ND 1 Petroleum oil 5

26. Celogen (blowing agent)

27. Lead and tin alloy

28. Ternary eutectic salt mixture $25 \% \mathrm{BaCl}, 35 \% \mathrm{NaCl}, 40 \% \mathrm{KCl}$

29. Ternary eutectic plus celogen

$x$

X-burns

\section{Comments}

Resulted in more of an oil fire than graphite in motor $0 i 1$.

Viscous dispersion; oil did not lose viscosity on application to burning lithium.

Viscosity not lowered when in contact with burning lithium. Very little oil fire.

Violent sparking.

Easy to apply; secondary fire burns with green flame for only a short time.

Burns giving off heavy black smoke.

Some frothing observed.

Loses viscosity at high temps.; flows away; secondary oil fire.

$x$ Poor results due to lack of flow and coverage.

No more effective than oil alone.

Excellent frothing-smothered fire rapidly; ineffective in petroleum oil and TMB.

Good flow properties. Fairly good smothering action.

Very effective.

Very effective. Forms liquid crust, Some blowing effect. 


\section{TABLE 14}

\section{EXTINGUISHANTS FOR MODERATE LITHIUM FIRES}

Effectiveness of selected extinguishants on moderate-sized lithium fires.

\section{Extinguishant}

(amounts exting.

used shown in

center columns)

\begin{tabular}{llllll}
\multicolumn{2}{l}{ Fire } & \multicolumn{6}{c}{ conditions } & & & \\
64 & 64 & 64 & 110 & 81 & 346 \\
0.4 & 0.6 & 0.8 & 1.0 & 3.5 & 3.0 \\
$1 / 2$ & $3 / 4$ & 1 & 2 & 5 & 14
\end{tabular}

$\mathrm{CaF}_{2}$

Celogen

$20 \%$ celogen, $80 \%$ MET-L-X

온

Powder chemicail concentrates

Lith-X

Lube oil

MET $-L-X$

Pyrene G-1

Salt ternary eutectic

TMB
Remarks

Highly dangerous; secondary fire, spark shower, explosions.

Not effective.

Secondary fire; black smoke.

No foaming or flotation effect observed. Did not appear to offer any advantage over straight MET-L-X.

Smoke; secondary yeílow fíames. Reíatively large amount required.

As above.

Fierce secondary fire; uncontrollable. Very effective. Did not sink in these experiments. Some suggestion of sodium formation.

Smoke; secondary flames; slow aftercooling. Carbon glows after lithium extinguishment.

Very effective. Sinking prevented by coral formation.

Not effective.

Secondary flames.

Dangerous fumes.

Note: Extinguishants applied by shovel.

Ref. 11. Table II 
- There is no difficulty in keeping extinguishants from sinking below the molten lithium surface despite the low density of liquid lithium. This is due to the relatively high surface tension of liquid lithium and low apparent density of lithium oxide, coupled with its wetting properties.

- Different results may be obtained if the burning lithium is at higher temperatures.

- The results of the manufacturers of MET-L-X's tests on their own product are considered erroneous. During the latter tests, applied MET-L-X sank beneath the burning lithium surface while that remaining on the surface appeared to react, yielding free sodium. In effect, a sodium fire was substituted for a lithium fire. The reasons for this discrepancy are that the manufacturer's tests used larger areas of burning lithium and higher temperatures. Also the amount of MET-L-X used by the manufacturer was large. Therefore the sheer weight of it alone may have caused sinking below the molten lithium surface. Instead, it was found that no sinking occurred when MET-L-X was applied to a lithium fire 3 inches deep. The light, porous, coral-like growth mentioned before acts as a flotation layer, sufficiently buoyant to support the agent. The effect is aided by the high surface tension of molten lithium.

The most efficient agent--a pulverized fused salt eutectic mixture (melting point: $640^{\circ} \mathrm{C}$ ) is composed mainly of barium chloride (25\%), sodium chloride $(35 \%)$ and potassium chloride (40\%). The preparation procedure is outlined in Table 15. Its extinguishing action depends on a blanketing effect since no chemical reaction was found between the salt mixture and burning lithium. Only the presence of the original agent components plus lithium oxide and lithium nitride were found in x-ray studies of the fire residue. The possibility of free sodium or potassium formation still exists. 
TABLE 15

LITHIUM FIRE EXTINGUISHANT PREPARATION

Ingredients of Ternary Eutectic Salt Mixture (100 lb

$\begin{array}{ll}\text { Barium Chloride } & 25 \% \text { by Weight } \\ \text { Sodium Chloride } & 35 \% \text { by Weight } \\ \text { Potassium Chloride } & 40 \% \text { by Weight }\end{array}$

\section{Procedure}

The crystalline salts were purchased as Technical Grade at 80 to 100 mesh grain size. Five 20 -pound batches were made. Each lot was tumbled in a five-gallon glass $j$ ar rotated on a set of ball mill rolls turning at about $44 \mathrm{rpm}$ for 30 minutes. The mixture of salts was distributed into six or seven 4-liter Pyrex glass beakers set inside one-gallon paint cans or steel beakers. The charges were heated for 2 hours at $720{ }^{\circ} \mathrm{C}$. At this temperature, the salt mixture was completely liquid. After stirring to insure uniformity, the masses were allowed to $c 00 l$ and the glass beakers broken away.

The entire 100-pound lot of solid fused salt was broken up by hammer and ground to pass a 200 mesh sieve. During the milling operation, 2.5 pounds of magnesium stearate were added to prevent caking of the product and to assure easy flow.

Ref. $44 ; 11$, Appendix B 
Met-L-X was found good on fires from 0.75 to 14 pounds in size. Almost 75 to $80 \%$ of the original lithium was present as lithium after extinguishment. Complete replacement of sodium in MET-L-X by lithium is not a requisite for successful extinguishment. Evidence exists that small amounts of metallic sodium are formed but no metallic sodium could be identified in the fire residue. During early application of the extinguishant, yellow flames were observed. Application in sufficient amounts can be performed without sinking of the agent into the molten lithium. In a 14-pound fire, MET-L-X was added to the center area of the fire with a shovel while working slowly outward to avoid bridging from the container walls.

Due to the sensitivity of the burning rate to even slight convection currents, once a lithium fire has started, attempts to ventilate the area could be detrimental to fire control. Any attempts to improve visibility through smoke removal of ventilation should be avoided. For this same reason, gas-propelled extinguishants are less effective than the same agents applied by shovel.

Application of an inert gas like argon to a well established lithium fire was completely ineffective. Direct application to the burning surface did retard the fire somewhat but removal of the argon gas source caused combustion to immediately resume. (11)

\section{LITHIUM REMOVAL}

Lithium spills may be transferred to buckets filled with 100 mesh powdered graphite. (1) Residual lithium contamination should be wiped clean with flameproof rags. Disposal of cold lithium residue is more difficult. The residues consist of a mixture of lithium, lithium oxide, nitride, and carbonates. Reactions of the residues with water may proceed quietly or violently. Residues in less than one pound lots should be placed in drums with wire mesh screens covering the tops. (11) If 
steel catch pans containing residue are included, all will sink to the bottom and the reaction will occur peacefully. ${ }^{11)}$ Burning in air or hydrolysis in natural bodies of water is not feasible due to the formation of noxious fumes and toxic acqueous waste harmful to human, animal, and vegetable life. (1) 
$\ominus$ .

0
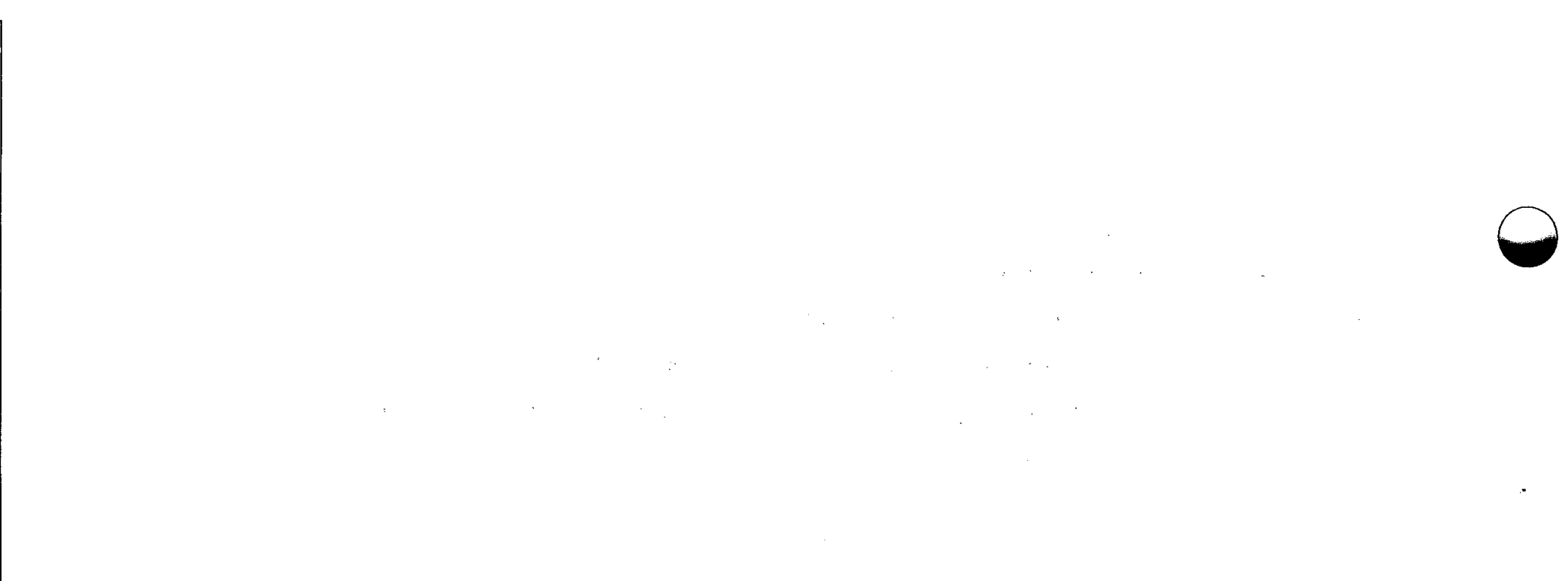<smiles>CCC</smiles>
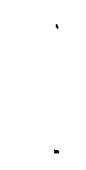<smiles>CCC</smiles>
.
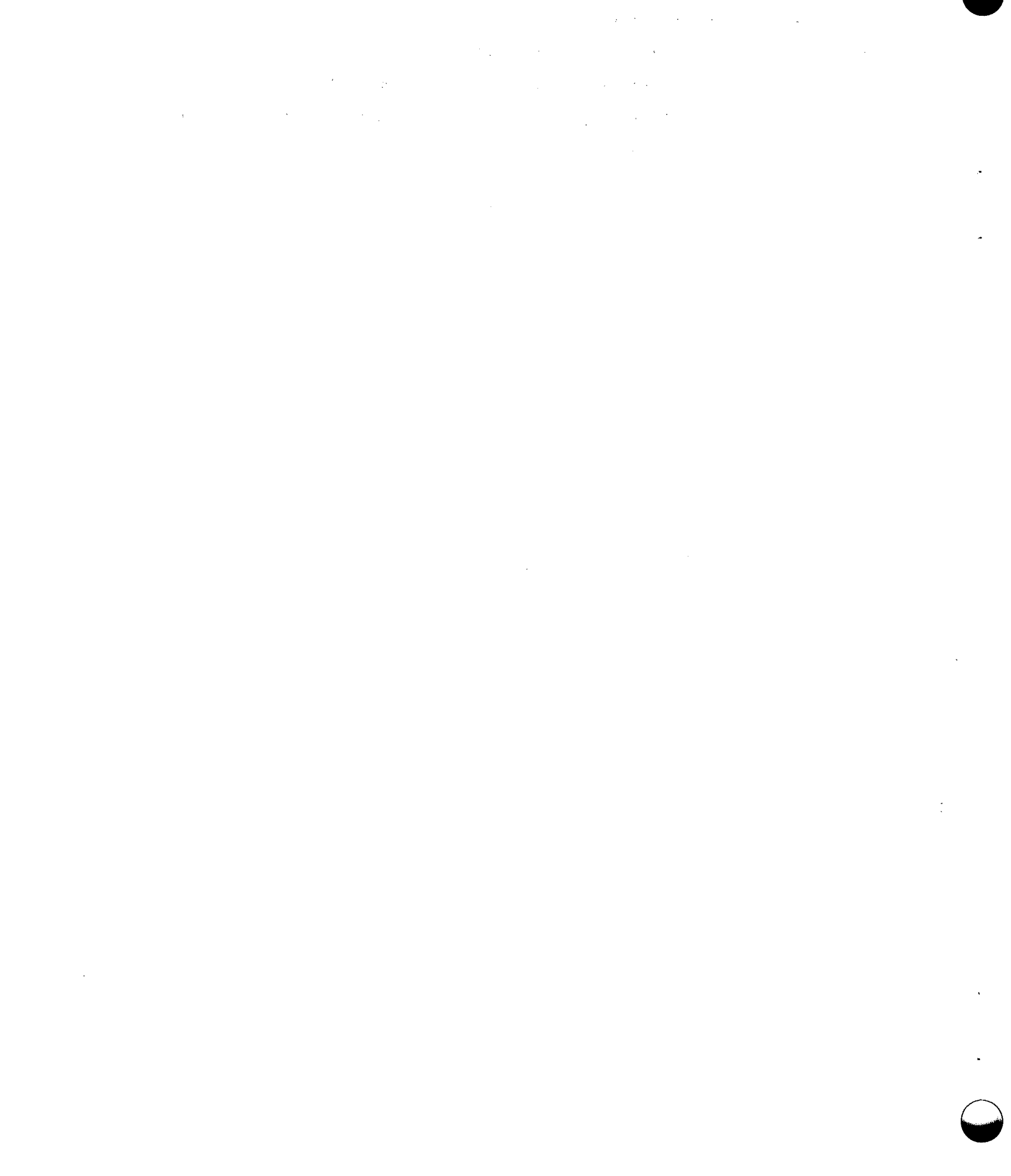


\section{FUTURE STUDIES AND EXPERIMENTATION}

The overall objective of the lithium spill studies project is to increase the state of knowledge concerning the effects of lithium spills under postulated accident conditions for the purpose of supporting magnetic fusion energy device safety assessments.

All reaction products resulting from lithium interactions should be characterized as well as their rate of formation and the temperatures involved, for all accident conditions plausible. Tests to determine reaction kinetics, the chemical nature of reaction products, heats of reaction, and aerosol properties for lithium reactions with the atmosphere, concrete, and insulating materials proposed for use in MFE facilities should be performed.

Testing under both static and dynamic conditions is suggested. The effects of radiation on the properties and interactions of lithium should be determined also. Further development and demonstration of effective materials and techniques for extinguishing smal1 and large lithium fires resulting from pool and spray accidents is needed. Flooding with a gas to induce an inert atmosphere should be further investigated. Finally, studies should involve methods for removing lithium smoke aerosols from cells and ventilation systems. An evaluation of lithium and sodium spills to determine the applicability of existing sodium fire and spill technology to lithium hazards may provide a more efficient method for developing lithium fire and spill technology.

Supportive and additional information about the characteristics of lithium and its interactions with other compounds are contained in References 45 through 98. 


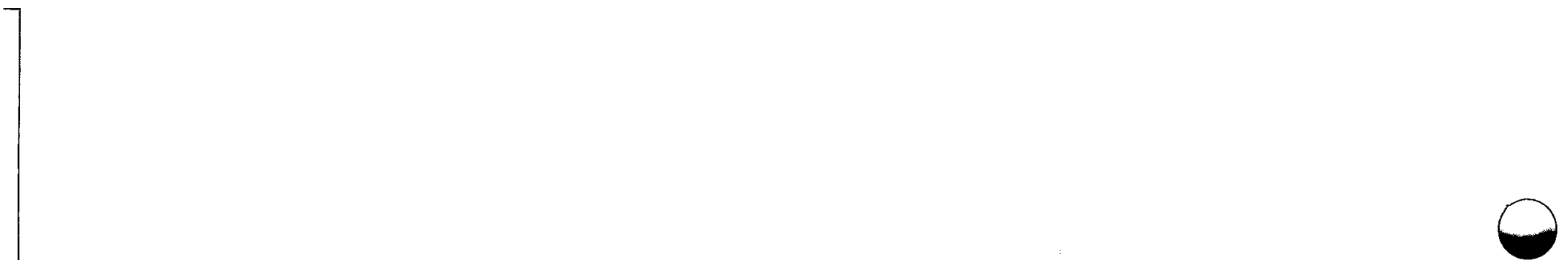

$\ominus$

.

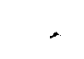

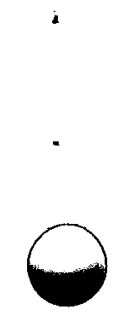

$\theta$ 


\section{REFERENCES}

1. J. 0. Cowles and A. D. Pasternak, Lithium Properties Related to Use as a Nuclear Reactor Coolant, UCRL-50647, Lawrence Radiation Laboratory, CA, Apri1 18, 1969.

2. E. E. Hoffman, Corrosion of Materials by Lithium at Elevated Temperatures, Dak Ridge National Laboratory, ORNL-2674, 1959.

3. D. L. Smith and K. Natesan, "Influence of Nonmetallic Impurity Elements on the Compatibility of Liquid Lithium with Potential CTR Containment Materials," Nuclear Technology 22, June 1974.

4. C. E. Messer, "Lithium and its Binary Compounds, in the Alkali Metals," International Symposium held at Nottingham on July 19-22, 1966, Special Publication No. 22, The Chem. Soc. (London).

5. R. C. Weast (Ed.), Handbook of Chemistry and Physics, 57th Edition, CRC Press, 1976-77.

6. F. W. Dorn, "Lithium Carbide," Knapsack A. - G., Ger. Offen. 2, 262, 898, 27 June 1974.

7. Yu I. Ostroushko, et al, Lithium, Its Chemistry and Technology, USAEC Division of Technical Information, AEC-TR-4940, JuTy 1962.

8. Atomic Energy Commission, Dept. of Navy, Washington, DC, Liquid Metals Handbook, 2nd Ed., June 1952.

9. P. E. Landolt and M. Sittig, "Lithium," Rare Metals Handbook, 2nd Edition, pp. 239-252, 1961.

10. M. M. Markowitz, "Alkali Metal-Water Reactions, J. Chem. Educ. 40(12): pp. 633-636, 1963 .

11. "Final Report on Development of Fire Extinguishing Agents for Lithium," Contract No. AT(30-1)-2527, C-62839, Arthur D. Little, Inc., Dec. 30, 1960, issued Feb. 15, 1961.

12. R. Hultgren, et al, Selected Values of Thermodynamic Properties of the Elements, Inorganic Materials Research Division, Lawrence Radiation Laboratory (Berkeley), University of California, January 1973.

13. E. I. Goltsova, "Densities of Lithium, Sodium, and Potassium at Temperatures up to $1500-1600^{\circ} \mathrm{C}$," High Temperature 4, p. 348, 1966. 
14. E. E. Shpil'rain, et al, "Experimental Investigation of Thermal and Electrical Properties of Liquid Alkali Metals at High Temperatures," High Temperature 3 , p. $870,1965$.

15. D. V. Rigney, S. M. Kapelner and R. E. Cleary, The Viscosity of Lithium, Pratt \& Whitney Aircraft (CANEL) Report TIM-849, 1965.

16. P. Y. Achener, Alkali Metals Evaluation Program, Quarterly Progress Report, AGN-8202, Allied General Nuclear, Nov. 1966.

17. J. Bohdansky and H. E. J. Schins, "The Surface Tension of the Alkali Metals," J. Inorg. Nucl. Chem. 29, p. 2173, 1967.

18. I. I. Novikov, V. A. Gruzdev, 0. A. Kraev, A. A. Odintsov, and V. V. Roshchupkin, "Thermophysical Properties of Liquid Alkali Metals at High Temperatures," High Temperature 7, p. 65, 1969.

19. T. B. Douglas, L. F. Epstein, J. L. Dever and W. H. Howland, "Lithium Heat Content from $0^{\circ}$ to $900^{\circ}$, Triple Point and Heat of Fusion and Thermodynamic Properties of the Solid and Liquid," J. Am. Chem. Soc. 77, p. 2144, 1955.

20. E. E. Shpil'rain and I. F. Krainova, "Measurement of the Thermal Conductivity of Liquid Lithium," High Temperature 8, p. 1036, 1970.

21. J. W. Cooke, "Experimental Determination of the Thermal Conductivity of Molten Lithium from $320^{\circ}$ to $830^{\circ} \mathrm{C}, " \mathrm{~J}$. Chem. Phys. 40 , p. 1902 , 1964.

22. R. 0. Bach, et a7, "Lithium and Lithium Compounds," Encyclopedia of Chemical Technology, Vo1. 12, 2nd Ed., pp. 529-556, 1967.

23. F. G. Burdi, SNAP Technology Handbook - Volume I - Liquid Metals, Atomics International, Rept. NAA-SR-8617, 1964.

24. H. 0sborg, Lithium: Theoretical Studies and Practical Applications, Electrochemical Society, Inc., New York, 1935.

25. M. M. Markowitz and D. A. Boryta, "Lithium Metal-Gas Reactions, Interaction of Lithium Metal with Air and its Component Gases," J. Chem. Eng. Data 7, pp. 586-591, 1962.

26. C. Tyzak and P. B. Longton, The 0xidation of Lithium, U.K. at Energy Authority Tech. Note 131, June 1955.

27. W. R. Irvine and J. A. Lund, "The Reaction of Lithium with Water Vapor," J. of the Electrochemical Society 110(2): pp. 141-144, Feb. 1963.

28. V. B. Cheburkov and A. N. Rozanov, "Reaction Kinetics of Molten Lithium with Oxygen and Nitrogen," Met. Matalloved. Chist. Metal No. 7, pp. 168-173, 1968, Russian. 
29. C. F. Wicks and F. E. Black, Thermkdynamic Properties of 65 Elements - - Their Oxides, Halides, Carbides, and Nitrides, Bureau of Mines Bulletin 605, 1963.

30. A. Glassner, The Thermochemical Properties of the Oxides, Fiuorides, and Chlorides, to $2500 \mathrm{~K}, \mathrm{ANL}-5750$, 957 .

31. C. C. Addison and B. M. Davies, "Reaction of Nitrogen with Stirred and Unstirred Liquid Lithium," J. Chem. Soc., Section A, pp. 1822$1827,1969$.

32. R. A. Rhein, The Ignition of Powdered Metals in Nitrogen and in Carbon Dioxide, NASA-CR-60125, NASA AcCession No. N65-14807.

33. L. Brewer, et al, "Thermodynamics and Physical Properties of Nitrides, Carbides, Sulfides, Silicides, and Phosphides, in the Chemistry and Metallurgy of Miscellaneous Materials," Thermodynamics, L. L. Quel1, Ed., McGraw-Hill Book Co., NY, 1950.

34. G. Parry and R. J. Pulham, "Rate of Reaction of Hydrogen with Liquid Lithium: Comparison with Sodium and Potassium," J. Chem. Soc., Dalton Trans. No. 19, pp. 1915-1917, 1975.

35. S. R. Gunn and L. G. Green, "The Heats of Formation at $25{ }^{\circ} \mathrm{C}$ of Crystalline Hydrides, Deuterides, and Aqueous Hydroxides of Lithium, Sodium, and Potassium," J. Am. Chem. Soc. 80, pp. 4782-4786, 1958.

36. B. E. Deal and J. J. Svec, "Kinetics of the Reaction Between Lithium and Water Vapor," J. Am. Chem. Soc. 75, pp. 6173-6175, 1953.

37. L. F. Epstein. "Recent Developments in the Study of Metal-Water Reactions," Progress in Nuclear Energy, Ser. IV, Technology, Engineering and Safety, 4: pp. 461-483, 1961.

38. J. H. Perry, Chemical Engineer's Handbook, 4th Edition, McGraw-Hill Book Company, NY, 1973.

39. R. N. Singh, "Compatibility of Ceramics with Liquid Na and Li," J. Am. Ceramic Society 59(3-4), pp. 112-115, 1976 .

40. W. D. Tuohig, J. T. A. Roberts and R. N. Singh, Material Studies in Support of Liquid Metal MHD Systems, CONF-740414-1, Argonne National Laboratory, Illinois, 1974.

41. W. H. Cook, Corrosion Resistance of Various Ceramics and Cermets to Liquid Metals, USAEC-0RNL-2391, 1960.

42. E. E. Hoffman, "Solubility of Nitrogen and Oxygen in Lithium and Methods of Lithium Purification," in ASTM Special Technical Publication No. 272, p. 195, 1960. 
43. J. C. Malet, H. Mellottee and-R. Delbourgo, "Experimental and Theoretical Study of the Ignition of Alkali Metals Lithium, Sodium, and Potassium," J. Chem. Phys. Physiochem. Biol. 69(9): pp.1315-1321, 1972, French.

44. L. H. Cope, The Extinguishing of Uranium and Plutonium Fires, The United Kingdom Atomic Energy Authority, 1960.

45. H. Hartman and R. Schneider, "Boiling Temperatures of Mg, Ca, Sr, Ba and Li," Z. Anorg. Allgem. Chem. 189, p. 275, 1929.

46. A. Bogros, "Saturated Vapor Pressure of Lithium," Compt. Rend. 191, pp. 322, 560, 1930.

47. M. Maucherat, "The Vapor Pressure of Lithium," Compt. Rend. 208, p. 499, 1939.

48. R. W. Ditchburn and J. C. Gilmour, "Vapor Pressure of Monatomic Vapors,". Rev. Mod. Phys. 13, p. 310, 1941.

49. P. Barbier and S. Bedere, "Differential Thermal Microanalysis, Determination of Free $\mathrm{Li}$ in Irradiated $\mathrm{LiH}, "$ Bull. Inform. Sci. Tech. (Paris): No. 180, pp. 39-42, 1973, French.

50. J. H. Miedel, Explosive and Toxic Hazardous Materials, H. N. Gruber, Ed., Glencoe Press, Beverly Hills, CA, p. 160.

51. G. DeVries, "The Corrosion of Metals by Molten Lithium," Corrosion by Liquid Metals, J. E. Draley and J. R. Weeks, (Eds.), PTenum Press, pp. 252-253, 1970.

52. J. W. Taylor, "The Surface Energies of the Alkali Metals," Phil. Mag. 근. 46 , pp. 867-876, 1955.

53. M. A. Mikheer (Ed.), "Problems of Heat Transfer," Academy of Sciences, USSR. Moscow, 1959. USAEC Report AEC-TR-4511, 1962.

54. M. Blander, et a1, Physiochemical and Thermodynamic Studies of Lithium-Containing Systems, Chemical Engineering Division Physical Inorganic Chemistry Semiannual Report, Jan-June 1973, ANL-8023, Argonne National Laboratory, Illinois.

55. R. M. Yonco, "Solubility and Thermal Decomposition of $\mathrm{Li}_{3} \mathrm{~N}$ in Lithium," Transactions of the Am. Nucl. Soc. 1975 Winter Meeting, pp. 159-160, Nov. 1975 .

56. F. Va. Kharitonov and I. V. Fedina, "Mechanisms of Corrosion of Ceramic Materi'als in Alkali Metals," Elektron. Tekh., Nauch-Tekh. Sb., Mater. No. 6, pp. 73-77, 1971, Russian. 
57. Liquid Metal Fire Control, PWAC-347, AEC Research and Development Report, Pratt and Whitney Aircraft Division of United Aircraft Corporation, June 1961.

58. P. Touzain, Kinetic Study of the Oxidation of Alkali Metals by Dry Oxygen, CEAR-3301, Commis. Energ. At. (Fr), Rapp, p. 93, 1967, French.

59. J. H. Stang, E. M. Simons, J. A. De:Mastry and J. M. Genco, Compatibility of Liquid and Vapor Alkali Metals with Construction Materials, AD-487718, Contract AF 33(615)3408, 1966.

60. M. Friedrich, "Fire Extinguishing Agents for Lithium, Sodium and Potassium," Meta11. 15, pp. 1173-1180, 1961.

61. D. G. Matthews, "A Simple Experimerital Test of Hess's Law," School Sci.Rev., 45(155): pp. 194-196, 1963.

62. M. R. Hobde 11 and A. C. Whittingham, "Reaction of Hydrogen with Solutions of Metals in Liquid Sodium," J. Chem. Soc., Dalton Trans. No. 15, pp. 1591-1594, 1975.

63. M. G. Barker, I. C. Alexander and J. Bentham, "Reactions of Liquid Lithium with the Dioxides of Titanium, Hafnium, and Thorium," J. Less-Common Metals 43(2): pp. 231-247, Sept. 1975.

64. V. A. Maroni, E. Veleckis and E. H. Van DeVenter, "Review of ANL Research on Lithium-Hydrogen Chemistry and Tritium-Containment Technology," ERDA-50, Argonne Naticinal Laboratory, I11ino is, pp. 120-132, June 1975 .

65. W. Grunedler, R. Friedemann, Nguyer Huu Thong and J. Schimpf, "Stability of Molecular Ions in the Lithium-Hydrogen Systems," Z. Anorg. Al1g. Chem. 410(3): pp. 287-292, 1974, German.

66. R. T. Pack, "Van der Walls Interactions of Carbon Dioxide," J. Chem. Phys. 61(5): pp. 2091-2094, 1974.

67. J. W. McCormick and C. R. Schmitt, "Extinguishment of Selected Metal Fires Using Carbon Microspheriods," Fire Technology 10(3): pp. 197-200, 1974.

68. W. D. Weatherford, Properties of Iriorganic Energy - Conversion and Heat Transfer Fluids for Space Applications, WADD TR 61-96, 1961.

69. I. I. Novikov, et al, "The Heat-Transfer and High Temperature Properties of Liquid Alkali Metals," J. Nuclear Energy 4, p. 387 , 1957. 
70. E. N. Da C. Andrade and E. R. Dobbs, "The Viscosities of Liquid Lithium, Rubidium and Cesium," Proc. Roy. Soc. (London), Azl1, pp. $12-30,1952$.

71. V. M. Anisimov and L. D. Volyak, "Experimental Determination of the Pressure of Saturated Lithium Vapor," High Temperature 7 , p. 340, 1969.

72. D. V. Rigney, S. M. Kapelner, and R. E. Cleary, The Vapor Pressure of Lithium Between 1307 and $1806 \mathrm{~K}$, CANEL Report TIM-844, September 1965.

73. J. Bohdansky and H. E. J. Schins, "Vapor Pressure of Different Metals in the Pressure Range of 50 to 4000 Ton," J. Phys. Chem. 71 , p. 215, 1967.

74. E. Veleckis and E. Van Deventer, in "Physical Inorganic Chemistry Semi annual Report, Jan-June 1972," USAEC Report ANL-7923.

75. F. D. Rossini, et al, Selected Values of Chemical Thermodynamic Properties, Nat. Bur. Std. Circ. 500, U.S. Government Printing Office, Washington, DC, 1952.

76. W. Borchkous, "Coming: More Reactive Lithium," Chem. Eng. News $\underline{36}$, p. $40,1958$.

77. J. Besson and W. Muller, "The Reaction of Nitrogen with Lithium at Ordinary Temperature and Role of Water Vapor in this Reaction," Compt. Rend. 247, pp. 2370-2372, 1958.

78. D. M. Gruen, The Chemistry of Fusion Technology, Plenum Press, New York-London, $\overline{1972 .}$

79. J. E. Selle, J. H. DeVan (ORNL), "Li-Stainless Steel Corrosion Studies," Transactions of the Amer. Nuclear Society 1975 Winter Meeting, San Francisco, CA, Nov. 16-21, 1975.

80. V. V. Rachev, B. K. Maslennikov and A. A. Lbov, "Behavior of the Surface of Metallic Lithium in Air and Argon of Low Humidity," Zh. Prik, Khim. 35, p. 189, 1962.

81. W. R. Warnock, "Fire Extinguisher Compositions for Metal Fires," (Ansul Chemical Co.), U.S. 3,090,749 (C1. 252-2), May 21, 1963, App 1. Jan 30, 1959.

82. D. Elliott, D. Cerini and L. Hays, Liquid MHD Power Conversion, Space Programs Summary No. 37-40, Vol. IV, NASA CR-79917, Jet Propulsion Laboratory, Pasadena, CA, 1966. 
83. E. Veleckis, E. H. Van Deventer and M. Blander, "Lithium-Lithium Hydride System," J. Phys. Chem. 78(19): pp. 1933-1940, Sept. 1974.

84. D. K. Size and W. E. Stewart, "Litrium Cooling for a Low-Beta Tokamak Reactor," CONF-721111, Univ. of Wisconsin, Madison, WI, pp. 584-594, 1974.

85. Fusion Power, An Assessment of Ultimate Potential, WASH-1239, Division of CT Research, USAEC, Feb. 1973.

86. Fire Protection Guide on Hazardous Materials, 4th Ed., NFPA No. SPP-1A, National Fire Protection Association, pp. 49-142, 143, 1972.

87. R. A. Rhein, The Utilization of Planetary Atmospheres as Chemical Energy Sources, Western States Sect. Combust. Inst. Paper WSS-C164-25, 1964.

88. E. F. MCFarlane and F. C. Tompkins, "Kinetics of 0xidation of Lithium," Trans. Faraday Soc. 58, pp. 1177-1186, 1962.

89. E. J. Cairns, A. D. Tevebaugh and J. D. Bingle, Energy Conversion, Compatibility Testing with Ceramic Insulator Materials at 400 to $550^{\circ} \mathrm{C}$ Under Cel1 Conditions, ANL-i575, pp. 136-169.

90. J. W. Mausteller, F. Tepper and S. J. Rodgers, Alkali Metal Handling and Systems Operating Techniques, Gordon and Breach, Science Publishers, 1967.

91. I. Glassman, Metal Combustion Process, Report No. 473, AFOSR-TN-59-1093, 1959.

92. A. Glassner, The Thermochemical Properties of the 0xides, Fluorides and Chlorides to $2500 \mathrm{~K}$, Argonne National Laboratory, ANL-5750, 1957.

93. H. L. Johnston and T. W. Bauer, "Low Temperature Heat Capacities of Inorganic Solids VII. Heat Capacity and Thermodynamic Functions of $\mathrm{Li}_{2} \mathrm{O}$. Thermodynamics of the $\mathrm{Li}_{2} \mathrm{O}-\mathrm{H}_{2} \mathrm{O}$ System, J. Am. Chem. Soc. $73(3)$, pp. 1119-1122, 1951 .

94. A. J. Friedland, "Coolant Properties, Heat Transfer, and Fluid Flow of Liquid Metals," Fast Reactor Technology - Plant Design, J. G. Yerick, Ed., MIT Press, Cambridge, 1966.

95. N. Z. Tkhin and L. A. Zharkova, "Heat of Formation of Lithium Molybdate," Zh, Fiz. Khim. 40(6), pp. 1370-1372, 1966. Translated in Russ. J. of Phys. Chem. $40(6)$, pp. 737-739, 1966.

96. L. G. Fasolino, "The Enthalpy of Formation of Lithium Aluminum Hydride," J. Chem. and Eng. Data 9(1), pp. 68-71, 1964. 
97. H. D. Jones, "Theory of the Thermodynamic Properties of Liquid Metals," Phys. Rev., Section A 8: No. 6, pp. 3215-3226, 1973.

98. S. J. Rodgers and W. A. Everson, "Extinguishment of Alkali Metal Fires," Quarterly Progress Report No. 3, Sept. - Dec., 1962, MSAR 63-19, MSA Research Corp., Callery, PA. 
APPENDIX

LITHIUM-CONCRETE STUDIES

BY DIFFERENTIAL THERMAL ANALYSIS

Prepared By: G. C. Burrow, R. E. Witkowski, and R. G. Charles Westinghouse Electric Corporation Research Center Pittsburgh, PA

September 1977 
Westinghouse

Electric Corporation

September 7, 1977
Research and Development Center

310 Beuiah Road

Pittsbuigh Pennsylvania 15235

Dr. Lewis D. Muhlestein

Westinghouse Hanford Company

P.O. Box 1970

Richland, WA 99352

Dear Lewis :

SUBJECT: Lithium-Concrete Studies by Differential Thermal Analysis, Your Requisition No. Y83259

As detailed in the above-referenced requisition, we have studied the chemical reactions between 1ithium and varfous concretes and dry Portland Cement (II) paste by Differential Thermal Analysis (DTA) over the temperature range of 25 to $800^{\circ} \mathrm{C}$. Eight DTA measurements were made on five concrete samples and one cement as detalled by your test matrix. The objective of these studies was to provide preliminary base data on the effects of lithium spills, under postulated accident conditions, for the purpose of supporting your CTR Facility Safety Analysis.

The concrete samples, which were characterized under a previous contract with the Westinghouse Hanford Company (I.W.R. Order No. Y6W-S44-35602), were used in these studies. The dry Portland Cement (II) paste sample was prepared at the Westinghouse R\&D Center by mixing the as-recelved cement with water followed by air cure for seven days. The DTA apparatus utilized in this work was that used in the sodium-concrete studies detailed in previous reports. $(1,2)$

Upon completion of the DTA scans, distillation to remove the excess lithium from the reaction products $\left(625^{\circ} \mathrm{C}\right.$ at $6 \times 10^{-4} \mathrm{~mm} \mathrm{Hg}$ for approximately nine hours) proved unsuccessful. Therefore, to remove the excess lithium, each DTA sample reaction product was reacted in air with distilled water in a stainless steel beaker. This procedure, for the removal of the lithium, resulted in two fractions of reaction product for each DTA sample; the water soluble and insoluble reaction products. The samples were centrifuged to separate the two fractions, the insoluble material then washed with ethanol and centrifuged again. The soluble fraction was obtained by evaporation of the distilled water on a hot plate. Both fractions were dried and loaded in appropriate XRD sample capillary tubes. The capillary tubes were sealed and 
Mr. Lewis ll. Nuhle:stein

September 7,1977

readied for analysis. Characterization of the reaction products for each of the three different types of concretes and one cement sample exposed to lithium were performed by X-Ray Diffraction (XRD), see Appendix I.

The DTA results of this effort are given in Table 1 which presents the temperature(s) at which the exotherm(s) occurred, and the heat evolution for each material. The heat evolution values $(-\Delta H, c a l / g r a m)$ are based on the calibration of the DTA apparatus with a $200 \mathrm{mg}$ sample of NiO which was run separately with excess 1ithium. The characteristic DTA curves for each run are presented in Figures 1 through 5; the NiO calibration run is shown in Figure 6. The endotherms noted in each figure at approximately $190^{\circ} \mathrm{C}$ represent the melting of the lithium metal.

Based on this abbreviated study, the following preliminary conclusions, related to lithium-concrete interactions, may be drawn:

A. The DTA studies of the concrete sample MI (magnetite aggregate) yielded inconclusive results; two entirely different plots were obtained as shown in Figure 1; a large difference in heat evolution values resulted. The presence of $\mathrm{Fe}$, as given in the $\mathrm{XRD}$ results for the insoluble reaction products, is indicative of the reduction of the magnetite component to elemental $\mathrm{Fe}$. The large differences in the DTA plots may be due to (1) the separation of magnetic and non-magnetic concrete components during sample preparation or (2) preliminary interaction of the lithium with the concrete sample prior to heating.

During previous studies involving sodium-concrete interactions, large differences in heat evolution values were also noted. (1) The funding available for this effort did not permit additional DTA runs to be made to resolve this problem.

B. The basalt aggregate concrete materials (CON-B1 and CON-B2) gave the highest apparent heat evolution values of all samples studied. The XRD results indicate the reduction of the silicates to silicides. Similar DTA plots were obtained for each sample as shown in Figure 2.

C. Concrete sample Ll (limestone aggregate) gave the most reproducible heat evolution values and exotherms, see Figure 3. The results of XRD analysis for both the water soluble and insoluble fractions of the reaction products do not offer a readily visible reaction mechanism.

D. The exotherms of the dry Portland Cement (II) paste, see Figure 4, can be attributed to the direct reduction of the silicates to silicides. The XRD analysis of the insoluble reaction products has identified silicides as a minor phase.

E. In general, these results show lithium to be, as expected, a stronger reducing agent than sodium. This is particularly evidenced by the reduction of the aggregate/cement silicates to silicides. 
Dr. Lewis D. Muhlestein

September 7, 1977

We hope this preliminary study, into the interaction of lithium with concrete, fulfills your near-term requirements. If you have any questions concerning this work or if we can be of further assistance, please feel free to give us a call.

Sincerely,

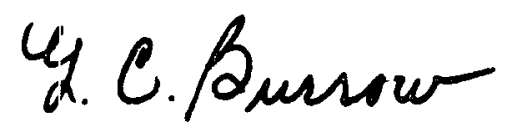

G. C. Burrow

Liquid Hetal Technology

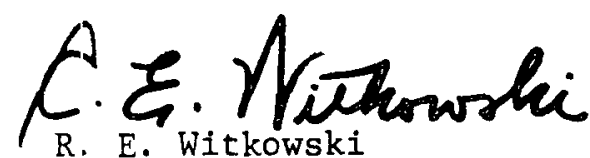

R. E. Witkowski

Liquid Metal Technology

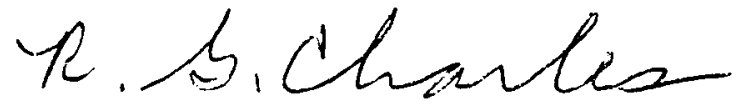

R. G. Charles

Spectal Projects

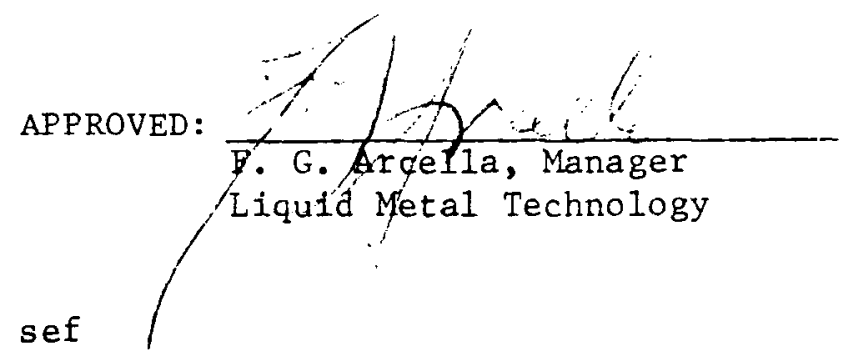

cc: J. Ballif, Westinghouse Hanford Company

W. T. Lindsay, Jr., R\&D Center

R. M. Lowy, R\&D Center

PIC-2-File 


\section{REFERENCES}

1. R. E. Witkowski and R. G. Charles, "A Preliminary Chemical Investigation of Sodium-Concrete Reactions by Differential Thermal Analysis", Proceedings of the International Conference on Liquid Metal Technology in Energy Production, ERDA Conf. 760503-P2, Champion, PA, May 1976.

2. R. E. Witkowski, R. G. Charles, and C. L. Jones, "A Chemical Investigation of Sodium-Concrete Reactions", Westinghouse Research and Development Center Unrestricted Report No. 77-8B6-NACON-R1, Pittsburgh, PA, January 10, 1977 
TABLE I

Differential Thermal Analysis Results for the Reaction of $300 \mathrm{mg}$ Samples in Excess lithium (1000 mg). 316 SS Sample Containers with Argon Cover Gas

\begin{tabular}{|c|c|c|c|c|}
\hline \multirow{2}{*}{$\begin{array}{c}\text { Sample } \\
\text { Identification }\end{array}$} & \multicolumn{2}{|c|}{$\begin{array}{l}\text { Exotherm } \\
{ }^{\circ} \mathrm{C}\end{array}$} & \multicolumn{2}{|c|}{$\begin{array}{c}\text { *Heat Evolution } \\
-\Delta H, \text { cal/gram }\end{array}$} \\
\hline & Run \#1 & Run \#2 & Run $\|_{1}$ & Run $\# 2$ \\
\hline $\mathrm{CON}-\mathrm{M} 1$ & $\begin{array}{l}482 \mathrm{w} \\
596 \mathrm{~s}\end{array}$ & $\begin{array}{l}351 \mathrm{~s} \\
593 \mathrm{w} \\
622 \mathrm{~m}\end{array}$ & +218 & +991 \\
\hline $\mathrm{CON}-\mathrm{BI}$ & $\begin{array}{l}268 \mathrm{w} \\
308 \mathrm{~s} \\
364 \mathrm{w}\end{array}$ & - & +1051 & - \\
\hline $\mathrm{CON}-\mathrm{B} 2$ & $\begin{array}{l}391 \mathrm{~s} \\
430 \mathrm{w}\end{array}$ & - & +770 & - \\
\hline CON-LI & $695 \mathrm{~s}$ & $702 \mathrm{~s}$ & +403 & +536 \\
\hline $\begin{array}{l}\text { Dry Portland } \\
\text { Cement (II) Paste }\end{array}$ & $690 \mathrm{~s}$ & $.558 \mathrm{~s}$ & +224 & +182 \\
\hline
\end{tabular}

* Based on calibration of the apparatus with a $200 \mathrm{mg}$ sample of NiO with excess lithium.

$\mathrm{w}=$ weak $\mathrm{m}=$ moderate $\mathrm{s}=$ strong 


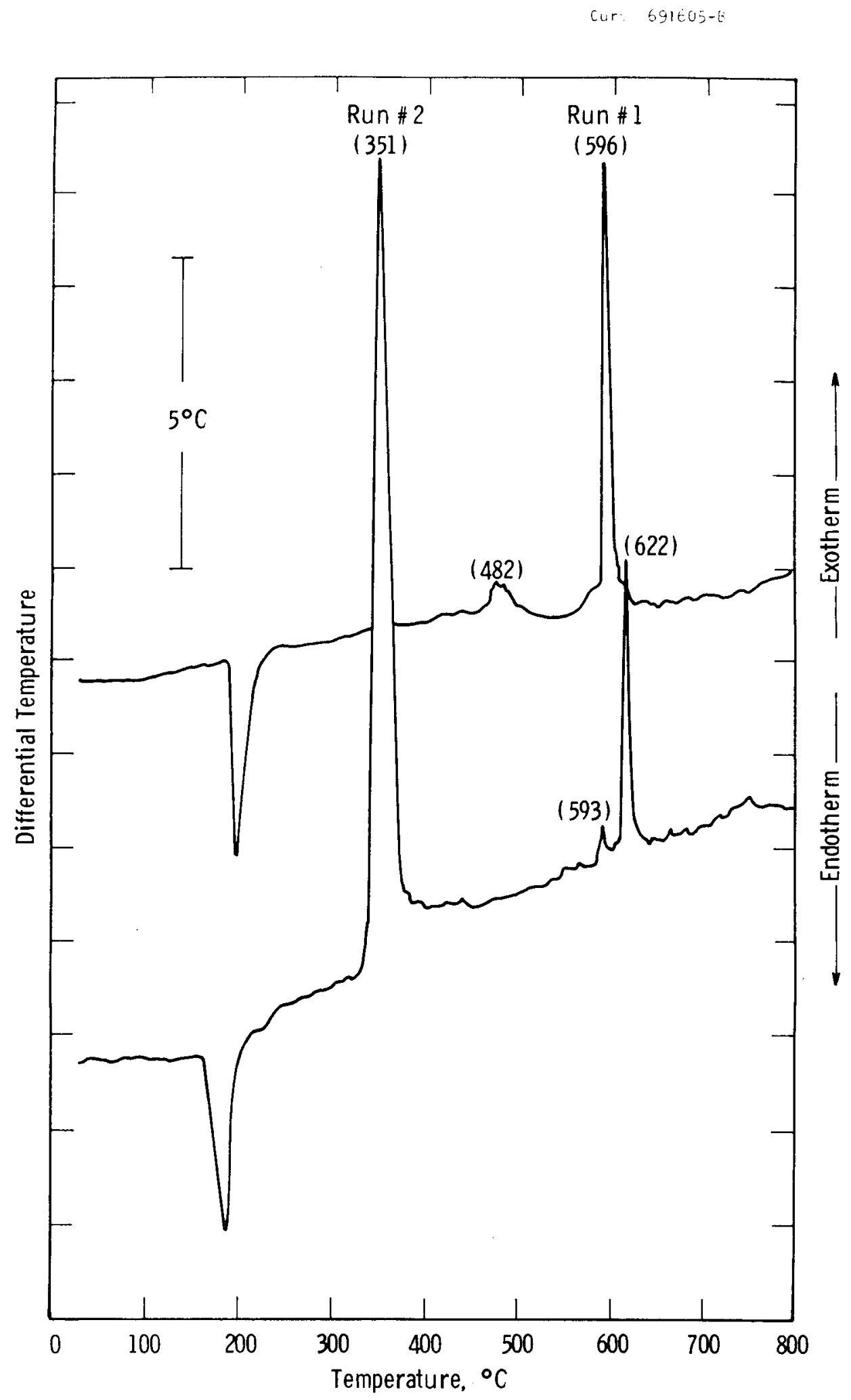

Fig. 1 - Differential thermal analysis (DTA) curves obtained for two individual $300 \mathrm{mg}$ samples of Con-Ml in excess lithium (1000 mg). 316 S. S. sample container with argon cover gas

A-8 


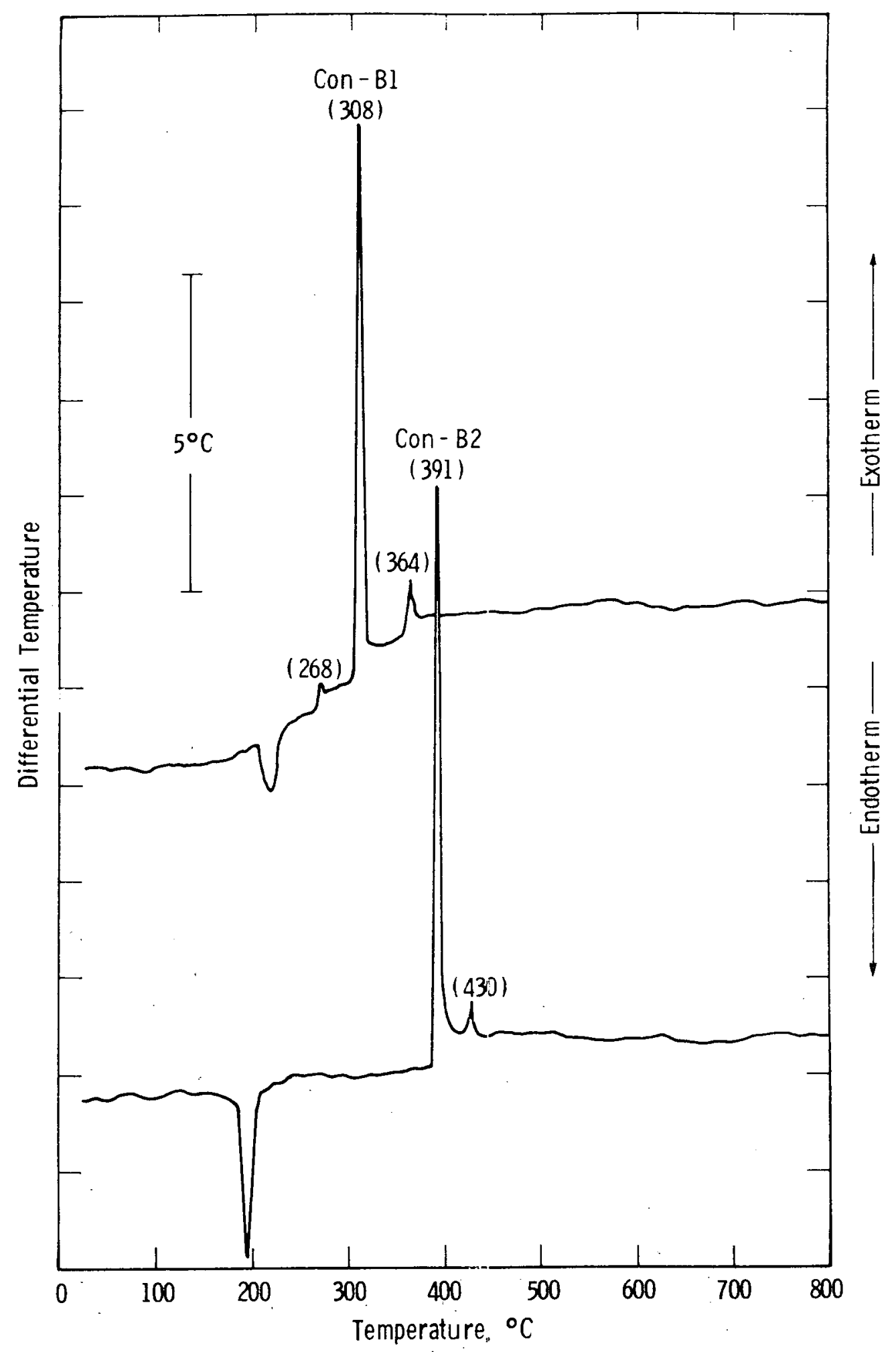

Fig. 2 - DTA curves obtained for $300 \mathrm{mg}$ samples of $\mathrm{Con}-\mathrm{Bl}$ and Con- $\mathrm{B} 2$ in excess lithium ( $1000 \mathrm{mg})$. $316 \mathrm{~S}$. S. sample container with argon cover gas 


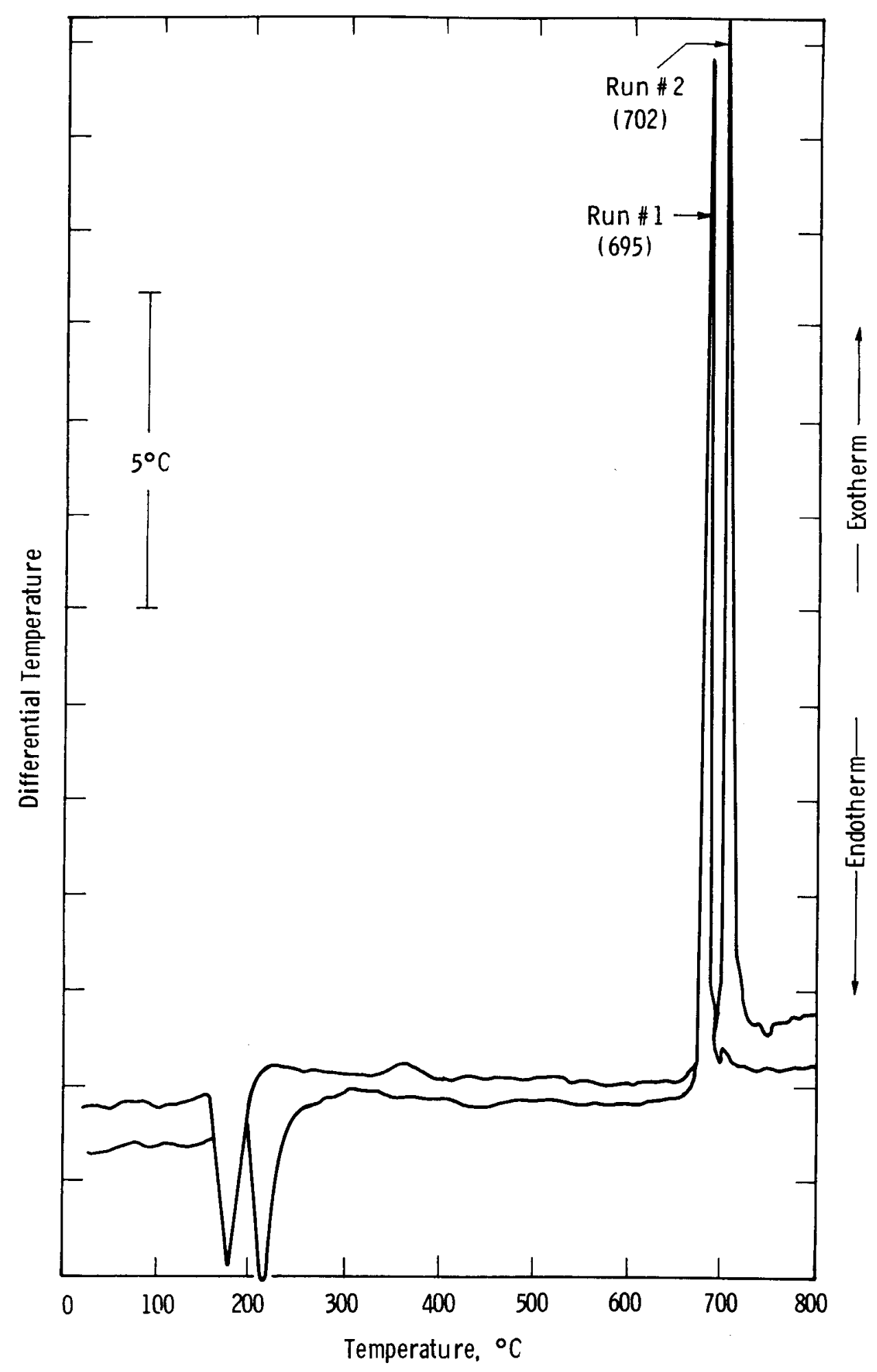

Fig. 3- DTA curves obtained for two individual $300 \mathrm{mg}$ samples of Con-LI in excess lithium ( $1000 \mathrm{mg}$ ). $316 \mathrm{~S} . \mathrm{S}$. sample container with argon cover gas

$$
\text { A-10 }
$$




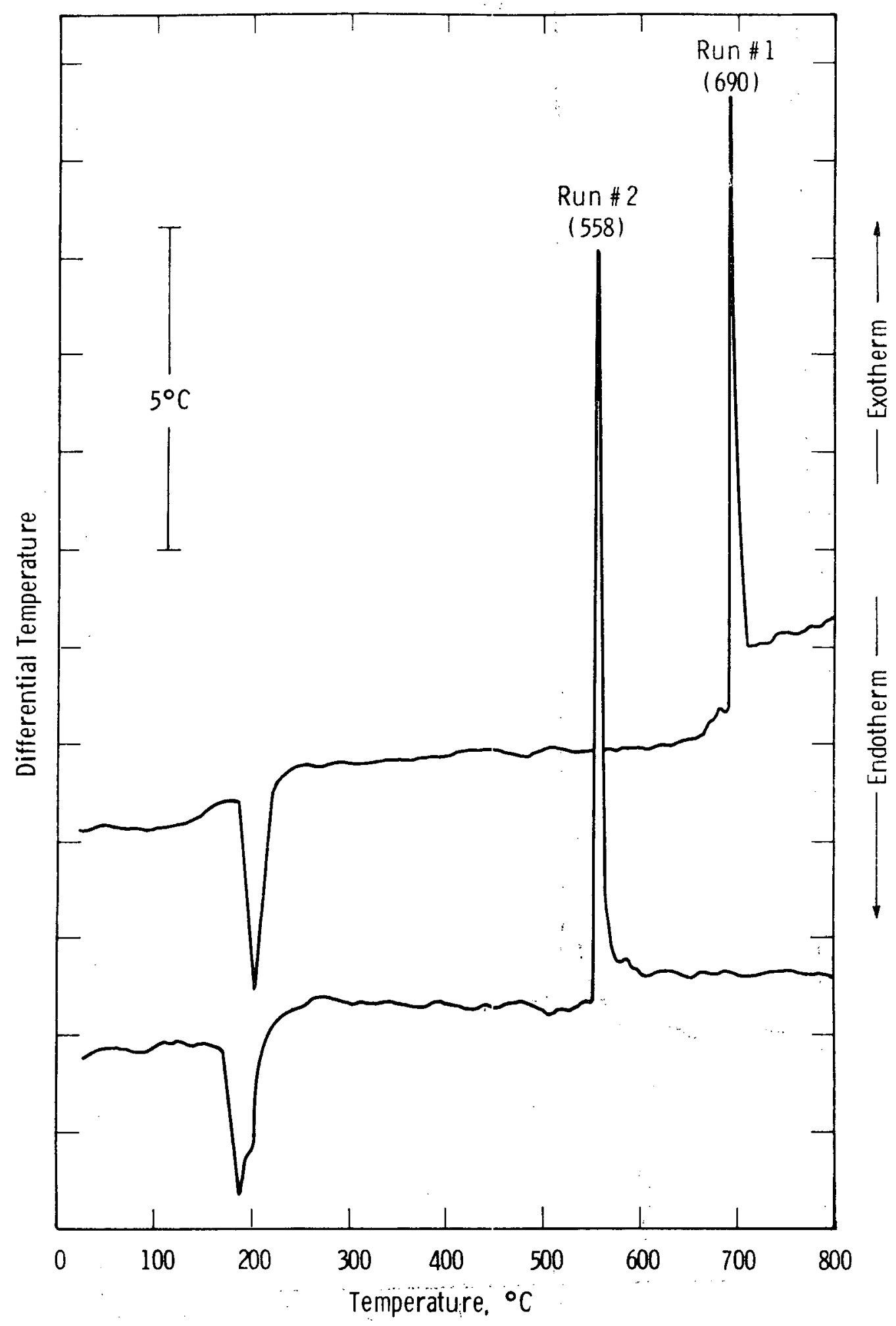

Fig. 4 - DTA curves obtained for two individual $300 \mathrm{mg}$ samples of air cured ( 7 days) dry portland cement (II) paste in excess lithium (1000 mg). 316 S. S. sample sample container with argon cover gas

$$
\text { A-11 }
$$




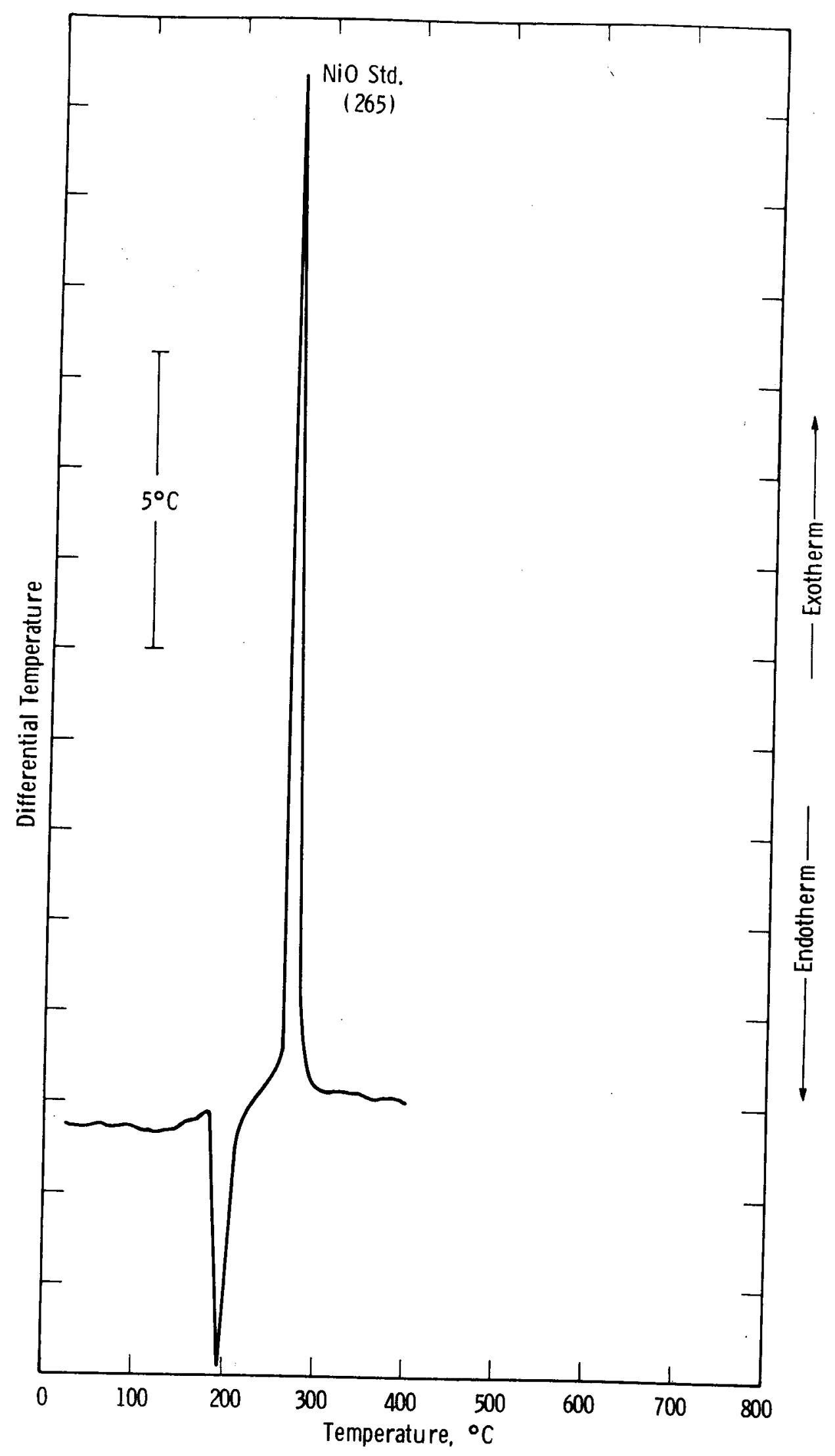

Fig. 5- DTA curve obtained for a $200 \mathrm{mg}$ sample of NiO standard in excess lithium ( $1000 \mathrm{mg}$ ). $316 \mathrm{~S}$. S. sample container with argon cover gas 
$X$-Ray Diffraction and Energy Dispersive Analysis by X-Ray of Lithium-Concrete Reaction Products 

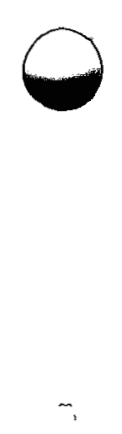

$=$

0 
From : R\&D CENTER

WIN

August 31,1977

Subject

R. E. Witkowski

R\&D 303

cc: G. C. Burrow, R\&D 303-2

Six samples of concrete (capillaries) treated with lithium were submitted to the $x$-ray diffraction laboratory and SEM laboratory for identification of the reaction phases.

Listed below are sample designations:

GCB \#1, CON-M1 + Li (water insoluble fraction)

GCB \#2 CON-L1 + Li (water insoluble fraction)

GCB \#3 3 CON-B1 + Li (water insoluble fraction)

GCB \#4 CMT $-1+\mathrm{Li}$ (water insoluble fraction)

GCB 非5 CON-L1 + Li (water soluble fraction)

GCB \#7 CON-M1 + Li (water soluble fraction) 
R. E. Witkowski

August 31,1977

$\underline{\mathrm{XRD}}$

Sealed capillaries of the reaction products were exposed in a Debye Scherrer powder camera $(114.6 \mathrm{~mm})$. Both chromium and copper radiation were used because certain elements cause fluorescence with copper radiation (e.g., Fe) while other elements cause fluorescence with chromium radiation (e.g., Ca). In addition, chromium radiation has a longer wavelength $(2.29 \AA)$ which permits better resolution of lines. This facilitates the analysis of samples with multiple phases. The XRD results are presented in Table 1. *

SEM and EDAX

The reaction products were removed from the capillary tubes and mounted on a standard aluminum sample mount. This mounting was done by using a small piece of double-stick tape. The powders were gently pressed on the tof surface of the tape and the entire mount was then coated with approximately $300 \AA$ of carbon to provide a conductive surface.

The samples were then examined in the SEM using an accelerating voltage of $20 \mathrm{KeV}$. The Energy Dispersive X-Ray Analyzer (EDAX) was used to detect and record the resulting $X$-rays produced from the electron bombardment. All elements with atomic rumbers greater than 10 (Neon) are detected simultaneousiy with the EDAX unit.

Results of the EDix identifications were correlated with the X-ray diffraction patterns to eliminate or confirm possible compound formations present. Table 2 summarizes the elements and relative amounts present in each of the six concrete samples.

* XRD patterns are referenced against standards as presented in "Joint Committee on Powder Diffraction Standards, 1976 Edition". 
R. E. Witkowski

August 31, 1977

\section{TABLE 1: XRD Fiesults}

Log No.

630-77

631-77

$632-77$

633-77

$634-77$

635-77

$636-77$

637-77

662-77

$664-77$

638-77

$639-77$

640-77

641-77
Sample

GCB \#1

GCB 非

GCB $\$ 3$

$\operatorname{GCB} \# 4^{* 3}$

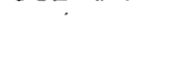$$
\text { . }
$$

$\operatorname{GCB} \# 5^{* 4}$$$
\text { GCB } \# 5^{* 4}
$$

GCB \#⿰ $7^{\star 4}$

$\mathrm{Li}(\mathrm{OH}) \cdot \mathrm{H}_{2} \mathrm{O}$ major

$\mathrm{Li}_{2} \mathrm{CO}_{3}$ major

Li $(\mathrm{OH})$ high minor

Fe minor:

(Lines are spotty indicating coarse grain size)

\footnotetext{
* See following pages for explanation.
} 
R. E. Witkowski

August 31, 1977

*1 A Comparison of d-spacings and Relative Line Intensities for GCB \#3, $\mathrm{Fe}, \mathrm{Fe}_{3} \mathrm{Si}$, and $\mathrm{Fe}_{2} \mathrm{Si}$ Reference Patterns

\begin{tabular}{|c|c|c|c|c|c|c|c|}
\hline \multicolumn{2}{|c|}{ GCB \# 3} & \multicolumn{2}{|r|}{$\mathrm{Fe}$} & \multicolumn{2}{|c|}{$\mathrm{Fe}_{3} \mathrm{Si}$} & \multicolumn{2}{|c|}{$\mathrm{Fe}_{2} \mathrm{Si}$} \\
\hline$d$ & Intensity & $d$ & Intensity & $d$ & Intensity & $d$ & Intensity \\
\hline & & & & 3.26 & 40 & & \\
\hline & & & & 2.80 & 40 & 2.80 & 40 \\
\hline 2.03 & $S$ & 2.03 & 100 & & & & \\
\hline 1.98 & $S$ & & & 1.97 & 100 & 1.99 & 100 \\
\hline & & & & 1.70 & 40 & & \\
\hline & & & & 1.62 & 20 & 1.62 & 10 \\
\hline 1.43 & W & 1.43 & 20 & & & & \\
\hline 1.41 & W & & & 1.41 & 100 & 1.406 & 60 \\
\hline & & & & & & 1.256 & 20 \\
\hline 1.178 & W & & & & & & \\
\hline 1.17 & W & 1.17 & 30 & & & & \\
\hline 1.15 & $S$ & & & 1.45 & 100 & 1.15 & 100 \\
\hline 1.01 & W & 1.01 & 10 & & & & \\
\hline 1.00 & W & & & .995 & 100 & .995 & 100 \\
\hline .90 & W & .906 & 12 & & & & \\
\hline .894 & W & & & & & & \\
\hline
\end{tabular}

The extra lines strongly resemble the $\mathrm{Fe}_{3} \mathrm{Si}$ and/or $\mathrm{Fe}_{2} \mathrm{Si}$. $\mathrm{Fe}_{3} \mathrm{Si}$ is F.C.C. (L.P. 5.64) [ $\mathrm{NaCl}$ structure] and $\mathrm{Fe}_{2} \mathrm{Si}$ is B.C.C. (L.P. 2.81) and $\mathrm{Fe}$ is B.C.C. (L.P. 2187). A search of literature produced no information on the (LiSi), (FeLi), or (FeliSi) systems. 
R. E. Witkowski

August 31, 1977

*2 Three Major d-Spacings for the Silicide Phase of GCB \#4

$$
\begin{array}{ll}
\text { d spaces } & 2.00 \mathrm{~S} \\
& 1.42 \mathrm{~W} \\
& 1.16 \mathrm{~W}^{+}
\end{array}
$$

Lattice parameter of $2.84 \AA$, similar to $\mathrm{Fe}$, however, the lattice parameter is contracted.

*3 Possible Assignments of Unidentified XRD Line for Sample GCB \#4

There was some concern over GCB $\# 2$ and GCB \#4 due to the similarity of both XRD and EDAX results. Another sample of GCB \#4 was prepared and analyzed - the results were identical with previous results of GCB \#14. All the lines (d spaces) of the X-ray pattern generated by GCB \#4 4 were identified with the exception of one - d space $7.30 \AA$. A positive identification is difficult with only one line, however, by using other lines coincidental with the other phases, the following compounds were possible.

$$
\begin{array}{lc}
\mathrm{Ca}\left(\mathrm{SO}_{4}\right) \cdot 2 \mathrm{H}_{2} \mathrm{O} \quad(\mathrm{ASTM} & 6-46) \\
\mathrm{Mg}_{3}(\mathrm{OH})_{5} \mathrm{Cl} \cdot 4 \mathrm{H}_{2} \mathrm{O} & 7-420 \\
\mathrm{KMg}\left(\mathrm{SO}_{4}\right) \mathrm{Cl} \cdot 2.75 \mathrm{H}_{2} \mathrm{O} & 25-1.237 \\
\mathrm{LiH}\left(\mathrm{AlO}_{2}\right) \cdot 5 \mathrm{H}_{2} \mathrm{O} & 24-61.7 \\
\mathrm{Li}{ }_{2} \mathrm{Al}_{2} \mathrm{O}_{4} \cdot 4 \mathrm{H}_{2} \mathrm{O} & 20-61.8
\end{array}
$$

*4 Possible Presence of $\mathrm{Li}_{2} \mathrm{C}_{2}$

$\mathrm{Li}_{2} \mathrm{C}_{2}$ is possibly present in samples $\mathrm{GCB}$ \# 5 and $\mathrm{GCB} \# 7$ primarily because the d spaces are superimposed on the three (3) previously identified phases $\mathrm{Li}(\mathrm{OH}), \mathrm{Li}(\mathrm{OH}) \cdot \mathrm{H}_{2} \mathrm{O}$, and $\mathrm{LI}_{2} \mathrm{CO}_{3}$. Is it possible that this phase can exist under these conditions? 
R. E. Witkonsk:

August 31,197 ;

\section{Table 2: EDAX Results}

$\underline{\text { Sample }} \quad \underline{\mathrm{Na}} \underline{\mathrm{Mg}} \quad \underline{\mathrm{Al}} \quad \underline{\mathrm{Si}} \underline{\mathrm{S}} \underline{\mathrm{Cl}} \underline{\mathrm{K}} \quad \underline{\mathrm{Ca}} \underline{\mathrm{Ti}} \underline{\mathrm{Fe}}$

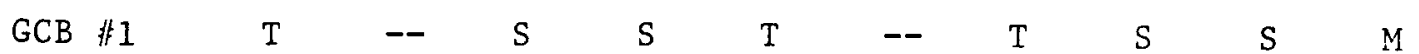

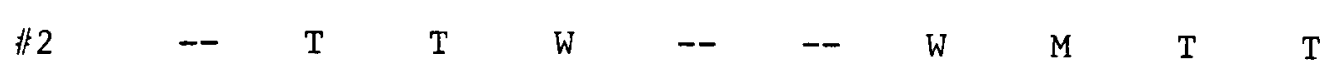
$\begin{array}{llllllllllll} & 3 & -- & W & W & M & T & T & T & M & T & W\end{array}$ $\begin{array}{lllllllllll} & 4 & \mathrm{~T} & \mathrm{~T} & \mathrm{~W} & \mathrm{~W} & \mathrm{~W} & \mathrm{~T} & \mathrm{~T} & \mathrm{M} & --\end{array}$ $\begin{array}{lllllllllllll}5 & \mathrm{~T} & \mathrm{~T} & \mathrm{~W} & \mathrm{M} & \mathrm{T} & -- & \mathrm{T} & \mathrm{W} & -\end{array}$ $\begin{array}{lllllllllllll} & 7 & \mathrm{~T} & \mathrm{~W} & \mathrm{~T} & \mathrm{M} & \mathrm{T} & \mathrm{T} & \mathrm{T} & \mathrm{M} & \mathrm{T} & -\end{array}$ $M=$ major. $\quad S=$ strong. $\quad W=$ weak. $\quad T=$ trace.
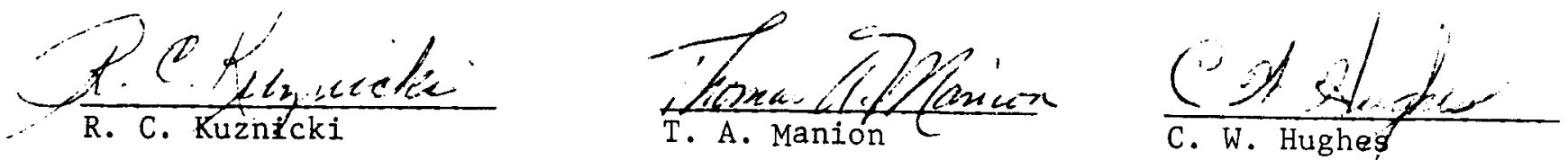


\section{DISTRIBUTION}

UC-20 (117)

DOE/RL (2)

Manager

Chief Patent Attorney

DOE/FFTFPO

(5)

Director

DOE/RRT-HQ

(2)

Program Division Director

HEDL (83)

HE Adkins

RP Anatatmula

JM Atwood

$J L$ Ballif

EO Badgett

JR Barreca

GB Barton

GR Bloome

DV Archer

AP Bohringer

RL Braaten

WF Brehm

FJ Carvo

RJ Cash

BE Chou

LE Chutos

RP Colburn

WV Cook

DR Dickinson

JH Ennen

EA Evans

FR Fisher

CW Funk

GM Gasser

HD Haberman

MD Hall

JA Hassberger

RK Hilliard

JJ Holmes

FE Holt

DW Jeppson

AJ Karnie

R. Kolowith

WL Kuhn

Central Files

W/A-11
W/C-51
W/C-45
W/C-45 (2)
W/C-51
W/221The
W/C-53
W/C-53
W/C-53
W/C-53
W/A-11
W/C-51
W/221The
W/A-11
W/221The (2)
W/C-51
W/C-51
W/221The
W/A-11
W/A-11
W/C-16
W/A-11
W/C-53
W/221The
W/A-11
W/C-51
W/A-11
W/221The
W/A-58
W/C-53
W/221The (2)
W/A-11
W/C-53
W/A-11

(10)

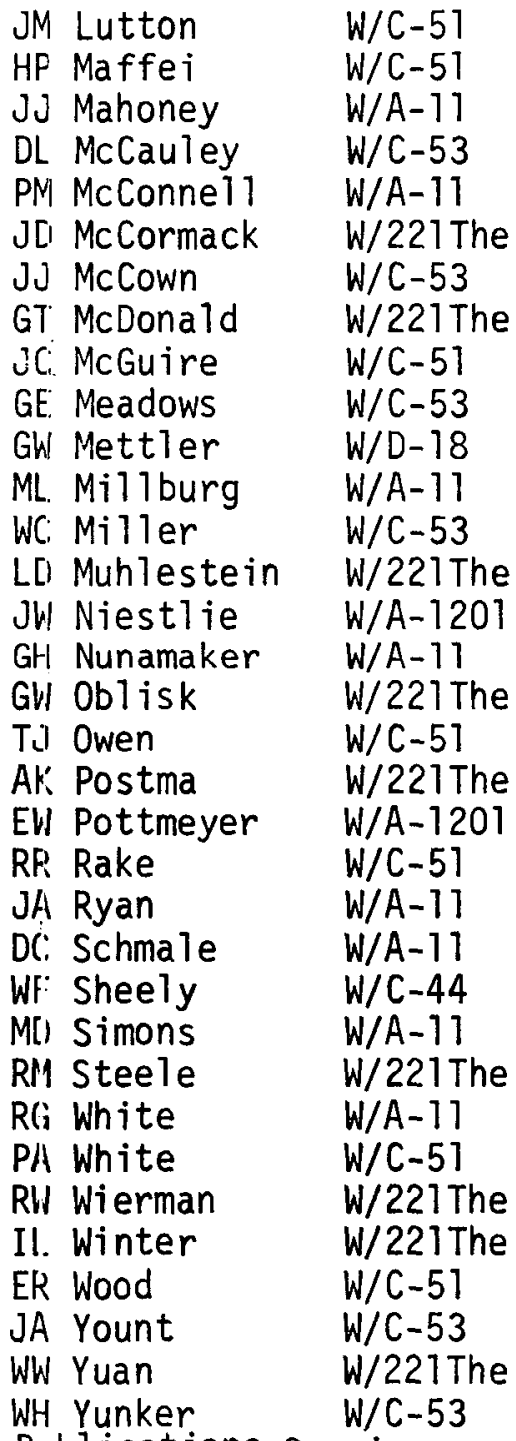

Publications Services 